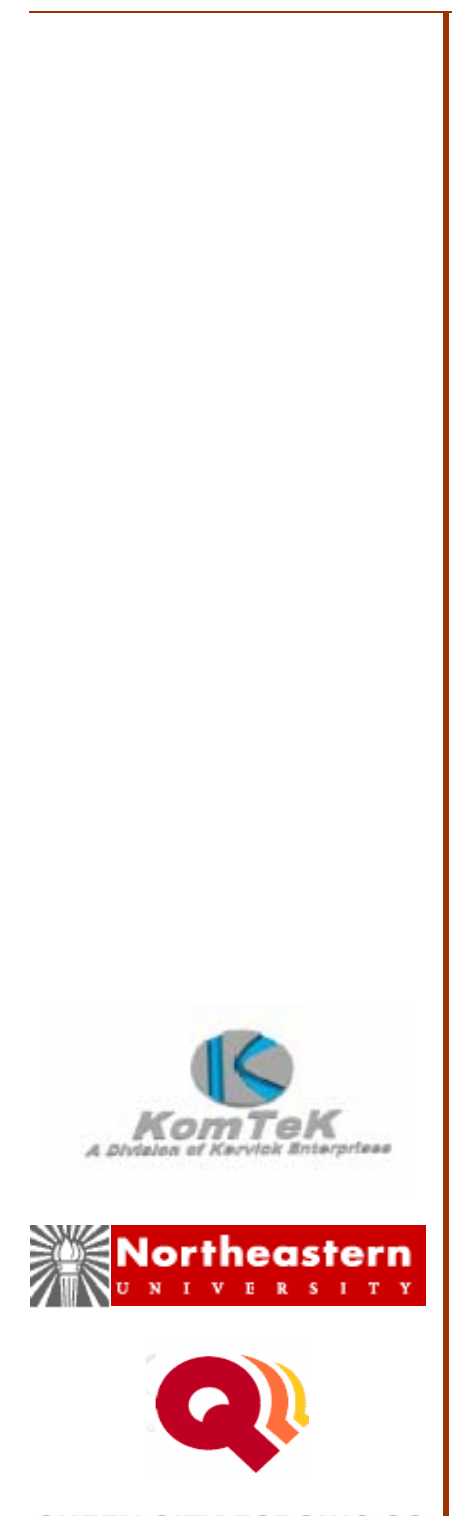

QUEEN CITY FORGING CO.


Managed by UT-Battelle, LLC
Final Technical Report

\section{Enhancement of Aluminum Alloy Forgings through Rapid Billet Heating}

June 2006

\section{Principal Investigators:}

\author{
Robert Kervick \\ KomTeK \\ Craig A. Blue and Puja B. Kadolkar \\ Oak Ridge National Laboratory \\ Teiichi Ando, Hui Lu, and Kozo Nakazawa \\ Northeastern University \\ Howard Mayer \\ The Queen City Forging Company \\ George Mochnal \\ Forging Industry Association
}




\section{DOCUMENT AVAILABILITY}

Reports produced after January 1, 1996, are generally available free via the U.S. Department of Energy (DOE) Information Bridge.

Web site http://www.osti.gov/bridge

Reports produced before January 1, 1996, may be purchased by members of the public from the following source.

National Technical Information Service

5285 Port Royal Road

Springfield, VA 22161

Telephone 703-605-6000 (1-800-553-6847)

TDD 703-487-4639

Fax 703-605-6900

E-mail info@ntis.fedworld.gov

Web site http://www.ntis.gov/support/ordernowabout.htm

Reports are available to DOE employees, DOE contractors, Energy Technology Data Exchange (ETDE) representatives, and International Nuclear Information System (INIS) representatives from the following source.

Office of Scientific and Technical Information

P.O. Box 62

Oak Ridge, TN 37831

Telephone 865-576-8401

Fax 865-576-5728

E-mail reports@osti.gov

Web site http://www.osti.gov/contact.html 


\section{FINAL TECHNICAL REPORT}

Project Title:

Award No:

Recipient Organization:

PI(s):

National Laboratory:

PI(s):

Sub-Contractors:

PI(s):

PI(s):

PI(s):

Project Period:

Date of Report:
Enhancement of Aluminum Alloy Forgings through Rapid Billet Heating

DE-FC36-01ID14205

KomTeK

40 Rockdale St.

Worcester, MA 01606

Robert Kervick

Phone: (508) 853-4500

E-mail: kervickr@,komtek-kei.com

Oak Ridge National Laboratory

1 Bethel Valley Road MS 6083

Oak Ridge, TN 37831

Craig A. Blue

Phone: (865) 574-4351

Puja B. Kadolkar

Phone: (865) 574-9956

E-mail: blueca@ornl.gov

E-mail: kadolkarpb@onrl.gov

Northeastern University

Department of Mechanical Engineering

343 Snell Engineering

Boston, MA 02115

Teiichi Ando

Hui $\mathrm{Lu}$

Phone: (617) 373-3811

Phone: (617) 373-4497

E-mail: tando@coe.neu.edu

Other Industrial Partners: The Queen City Forging Company

235 Tennyson Street

Cincinnati, OH 45226

Howard Mayer

Phone: (513) 321-7200

E-mail: rob@qcforge.com

Forging Industry Association

25 Prospect Avenue, Suite 300

Cleveland, $\mathrm{OH} 44115$

George Mochnal

Phone: (216) 781-6260

E-mail: george@forging.org

October 1, 2001-September 30, 2005

December 31, 2005 

ORNL/TM-2006/30

\title{
Enhancement of Aluminum Alloy Forgings through Rapid Billet Heating
}

\author{
Robert Kervick \\ KomTeK \\ Craig A. Blue \\ Puja B. Kadolkar \\ Oak Ridge National Laboratory \\ Teiichi Ando \\ Hui Lu \\ Kozo Nakazawa \\ Northeastern University \\ Howard Mayer \\ Queen City Forging Company \\ George Mochnal \\ Forging Industry Association
}

June 2006

\author{
Prepared by \\ OAK RIDGE NATIONAL LABORATORY \\ P.O. Box 2008 \\ Oak Ridge, Tennessee 37831-6283 \\ managed by \\ UT-Battelle, LLC \\ for the \\ U.S. DEPARTMENT OF ENERGY \\ under contract DE-AC05-00OR22725
}




\section{Acknowledgments and Disclaimer}

\section{Acknowledgments}

This report is based upon work supported by the U.S. Department of Energy, Energy Efficiency and Renewable Energy, Industrial Technologies Program, Supporting Industries, under Award No. DEFC36-01ID14205. The work performed in FY 2005 was supported by the Industrial Technologies Program, Industrial Materials for the Future and the Aluminum Industries of the Future.

The authors would like to acknowledge Randy Howell, Jackie Mayotte, Vinod Sikka, Greg Engleman, Evan Ohriner, Michael K. Miller, Kaye Russell, Neal D. Evans and Kathy A. Thomas at ORNL for their valuable contributions and participation in the project. In addition, support from Hui Lu and Kozo Nakazawa of the Northeastern University is greatly appreciated. The authors would like to thank Dr. Peter Angelini for project guidance and Carolyn Moser for editorial review.

Oak Ridge National Laboratory is operated by UT-Battelle, LLC, for the U.S. Department of Energy under contract DE-AC05-00OR22725.

\section{Disclaimer}

This report was prepared as a summary of research and development sponsored by an agency of the United States Government. Neither the United States Government nor any agency thereof, nor any of their employees, makes any warranty, express or implied, or assumes any legal liability or responsibility for the accuracy, completeness, or usefulness of any information, apparatus, product, or process disclosed, or represents that its use would not infringe privately owned rights. Reference herein to any specific commercial product, process, or service by trade name, trademark, manufacturer, or otherwise, does not necessarily constitute or imply its endorsement, recommendation, or favoring by the United States Government or any agency thereof. The views and opinions of authors expressed herein do not necessarily state or reflect those of the United States Government or any agency thereof. 


\section{Contents}

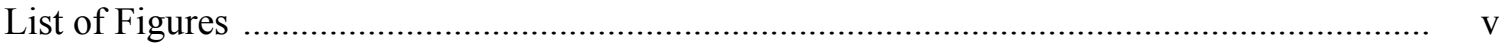

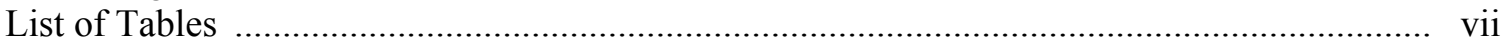

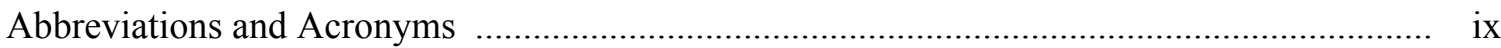

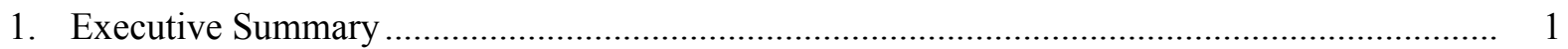

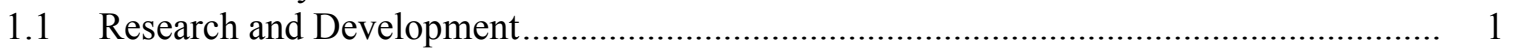

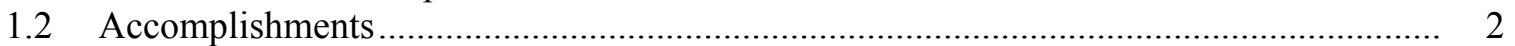

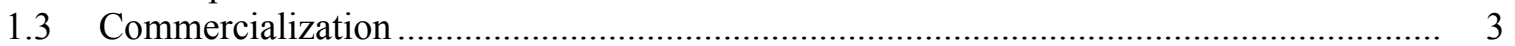

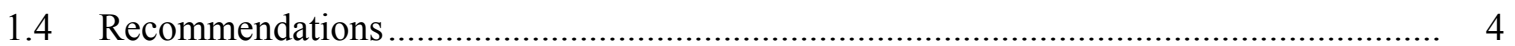

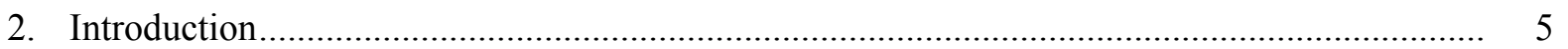

2.1 Domestic Technology Stauts Including Emerging Technology ................................. 5

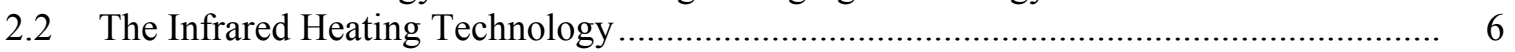

2.2 Benefits to the Domestic Technology and Industry Sector ............................................... 6

2.4 Assumptions and Detailed Calculations of Energy Savings to the Overall Domestic

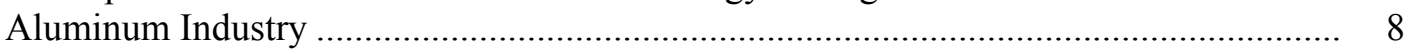

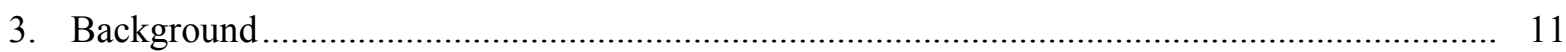

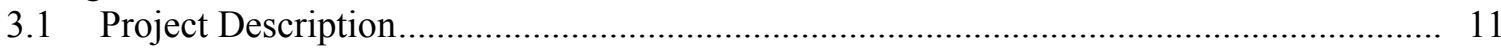

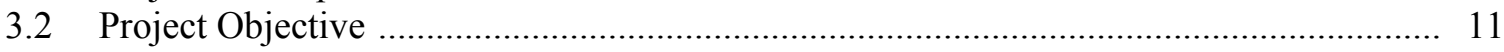

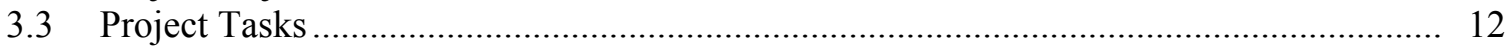

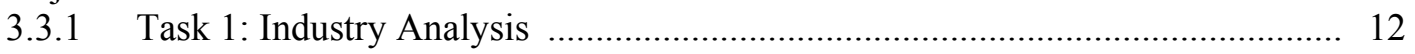

3.3.2 Task 2: Equipment Design and Fabrication ................................................. 12

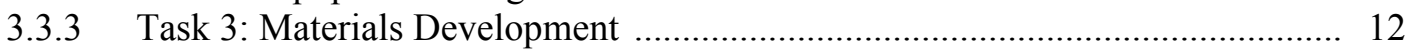

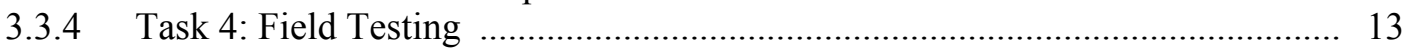

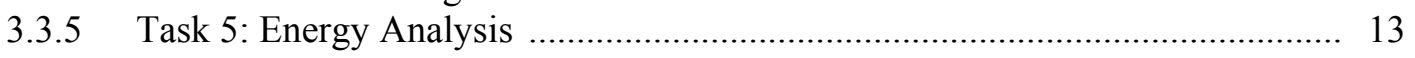

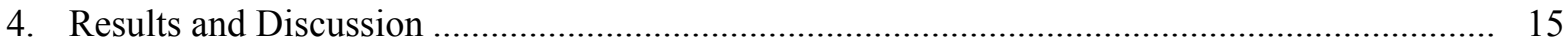

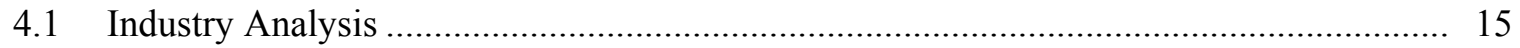

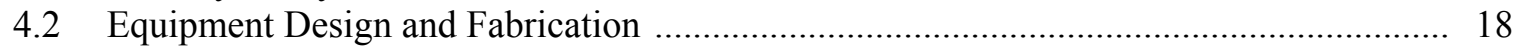

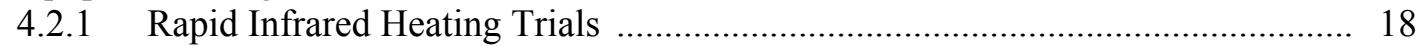

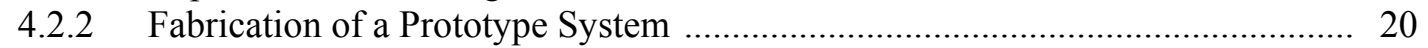

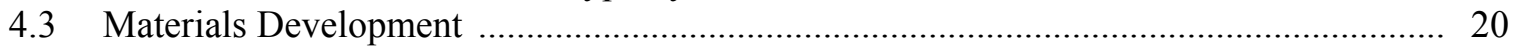

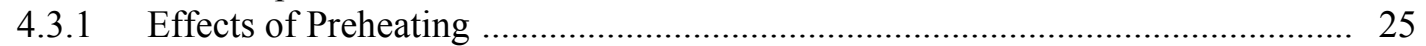

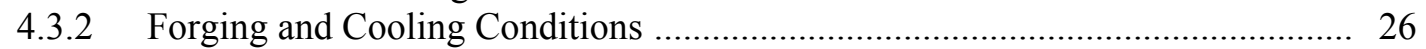

4.3.3 Effects of Heat Treatment ........................................................................ 28

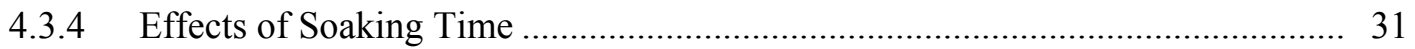

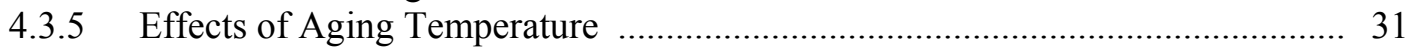

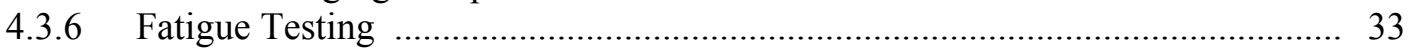

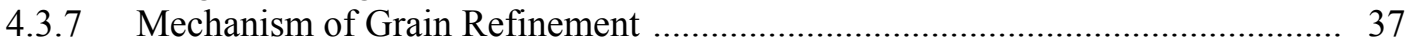

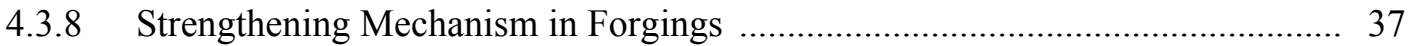

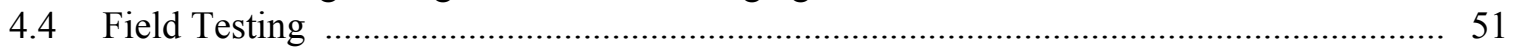

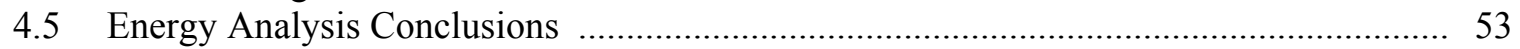




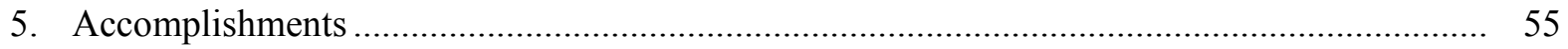

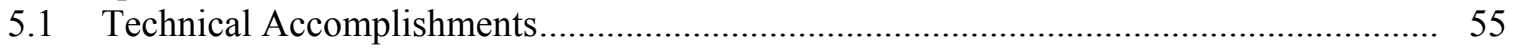

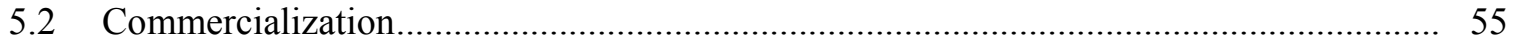

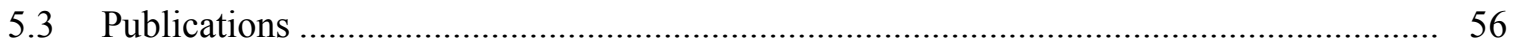

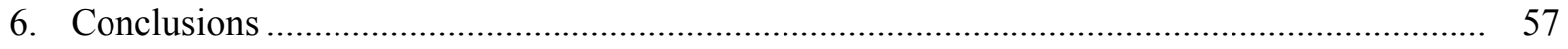

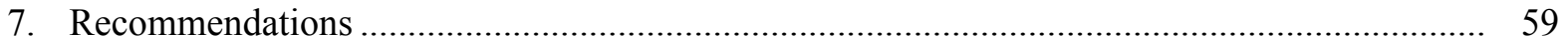

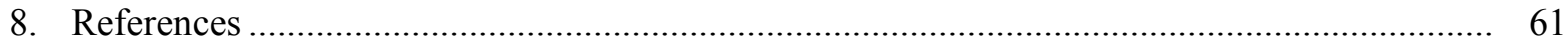




\section{List of Figures}

4.1 Optical micrographs of as-extruded aluminum alloy 2014 billet along (a) transverse and (b) longitudinal orientations to the extrusion direction

4.2 Optical micrographs of as-extruded aluminum alloy 2618 billet along (a) transverse and (b) longitudinal orientations to the extrusion direction.

4.3 Optical micrographs of as-extruded aluminum alloy 6061 billet along (a) transverse and (b) longitudinal orientations to the extrusion direction.

4.4 ORNL's 88-kW batch-type drop-bottom IR furnace.

4.5 Heating rate for various diameters of aluminum bars in the flat-bed IR furnace at $70 \%$ power.

4.6 Temperature profile for 2.25-in.-diameter, 6-in.-long aluminum alloy 2618 billet preheated using IR heating.

4.7 Heating profile for 2.25-in.-diameter, 0.5-in.-long aluminum alloy 2618 billet preheated using an electric furnace.

4.8 Optical micrographs showing transverse cross sections of aluminum alloy 2618 billets preheated for $30 \mathrm{~min}$ and $8 \mathrm{~h}$ at $450^{\circ} \mathrm{C}$ (various magnifications).

4.9 Optical micrographs showing longitudinal cross sections of aluminum alloy 2618 billets preheated for $30 \mathrm{~min}$ and $8 \mathrm{~h}$ at $450^{\circ} \mathrm{C}$ (various magnifications).

4.10 Temperature profile from the center of the billet during IR solution heat treatment

4.11 Optical micrographs of specimens with rapid vs conventional preheating, under two different magnifications.

4.12 Optical micrographs of rapidly preheated and conventionally preheated specimens with different cooling conditions after forging.

4.13 Grain sizes of a conventionally processed specimen (C-C) versus those of a specimen processed with IR rapid heating (IR-40).

4.14 (a) High-resolution SEM micrograph of specimen IR-40 showing intermetallic particles at the grain boundaries (b) Energy-dispersive X-ray spectroscopy analysis showing that the particles could be $\mathrm{Al}_{9} \mathrm{FeNi}$

4.15 Stress-strain curves for heat-treated specimens........................................................ 30

4.16 Schematic and picture of the tensile and fatigue test specimens ....................................... 30

4.17 Optical micrographs showing effects of different soaking times and different aging temperatures on microstructure.

4.18 Results of fatigue testing: (a) Comparison of fatigue properties for the IR treated and conventionally processed forgings; $(b) \mathrm{S}-\mathrm{N}$ curves for various heat treating conditions.

4.19 SEM fractographs of C-C no. 2 fatigue specimen at a stress amplitude of $129 \mathrm{MPa}$

4.20 SEM fractographs of IR-40 no. 3 fatigue specimen at a stress amplitude of $120 \mathrm{MPa}$ 
4.21 Crack initiation started from pores in rapidly preheated specimens: (a) RI-40 after fatigue testing at stress amplitude of $129 \mathrm{MPa} ;(b) \mathrm{C}-\mathrm{C}$ after fatigue testing at stress amplitude of $120 \mathrm{MPa}$

4.22 Vickers hardness and lattice parameter variations of solutionized specimens as a function of natural aging.

4.23 Effects of specimen thickness on the lattice parameter of specimen aged at $200^{\circ} \mathrm{C}$ for $80 \mathrm{~h}$

4.24 Variations in hardness for specimens artificially aged under varying conditions and temperatures

4.25 Effects of natural aging time on age hardening at 150,180 and $200^{\circ} \mathrm{C}$

4.26 Variations in lattice parameter for specimens artificially aged under varying conditions and temperatures

4.27 Schematic of the sequence of the lattice parameter changes vs artificial aging time

4.28 DSC thermograms of aluminum alloy 2618 at $20^{\circ} \mathrm{C} / \mathrm{min}$, as-quenched and artificially aged at $200^{\circ} \mathrm{C}$ for 5,10 , and $20 \mathrm{~min}$

4.29 DSC thermograms of aluminum alloy 2618 at $20^{\circ} \mathrm{C} / \mathrm{min}$ artificially aged at $200^{\circ} \mathrm{C}$ for $40 \mathrm{~min}, 5 \mathrm{~h}$, and $20 \mathrm{~h}$.

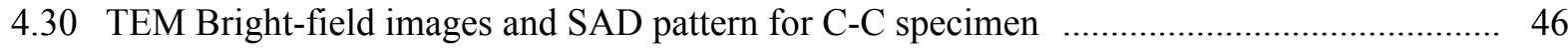

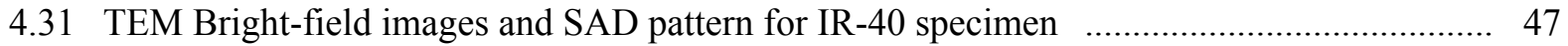

4.32 Electron diffraction indexed scheme characteristic of the $\mathrm{S}^{\prime}$ phase ..................................... 48

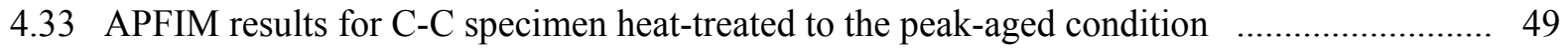

4.34 APFIM results for IR-40 specimen heat-treated to the peak-aged condition ......................... 50

4.35 Continuous-belt IR heating furnace installed at Queen City Forging Company, Cincinnati, Ohio

4.36 Calibration of the continuous-belt IR heating furnace for preheating 2.25-in.-diameter aluminum alloy 2618 billets

4.37 Optical micrographs of IR preheating forgings preheated using the continuous-belt setup at Queen City Forging and using ( $a$ ) lower deformation rate of $0.625 \mathrm{~s}^{-1}$ and (b) higher deformation rate of $2.5 \mathrm{~s}^{-1}$. 


\section{List of Tables}

2.1. Energy consumption of hybrid IR furnace vs conventional gas-fired furnace during



2.2. Energy and cost savings with the implementation of IR heating technology........................ 9

4.1. Chemical composition and secondary-phase particles for aluminum alloys 2014, 2618,

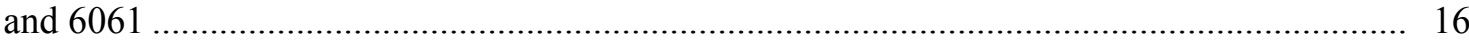

4.2. Design specifications of IR conveyor oven system .......................................................... 23

4.3. Processing conditions for aluminum alloy 2618 specimens ................................................ 24

4.4. Properties of heat-treated aluminum alloy 2618 specimens ............................................... 28 



\section{Abbreviations and Acronyms}

$\alpha$

APFIM

$\mathrm{BF}$

Btu

DMF

DOE

DSC

EDX

EMP

FIA

GP

GPB

IR

ORNL

PFZ

PLC

QCF

SAD

SEM

SI

TEM

TMS

UTS

XRD

1DAP

3DAP alpha aluminum

atom probe field ion microscope

bright field

British thermal unit

dissolution microvoid formation

U.S. Department of Energy

differential scanning calorimetry

energy-dispersive X-ray spectroscopy

eutectic melting porosity

Forging Industry Association

Guinier-Preston

Guinier-Preston-Bogaryatsky

infrared

Oak Ridge National Laboratory

precipitate-free zone

programmable logic controller

Queen City Forging Company

selected area diffraction

scanning electron microscope

supporting industries

transmission electron microscopy

The Minerals, Metals and Materials Society

ultimate tensile strength

X-ray diffraction

one dimensional atom probe

three dimensional atom probe 



\section{Executive Summary}

\subsection{Research and Development}

Forging is a manufacturing process in which metal is pressed, pounded or squeezed under great pressure and, often, under high strain rates into high-strength parts known as forgings. The process is typically performed hot by preheating the metal to a desired temperature before it is worked. The forging process can create parts that are stronger than those manufactured by any other metalworking process. Forgings are almost always used where reliability and human safety are critical. Forgings are normally component parts contained inside assembled items such airplanes, automobiles, tractors, ships, oil drilling equipment, engines, missiles, and all kinds of capital equipment. Forgings are stronger than castings and surpass them in predictable strength properties, producing superior strength that is assured, part to part.

Impression die forgings totaled approximately $\$ 4$ billion in 1999. The automotive sector (passenger cars, trucks, SUVs, and parts) made up the largest percentage of sales, at $34.8 \%$. Aerospace applications - engines, aircraft parts, auxiliary equipment and guided missiles and space vehiclescomposed the second largest segment, at $27.1 \%$. These applications include a large percentage of aluminum. Through grain refinement, it may be possible to reduce the size of some of these parts, thereby reducing energy consumption in the automotive and aerospace industries. This energy consumptions savings is in addition to the immediate energy saving realized by the forge shops when utilizing real-time heating of aluminum.

Even with the properties obtainable from aluminum forgings, the forge stock has to be reheated after it has been produced by casting or extrusion, and the reheating process consumes energy and time. In most instances, aluminum forge stock is preheated to temperatures in excess of $426^{\circ} \mathrm{C}\left(800^{\circ} \mathrm{F}\right)$ with gas-fired convection furnaces; preheating takes one to two hours if the furnace has been preheated and up to four to five hours if not. Therefore, the furnaces have to be maintained at a moderate to high temperature around the clock if preheating of forge stock is going to be accomplished in a reasonable amount of time-more energy consumption. In addition to these types of energy losses, longer heating times also lead to excessive grain growth in the final forging, resulting in shorter fatigue life for the component and increasing the risk of catastrophic failures. High-strength aluminum forged components are extremely beneficial to automotive and aerospace applications. They are lightweight, less expensive, and a possible substitute for the currently used expensive titanium components.

The goal of this project was to investigate the application of a new hybrid infrared (IR) heating technique to aluminum forging and subsequent heat treatment operations and evaluate the energy and materials benefits. In an earlier effort by the researchers [1], it was found that rapid heating using hybrid IR heating provides a huge potential to reduce preheating and heat treatment cycle times, thus giving an opportunity to reduce energy consumption and increase process productivity. In addition to providing an opportunity to save energy and make the industrial process more energy-efficient, the application of rapid preheating using hybrid IR for aluminum billets reduced the final grain size in 2014 aluminum alloy forgings by nearly an order of magnitude. Since the mechanical properties of 
forgings are strongly affected by (a) the grain size and shape, and (b) the size and distribution of second-phase particles, inclusions, and precipitates, it was extremely important to understand how structural changes in the material relate to the various thermal conditions. Based on this earlier research work, the following objectives were outlined to achieve the primary goal:

- Develop an energy-efficient hybrid IR billet heating system capable of delivering consistent preheated billets for forging in an industrial environment

- Develop a basic understanding of aluminum microstructural evolution from forge stock to final part as a function of preheating and heat treatment parameters

The following approach was taken to meet the final goal and objectives:

- Identify the mechanisms and rates of rapid preheating of billets required to obtain an order of magnitude refinement in grain size, when compared to convection heating, of a range of aluminum alloys during the forging operation

- Design, construct, and implement the hybrid rapid preheating in order to evaluate the energy efficiency, benefits, and competitiveness of the IR heating technology

- Perform energy analysis and predict cost savings through application of this technology to aluminum forgings

- Determine the improvement in mechanical properties produced by an order of magnitude grain refinement

Studies were conducted to study the effects of rapid heating on the microstructure and mechanical properties in 2618 aluminum alloy forgings. Rapid IR heating was applied to both the preheating of the billet and the subsequent heat treatment process, and the combined effect of these two thermal conditions on the final microstructure was investigated in detail. Efforts were also made to study the effects of various aging conditions on the final properties. This additional study was intended to understand the aging kinetics in this alloy and also to find out if maintaining higher aging temperatures or shorter aging times (similar to shorter solution heat treatment times) can provide additional reduction in the energy cost and production time without degrading the end properties in the forgings.

\subsection{Accomplishments}

The application of rapid IR heating successfully

- Reduced the preheating time from $4 \mathrm{~h}$ to $16 \mathrm{~min}$ for a particular size of 2618 aluminum alloy billet. This indicated almost an order of magnitude reduction in the preheating times.

- Enabled reducing the heat treatment times for 2618 aluminum alloy forgings from $8 \mathrm{~h}$ to $1 \mathrm{~h}$, consuming only $20 \%$ of the energy used by current conventional techniques and still producing superior mechanical properties in the final forgings

- Improved the energy efficiency of the preheating process more than three times, thus saving 2 trillion British thermal units (Btu) of energy in natural gas consumption

- Increased the production rate four times by reducing the preheating times

- Reduce the final grain size by $30 \%$ as compared to the grain size in forgings produced with longer preheating time and longer heat treatment schedules using conventional gas-fired convection furnaces 
- Resulted in a $14 \%$ increase in hardness, a 9\% increase in ultimate tensile strength, and a $100 \%$ increase in fatigue life as compared to forgings produced using conventional heat treatment processes. This property enhancement is attributed to the grain refinement and the finer precipitate distribution produced with the modified preheating and heat treating parameters made possible through the rapid IR heating technique

The key outcome of this project was the development and successful implementation of a productionscale, continuous-belt hybrid electric IR preheating system at the Queen City Forging Company (QCF) in Cincinnati, Ohio. The calibration and the field test runs that followed the implementation of the system showed that

- the heating rates identified and the grain refinements achieved in a laboratory setup were reproducible in a shop-floor environment;

- the replacement of the batch-type convection gas-fired furnace with a continuous-belt electric IR preheating system resulted in energy savings of more than $75 \%$; and

- the reduced energy consumption, increased throughput, and improved consistency in the process and the product using this new heating technique has a potential to generate an overall cost savings of up to $40-50 \%$.

The potential annual energy savings through

the implementation of

this technology at

aluminum forge shops in

the United States is

estimated to be

7.2 trillion Btu.

The potential annual energy savings through the implementation of this technology at aluminum forge shops in the United States is estimated to be 7.2 trillion Btu. With the replacement of a gas-fired unit with an electric IR unit, the research efforts in this project comply with the focus of DOE's "Save Energy Now" initiative on reducing natural gas consumption.

\subsection{Commercialization}

Successful implementation of the production-scale hybrid IR preheating unit at QCF has led to its commercialization in the forging industry. Today, QCF is producing 1000 forging components per day using a 2000 series aluminum alloy for a customer in the transportation industry. QCF also intends to use the equipment for toll processing of aluminum forgings on a commercial basis. Discussion about licensing the furnace designs and concepts resulting from this project for scale-up to sizes needed by different forging, extrusion, and rolling companies is ongoing between the project team members and a potential equipment manufacturer. The technical data obtained through the successful trials at QCF have been and will continue to be made available to aluminum, steel, and nickel-based alloy forging companies by the Forging Industry Association (FIA). FIA's endorsement of the use of the technology on the commercial floor at KomTeK and QCF will maximize the technology's acceptance by other forging companies.

Commercialization efforts have also included technical presentations and papers at conferences sponsored by FIA and The Minerals, Metals and Materials Society (TMS) [2, 3]

Finally, receipt of the prestigious R\&D 100 Award in 2004 significantly reinforced commercialization efforts by designating this technology as an engineering and scientific advancement with a potential to revolutionize the materials and manufacturing industry beyond the forging industry. The R\&D 100 Awards are presented annually by $R \& D$ Magazine in recognition of the year's most significant technological innovations. $R \& D$ Magazine is a magazine for engineers, 
scientists, and research administrators in applied research and development. Published twelve times a year, this magazine has the largest circulation in the general $R \& D$ field.

\subsection{Recommendations}

The principal application intended for the hybrid IR system developed through this project is the heating of extruded or cast aluminum bars prior to forging. However, this process can be extended to additional heat treating processes, including stress-relieving, annealing, solutionizing, and aging treatments performed after the forging operation. The system can be used for many additional thermal processes that currently use convection gas-fired or induction heating systems. These include annealing and stress relieving; preheating and postweld annealing during joining; and preheating prior to extrusion, rolling, and similar hot-working processes. Furthermore, the hybrid IR heating technology can also be extended to other materials, including steel, brass, and bronze; titanium alloys; and nickel- and cobalt-based alloys. Similar energy savings and potential property enhancements through grain refinement using rapid heating of these materials may be possible. It is recommended that similar efforts focused on additional generic industrial heating processes (other than forging such as extrusion, rolling, etc.) be initiated to widely distribute the benefits of energy savings across additional industrial sectors. 


\section{Introduction}

\subsection{Domestic Technology Status Including Emerging Technology}

As a class of alloys, aluminum alloys are considered to be more difficult to forge than carbon steel and many other alloys. Aluminum forging is typically performed at an elevated temperature (approximately $426^{\circ} \mathrm{C}$, or $800^{\circ} \mathrm{F}$, for $2014,6069,7075$, and $2024 \mathrm{Al}$ ), where the preform is heated with a convection, electric, or gas-fired oven to temperature. Heating of the preforms, which are typically extruded or cast aluminum bars, can take up to $4 \mathrm{~h}$, depending on the diameter of the preforms and whether the oven has been running for a prolonged period of time. These long preheat cycles can cause extensive grain growth and dissolution of second-phase particles. A typical practice is to load a $3 \times 2 \times 2 \mathrm{ft}$ high furnace with aluminum billets the night before a forging run is to be performed. The preheated forge stock is then forged on hydraulic presses, mechanical presses, and hammers with capacities of up to 50,000 tons, 20,000 tons, and $50,000 \mathrm{lb}$, respectively.

Currently in the domestic industry, aluminum alloys are heated for forging with a wide variety of equipment: electric furnaces, fully muffled or semi-muffled gas furnaces, oil furnaces, induction heating units, fluidized bed furnaces, and resistance heating units. Gas-fired semi-muffled furnaces are the most widely used. Induction heating, resistance heating, and fluidized bed heating are typically used in cases in which the forging processes are highly automated and handle very large quantities. Induction and resistance heating are usually limited to simple bar stock. Induction heating, resistance heating, and fluidized bed heating all have many materialhandling restraints.

Aluminum alloys can be forged only with a relatively narrow temperature range; this necessitates precise temperature control in preheating. The heating equipment should have pyrometric controls which can maintain temperature within $\pm 5^{\circ} \mathrm{C}$. Continuous furnaces typically have three zones: preheat, high heat, and discharge. Most furnaces are equipped with recording and control devices and are frequently checked for temperature uniformity in a manner similar to that used in solution treatment and aging furnaces.

The forging industry in the United States and Canada employs approximately 45,000 people from coast to coast. Because the modern forging process is capital-intensive and requires an abundance of heavy equipment for manufacture, most forging plants are small businesses employing 50 to 500 employees each, with a few larger facilities employing more than 1000 people. These facts make it highly unlikely that the large majority of companies will utilize expensive, highly partgeometry-dependant heating equipment such as induction, electrical resistance, and fluidized bed heating. The gas-fired semi-muffled furnaces that are the most widely used in the forging industry require long lead times and long heat-up times. Gas-fired convection furnaces require several hours to bring aluminum forging loads to full temperature, making them impractical for jobs with small batch sizes and short lead times. These types of furnaces also do not allow control of the metallurgy of aluminum during the entire forging process. In addition, the efficiencies of these types of furnaces are typically well below $25 \%$ and, coupled with the long makeup times, produce overall efficiencies of less than $10 \%$. Energy consumption analysis performed during this project has shown that a batch-type gas convection oven takes approximately 1.2 million Btu to heat a 500-lb load of billet to temperature in a 5- to 6-h period; by contrast, a hybrid IR system with a continuous-belt setup takes only 250,000 Btu to heat the same load in $1.5 \mathrm{~h}$. 


\subsection{The Infrared Heating Technology}

The hybrid IR heating technology provides a new method for rapid and uniform heating of aluminum billets prior to the forging process. The term "hybrid" refers to the use of an optimized combination of both radiant and convection heating. The radiant heating is delivered through short-wavelength $(0.78-2.0 \mu \mathrm{m})$ IR radiations emitted by heating an array of tungsten-halogen filaments to very high temperatures (in excess of $2200^{\circ} \mathrm{C}$ ). The heat flux, $Q$, from heated elements is given by Stefan-Boltzmann's law,

$$
Q=\sigma \varepsilon\left(T_{f}^{4}-T_{s}^{4}\right)
$$

where $\sigma$ is the Stefan Boltzmann constant, $\varepsilon$ is the emissivity, $T_{f}$ is the filament temperature, and $T_{s}$ is the surrounding temperature. Due to very high temperatures, the heat fluxes resulting from these filaments are nearly an order of magnitude higher than fluxes resulting from conventional heating elements. Such high fluxes, together with the low thermal mass of these filaments, provide extremely fast heating rates, reducing the heating cycle time. Once the surface is heated, the high thermal conductivity of the aluminum (about 4 to 5 times that of steel) causes the heat to be conducted quickly to equalize the temperature across the billet. For a continuous-production operation, the equalization of temperature is further aided by convection heating, which is delivered by blowing air at certain velocities to force the trapped heat between the elements and other furnace surfaces across the billet. The radiant heating and convective heating are further optimized by controlling the belt speed, which in turn depends upon the geometry of the component being heated. For example, for the system installed in a full-production setup, the nominal belt speed for heating 2.25-in.-diameter, 6-in.-long aluminum alloy 2618 billets is $3 \mathrm{in} . / \mathrm{min}$. Such belt speeds provide uniform and consistent heating of billets with exceptionally higher throughputs.

The development of hybrid IR technology for heating and processing of aluminum forgings was primarily driven by the need for shorter cycle times, lower costs, and improved efficiency. The system designed using this technology has a very low installation cost, and operational costs are 10 $50 \%$ less expensive than costs for the heating furnaces currently used. Also, the IR furnace converts electric energy into radiant energy (heat) with a greater than $90 \%$ efficiency; the radiant energy not directly absorbed by the

Replacement of a gas-fired convection furnace with the newly developed radiationconvection-based IR heating system at Queen City Forging Company has resulted in energy savings of more than $75 \%$ parts is absorbed by the internal ceramic components of the furnace and is reradiated at longer wavelengths. The hybrid IR system is designed to minimize radiation losses and maximize the utilization of energy within the furnace. Replacement of a gas-fired convection furnace with the newly developed radiation-convection-based IR heating system at Queen City Forging Company has resulted in energy savings of more than $75 \%$.

\subsection{Benefits to the Domestic Technology and Industry Sector}

Infrared heating offers a low-cost, energy-efficient, and environmentally friendly heating methodology for process heating with significant enhancement in the material properties. The reduced energy consumption, reduced environmental impacts, and enhanced economic and technological competitiveness offered by this technology are of significant importance to the heat treating, process heating, and forging industries of DOE's SI Program. The outcome of this project is in line with the goal outlined in SI portfolio, which is "to improve energy and 
environmental performance of the manufacturing processes while simultaneously reducing the product costs" [4].

The following are examples of the ways in which this project addresses DOE's and the federal government's goals:

1. The Executive Summary of the Heat Treating Road Map, Exhibit 1.1: Major Technology Needs of the Heat Treating Industry, lists the following need:

- Advanced processes: Heat treating processes that allow a shorter cycle time and required lower-cost equipment and associated materials. This need also includes alternative heat sources, improved equipment maintenance, and more effective insulation.

The research on hybrid IR heating technology and its outcome are directly relevant to the number 1 need of the heat treating industry. Infrared heating provides an alternative heat source that can decrease cycle time and will require comparable or lower equipment cost.

2. The Process Heating Road Map (draft copy) identified the priority research and development goals to overcome major barriers. One of the top-priority R\&D goals was the following:

- Heating technologies that simultaneously reduce emissions, increase efficiency, and increase heat transfer.

This research effort is directly relevant to this R\&D goal. The hybrid IR system converts electric energy into radiant energy and heat and is more than $90 \%$ efficient; the radiant energy not directly absorbed by the parts is absorbed by ceramic internals and reradiated at a longer wavelength. The furnace is designed to keep all the energy within the furnace where convective heating can also play a role in the heating process. The technology is electric and therefore produces no emissions.

3. From the Forging Industry Vision of the Future, Technology, Energy and Environment [5]:

- By 2020, forging will be the cost-effective, preferred method by which metal components of superior quality, integrity, and performance are produced for critical applications. Significant advances in materials and manufacturing technologies will ensure the U.S. forging industry's profitability through higher productivity, shorter lead times, and superior quality near-net-shape products.

- Energy efficiency: reduction in heating cycles is a strategic target of the forging industry.

The outcome of this research effort fits directly into FIA's vision. The hybrid IR system provides an energy-efficient methodology to further refine grain size, improve properties, and enhance product quality. Faster heating rates ensure reduction in heating cycles and higher productivity. 


\subsection{Assumptions and Detailed Calculations of Energy Savings to the Overall Domestic Aluminum Industry}

The energy benefits associated with the IR furnace are primarily due to its efficient design and reduced cycle times. The hybrid IR system is based on tungsten halogen filaments that convert electric energy into radiant energy (heat) with greater than $90 \%$ efficiency. These filaments can be switched on at room temperature, can come to full power in less than one second, and provide an order of magnitude higher power densities than conventional heating technologies. These attributes lead to shorter heating cycle times, drastically reducing the overall processing time for the billets. In contrast, conventional furnaces, both gas and electric, take many hours to bring the aluminum forging loads to full temperature. Also, as noted earlier, the efficiencies of conventional gas and electric furnaces are typically well below $25 \%$, and when coupled with the large makeup times, the overall efficiencies are less than 10\%. Preliminary calculations based on the field test results at Queen City Forging Company have shown that a conventional gas-fired convection furnace takes approximately 1.2 million Btu to heat a 500-lb load of billet to temperature in a 5- to 6-h period, whereas a hybrid IR system takes about 250,000 Btu to heat the same load in $1.5 \mathrm{~h}$ a continuous-belt setup. Table 2.1 compares the energy consumption of a continuous-belt hybrid rapid IR furnace with that of a conventional convective gas-fired furnace.

Table 2.1. Energy consumption of hybrid IR furnace vs conventional gas-fired furnace during aluminum billet preheating

\begin{tabular}{|c|c|c|c|}
\hline Attribute & $\begin{array}{l}\text { Continuous- } \\
\text { belt hybrid IR } \\
\text { furnace }\end{array}$ & $\begin{array}{l}\text { Batch-type gas- } \\
\text { fired convection } \\
\text { furnace }\end{array}$ & Comments \\
\hline Billet heating time, $\min ^{b}$ & 20 & 240 & $\begin{array}{l}\text { IR heating provides an order of } \\
\text { magnitude faster heating }\end{array}$ \\
\hline $\begin{array}{l}\text { Throughput (production } \\
\text { rate), Ib/h }\end{array}$ & 350 & 80 & $\begin{array}{l}\text { Rapid heating using IR increases } \\
\text { production rate four times }\end{array}$ \\
\hline $\begin{array}{l}\text { Energy used for Al billet } \\
\text { heating, Btu/lb }\end{array}$ & 500 & 2500 & $\begin{array}{l}\text { Energy consumption using IR system } \\
\text { is reduced by a factor of } 5\end{array}$ \\
\hline $\begin{array}{l}\text { Overall system } \\
\text { efficiency, } \%\end{array}$ & $\sim 30$ & $\sim 10$ & $\begin{array}{l}\text { IR systems are three times more } \\
\text { efficient than convection gas-fired } \\
\text { furnaces }\end{array}$ \\
\hline
\end{tabular}

\footnotetext{
${ }^{a}$ The majority of small and medium-size forging shops in United States use fully muffled or semi-muffled batch-type gas-fired convection furnaces to heat aluminum alloy billets prior to forging.

${ }^{b}$ Heating load used for comparison purposes consists of 2.25 -in.-diameter $\times 6$-in.-long aluminum alloy 2618 billets.
}

In addition to the energy savings during preheating of the aluminum billets, considerable savings in time and energy have also been demonstrated during the solution heat-treatment of aluminum forgings. During the course of this project, it was proven that a 10 -h solutionizing cycle for aluminum alloy 2618 could be reduced to $1 \mathrm{~h}$, consuming only $20 \%$ of the energy currently used by conventional techniques and still producing superior mechanical properties. Table 2.2 presents a more detailed energy analysis for the IR and convection gas-fired heating systems during aluminum billet preheating and heat-treating operations for forging taking into consideration these additional energy

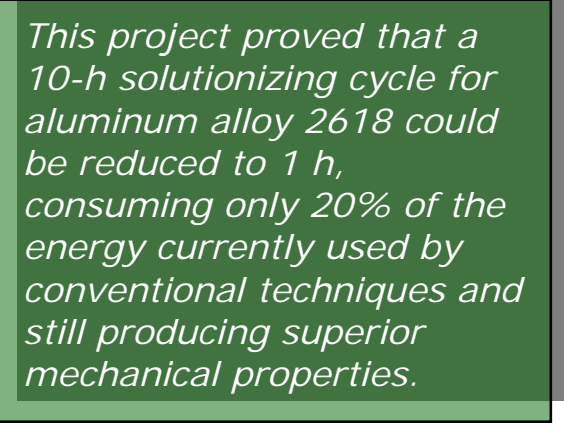

\section{This project proved that a} aluminum alloy 2618 could be reduced to $1 \mathrm{~h}$, consuming only $20 \%$ of the energy currently used by conventional techniques and still producing superior mechanical properties. 
savings. The projected cost savings include costs associated with reduced materials rejection and reprocessing of the generated scrap. IR heating produces consistent and reproducible heating of the work piece, thus allowing the system to undergo full automation. Full automation will further reduce rejection, produce less scrap, and decrease labor costs as well.

Analysis shows that implementation of the newly developed hybrid rapid IR heating technology could result in national energy savings up to 7.2 trillion Btu/year, with cost savings of $\$ 84$ million per year. Since this project replaces a gas-fired unit with an electric IR unit, the project's research efforts also relate to the focus of DOE's "Save Energy Now" initiative on reducing natural gas consumption.

Table 2.2. Energy and cost savings with the implementation of IR heating technology

\begin{tabular}{|c|c|c|}
\hline \multirow[b]{2}{*}{ Operation } & \multicolumn{2}{|c|}{ Energy consumption (Btu) } \\
\hline & IR heating & $\begin{array}{l}\text { Gas-fired } \\
\text { convection furnace }\end{array}$ \\
\hline Preheating a 500-lb load & $255,294.03^{a}$ & $4,800,000^{b}$ \\
\hline Preheating per lb of $\mathrm{Al}$ & 510.58 & 9,600 \\
\hline Heat treating a $500-\mathrm{lb}$ load & $921,895.10^{c}$ & $10,600,000$ \\
\hline \multirow[t]{2}{*}{ Heat treating per $\mathrm{lb}$ of $\mathrm{Al}$} & $1,843.79$ & 21,200 \\
\hline & \multicolumn{2}{|c|}{ Energy/cost savings } \\
\hline $\begin{array}{l}\text { Energy savings in preheating and heat treating per lb } \\
\text { of } \mathrm{Al}, \mathrm{Btu}\end{array}$ & \multicolumn{2}{|c|}{28445.63} \\
\hline $\begin{array}{l}\text { Energy savings in preheating and heat-treating } \\
95,550 \text { tons of Al per year, Btu }\end{array}$ & \multicolumn{2}{|c|}{$5.97 \times 10^{12}$} \\
\hline \multicolumn{3}{|l|}{$\begin{array}{l}\text { Energy savings (Btu/year) from other sources, } \\
\text { including energy associated with }{ }^{e}\end{array}$} \\
\hline (a) Material that does not have to be reprocessed & \multicolumn{2}{|c|}{$8.6 \times 10^{11}$} \\
\hline (b) Melting of the rejected material & \multicolumn{2}{|c|}{$1.52 \times 10^{11}$} \\
\hline (c) Dross formation during smelting of $\mathrm{Al}$ & \multicolumn{2}{|c|}{$2.01 \times 10^{11}$} \\
\hline Total energy savings, Btu/year & \multicolumn{2}{|c|}{$7.2 \times 10^{12}$} \\
\hline Total cost savings, $\$ /$ year $^{f}$ & \multicolumn{2}{|c|}{$84 \times 10^{6}$} \\
\hline
\end{tabular}

${ }^{a}$ IR systems operate at $480 \mathrm{~V}, 60 \mathrm{~A}$, electrical settings during preheating.

${ }^{b}$ Convection gas-fired furnaces consume 200,000 Btu of energy per hour per load of $500 \mathrm{lb}$; this figure also considers energy consumed by the furnace with idle conditions with no load.

${ }^{c}$ IR systems operate at $480 \mathrm{~V}, 100 \mathrm{~A}$, during heating; and at $480 \mathrm{~V}, 50 \mathrm{~A}$, during soaking.

${ }^{d}$ According to the U.S. Department of Commerce's 2002 Economic Census for Manufacturing of NonFerrous Forging [6], about 95,500 tons of hot-impression die impact, press, and upset aluminum and aluminum alloy forgings were shipped in 2002.

${ }^{e}$ Assuming a fraction of 0.33 of 95550 tons of aluminum that has to be reprocessed in preheating and heat treating each year, a fraction of 0.33 that has to be remelted each year, and $4 \%$ losses in dross formation during smelting of aluminum each year. Energy used for melting equals 2,200 Btu/lb [7] and for smelting, is 72,500 Btu/lb [8].

${ }^{f}$ Cost savings are calculated on the basis of the average total natural gas price of $\$ 1.24 /$ therm and the average total price for electricity of $\$ 0.167 / \mathrm{kwh}$ for the state of Ohio in September 2005. 



\section{Background}

\subsection{Project Description}

This project dealt with development of a hybrid infrared furnace/heating technology that would enable enhancement in aluminum metallurgy through a finer final grain size. This grain reduction came out of work where energy conservation through shorten cycle times was the main objective [1]. The goal of this project was to investigate the application of a new hybrid infrared (IR) heating technique to aluminum forging and subsequent heat treatment operations and evaluate the energy and materials benefits.

The research effort was conducted by a team consisting of end users (KomTeK and Queen City Forging), a national forging association (FIA), an equipment manufacturer (IR Heating Technologies), a university (Northeastern University), and a national laboratory [Oak Ridge National Laboratory (ORNL)]. The forging companies (KomTeK and Queen City Forging) participated by bringing their extensive experience in forging and die manufacturing. They assisted in the design and testing of the hybrid IR system for billet-on-demand forging of aluminum. All forgings required for the metallurgical and mechanical testing studies in this project were produced at KomTeK and Queen City Forging. These companies also studied and quantified the energy savings realized in the field while utilizing the hybrid IR furnace. Their feedback was essential for the success of this new type of billet heating process. Northeastern University worked closely with ORNL in the analysis of forged parts from industry. The analysis included metallurgical analysis, mechanical testing, and high-cycle fatigue testing. IR Heating Technologies and ORNL worked closely with the forging companies in the design, construction, and testing of the furnace technology. FIA provided guidance and direction to the project through active participation by identifying and monitoring project deliverables and technical progress. FIA also assisted in the dissemination of the technology from this project to the forging industry members.

\subsection{Project Objectives}

Rapid IR heating provides higher heating fluxes that result in faster heating of aluminum billets. It offers a means to reduce heating cycle times and reduce energy consumption at various stages in a forging operation. The rapid heating through IR-based heating of aluminum alloy billets also results in grain sizes that are an order of magnitude finer than those produced through convection heating processes. This dramatically smaller grain size results in superior tensile and fatigue properties. The primary goal of this project was to investigate the energy benefits and product quality improvements achieved through grain refinement using the hybrid IR heating technology.

The specific objectives of the project were

- to develop an energy-efficient hybrid IR billet heating system capable of delivering consistent preheated billets for forging in an industrial environment and

- to develop a basic understanding of the microstructural evolution of aluminum from forge stock to final part as a function of preheating and heat treatment parameters.

The key targets in the research effort were the following:

- to produce grain sizes in forged aluminum alloy billets that are an order of magnitude finer than the starting grain size by a rapid heating process based on the hybrid IR system; 
- to verify that an order of magnitude grain refinement will result in significant enhancement in mechanical properties, especially reduction in fatigue; and

- to use experimental results to guide the design of a hybrid IR-based billet heater, which would be tested in the laboratory and at partner forging companies prior to broad implementation in the forging industry.

The major hurdles overcome through this research effort were

- development of a full-scale production-type hybrid IR furnace system capable of delivering consistent preheated billets for forging in an industrial environment and

- basic understanding of aluminum microstructural evolution and improvement in mechanical properties from forge stock to final parts as a function of the preheating and heat treatment parameters.

\subsection{Project Tasks}

\subsubsection{Task 1: Industry Analysis}

The focus of Task 1 was to carefully study the needs of the forging companies in the aluminum forging area. The team worked closely with industry to understand the critical needs of the forging industry in an effort to develop a billet-on-demand hybrid IR furnace. This task involved the following subtasks:

1. surveying the different billet heating methods, the billet sizes used, and the forging grain sizes and

2. establishing baseline metallography for various aluminum alloys.

\subsubsection{Task 2: Equipment Design and Fabrication}

Task 2 involved designing and fabricating a hybrid IR furnace capable of real-time operation. Working from ORNL's extensive IR processing and furnace experience, a system was designed that was capable of going from cold to full power in a matter of min; retained a large portion of the energy produced within the furnace, making it more energy efficient; and was capable of delivering billets at a rate at which a hammer operator can efficiently forge them. The following subtasks were performed:

1. performance of rapid-heating trials for various sizes of billets and at various power settings using a laboratory setup to establish a heating rate that is reproducible in a forging industry environment and

2. fabrication of a prototype system based on these preliminary experiments.

\subsubsection{Task 3: Materials Development}

The objective of Task 3 was to develop a basic understanding of the metallurgy and how it evolves in the case of convection heating versus rapid IR heating. This work involved metallurgical analysis of the forging stock all through the preheating, forging process, and heat treating process for convection heating and IR heating. The aluminum material forged in the field under varied heating conditions and standard final heat treatments were also systematically tested for mechanical properties. This basic understanding provided guidelines for the application of the technology to other aluminum alloy systems. Task 3 involved the following subtasks: 
1. performing microstructural studies using optical microscopy, scanning electron microscopy (SEM), transmission electron microscopy (TEM), and atom probe field ion microscopy (APFIM) on forgings produced at various stages in the forging operation;

2. performing tensile, high cycle fatigue, and hardness tests on forgings produced under selected heat treating conditions;

3. performing differential scanning calorimetry (DSC) and X-ray diffraction (XRD) studies to understand the precipitation kinetics affecting the mechanical properties; and

4. establishing a relationship between the evolved microstructure, materials properties, and the preheating and heat treating parameters.

\subsubsection{Task 4: Field Testing}

The focus of Task 4 was to perform field testing of the hybrid IR furnace and to fabricate metallurgical and mechanical testing specimens at industrial sites. The following subtasks were completed:

1. calibrating and tuning the IR system to reproduce the heating rates achieved in the laboratory trials and

2. producing forgings by preheating the billets using the industry-installed unit and verifying the grain structure of these materials.

\subsubsection{Task 5: Energy Analysis}

During implementation of the technology, an analysis was performed to estimate the energy savings that can be realized by utilization of the hybrid IR billet-on-demand heater. The estimated cost savings due to improved product quality and reduced rejection rate in the forging operation were also analyzed.

Estimated energy and cost savings are shown in Table 2.2. 



\section{Results and Discussion}

The major emphasis of the research in this project was to develop a hybrid IR billet heating system that will save energy and result in a grain size in aluminum alloy forgings that is an order of magnitude finer than grain sizes produced by conventional forging methods. The following sections explain how completion of various tasks led to a successful implementation of this technology in one forging industry.

Sections 4.1 and 4.2 below discuss the experiments performed at the laboratory scale which form the basis of the furnace design. Section 4.3 discusses the mechanism of grain refinement and proposes a strengthening mechanism based on the finer grain size and the changing solutionizing and precipitation kinetics as a function of the heat treating parameters. The last two sections of this chapter explain how the IR heating furnace was implemented and how the benefits of this technology were conveyed within an industrial environment.

The key findings and outcomes of these research efforts were the following:

- The project developed a full-scale hybrid IR billet heating system that is three times more energy efficient and four times more productive than the current convection gas-fired furnace.

- Energy analyses showed that the newly developed technology has a potential to provide energy savings of $7.2 \times 10^{12}$ Btu/year if fully utilized by the domestic aluminum forging industry.

- Grain growth during IR heating of aluminum alloy 2618 forgings was largely controlled by the lower thermal input. Excessive grain growth during longer heat-up times was inhibited by the pinning of the grain boundaries by the aluminum-iron-nickel $\left(\mathrm{Al}_{9} \mathrm{FeNi}\right)$ intermetallic particles.

- The improved mechanical properties of forgings produced by the IR heating process were attributed to grain refinement as well as retention of larger amounts of solute elements in the matrix during the short heat treatment time. Large amounts of solute elements help produce a fine distribution of precipitates that increases the strength of the material

\subsection{Industry Analyses}

Research for this project commenced with a meeting of all team members to perform an industry analysis and decide which aluminum alloys, types of forge stock (i.e., extrusion), heating rates and hold times at forging temperature would be investigated by ORNL and Northeastern University. As a result of the discussions, it was decided that rapid IR heating would be applied to 0.625-, 1.0-, 1.625-, 2.25-, 3-, and 4-in.-diameter 6061, 2618 and 2014 aluminum billets at varied powers of 50, 60, 70, and $80 \%$. Participants also decided to carry out sampling of aluminum parts during each phase of a typical aluminum part fabrication to map the microstructural evolution during the forging process. This sampling would include the initial forge stock as received from the vendor and the same material after conventional preheating (quench), after forging (quench), and after a final heat treatment.

To determine baseline metallurgy, optical microscopy examination and X-ray analysis were performed on the as-extruded billets of aluminum alloys 2014, 2618 and 6061 to identify the secondphase particles and the possible precipitating constituents that would enable grain refinement and strengthening of the alloy material. Optical examinations were performed on cross sections that were 
cut longitudinally and transverse to the extrusion direction. Due to the limitations of optical microscopy and X-ray methods in resolving the nanometer size and lower- volume-fraction minor phases, it was possible to clearly identify only the major phases within these alloys.

Figures 4.1-4.3 show the optical micrographs for alloys 2014, 2618 and 6061 lengthwise and transverse to the extrusion direction. The micrographs in Figure 4.1 reveal that the predominant major secondary-phase particles in aluminum alloy 2014 were $\mathrm{CuAl}_{2}, \mathrm{CuMgAl}_{2}$ and $\mathrm{Mn}_{3} \mathrm{SiAl}_{12}$. Similarly, the secondary-phase particles identified for aluminum alloy 2618 were $\mathrm{Al}_{9} \mathrm{FeNi}$ and $\mathrm{CuMgAl}_{2}$, and for aluminum alloy 6061 were $\mathrm{Mg}_{2} \mathrm{Si}$ (Figs. 4.2 and 4.3, respectively). Table 4.1 summarizes the secondary phase particles for these alloys and identifies the alloy compositions. Phase identification was in accordance with the published literature [9].

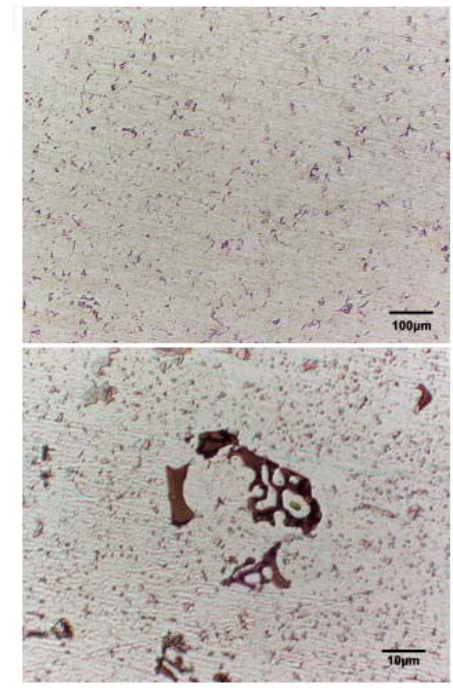

(a)

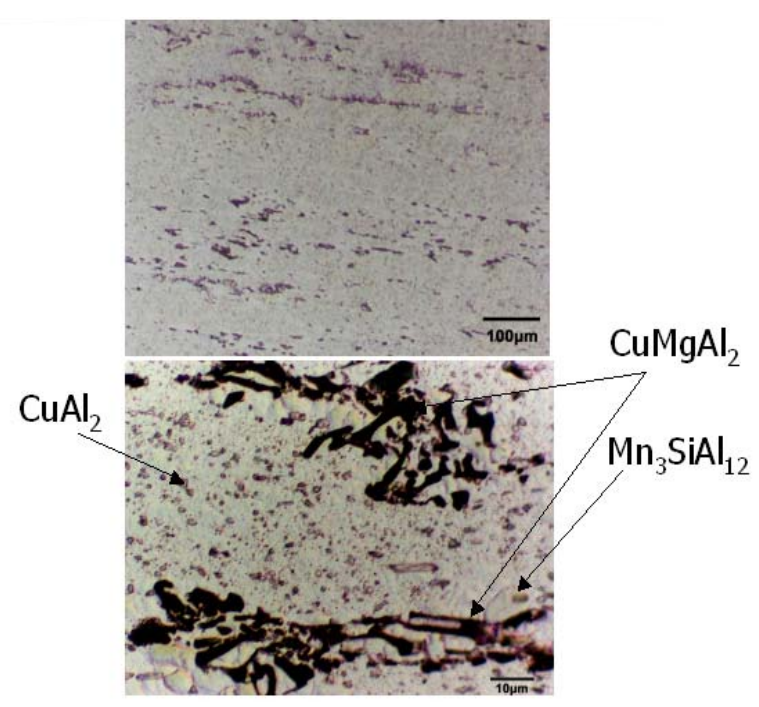

(b)

Fig. 4.1. Optical micrographs of as-extruded aluminum alloy 2014 billet along (a) transverse and (b) longitudinal orientations to the extrusion direction.

Table 4.1. Chemical composition and secondary-phase particles for aluminum alloys 2014, 2618, and 6061

\begin{tabular}{cll}
\hline Aluminum alloy & \multicolumn{1}{c}{$\begin{array}{c}\text { Alloy chemical composition } \\
\text { (wt \%) }\end{array}$} & \multicolumn{1}{c}{ Secondary-phase particles } \\
\hline 2014 & $\mathrm{Al}-4.4 \mathrm{Cu}-0.5 \mathrm{Mg}-0.8 \mathrm{Mn}-0.8 \mathrm{Si}$ & $\mathrm{CuAl}_{2}, \mathrm{CuMgAl}_{2}, \mathrm{Mn}_{3} \mathrm{SiAl}_{12}$ \\
2618 & $\mathrm{Al}-2.3 \mathrm{Cu}-1.6 \mathrm{Mg}-0.18 \mathrm{Si}-1.0 \mathrm{Ni}-1.1 \mathrm{Fe}-0.07 \mathrm{Ti}$ & $\mathrm{Al}_{9} \mathrm{FeNi}$ and $\mathrm{CuMgAl}_{2}$ \\
6061 & $\mathrm{Al}-0.27 \mathrm{Cu}-1.0 \mathrm{Mg}-0.6 \mathrm{Si}-0.2 \mathrm{Cr}$ & $\mathrm{Mg}_{2} \mathrm{Si}$ \\
\hline
\end{tabular}




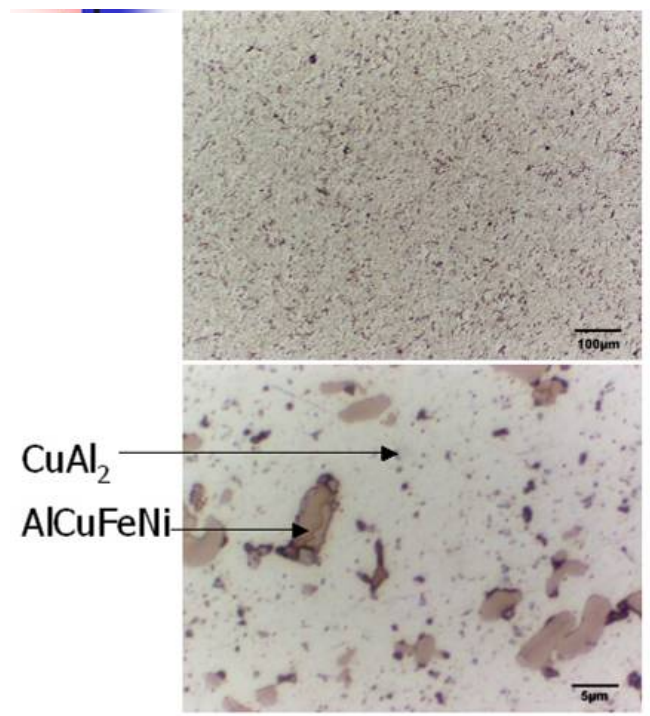

(a)

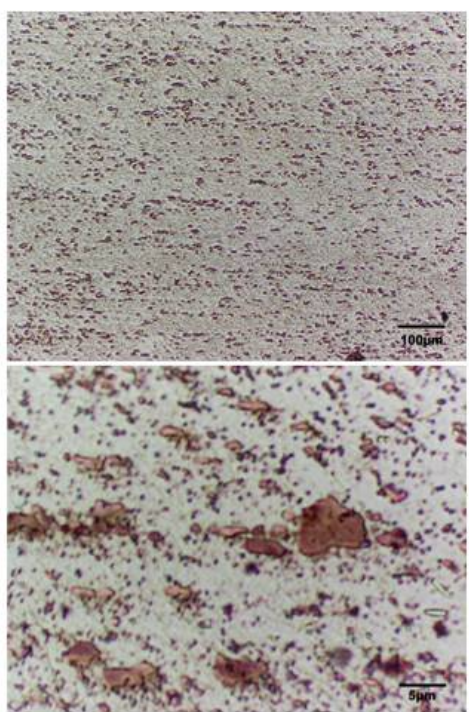

(b)

Fig. 4.2. Optical micrographs of as-extruded aluminum alloy 2618 billet along (a) transverse and (b) longitudinal orientations to the extrusion direction.

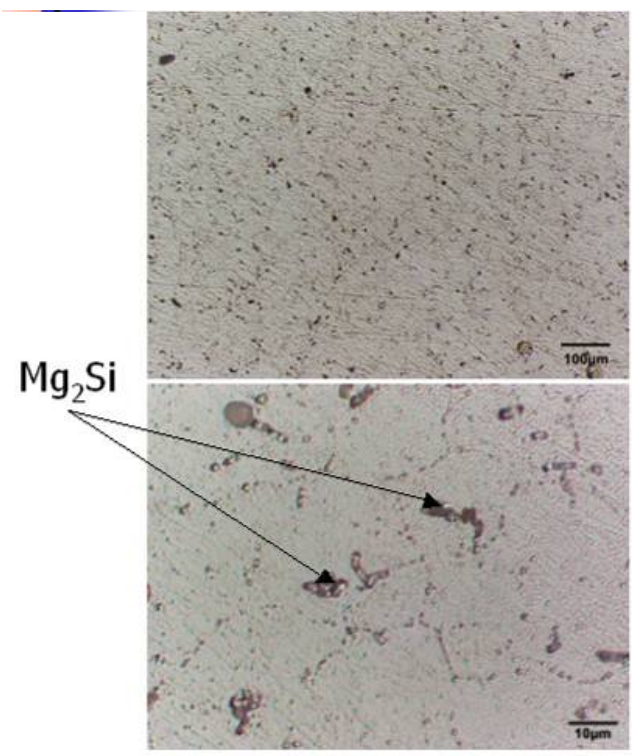

(a)
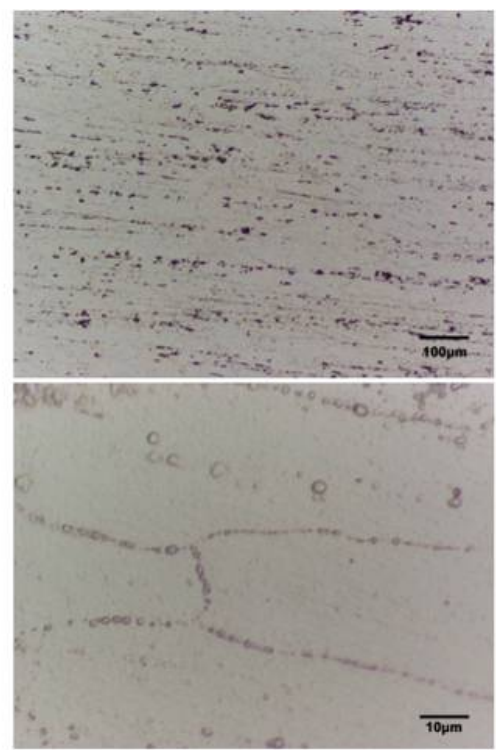

(b)

Fig. 4.3. Optical micrographs of as-extruded aluminum alloy 6061 billet along (a) transverse and (b) longitudinal orientations to the extrusion direction. 


\subsection{Equipment Design and Fabrication}

\subsubsection{Rapid Infrared Heating Trials}

Aluminum forge stock 6061, 2014, and 2618 was subjected to rapid preheating in the batch-type drop-bottom IR furnace at ORNL (Fig. 4.4). This furnace is an 88-kW unit consisting of two halves: an upper half carrying an array of tungsten halogen quartz lamps and a lower half with a drop-down arrangement used to load specimens into the furnace. The main body of the upper and the lower halves is made of water-cooled stainless steel plates lined with firebrick.

Thermocouples were placed in the centers and on the surfaces of the 0.625 - to 4 -in.-diameter billets. Power was varied from 50 to $80 \%$ in $10 \%$ increments, and the time and temperature profiles were recorded with a multichannel data acquisition system. Figure 4.5 shows a typical IR heating cycle for all the given billets at $70 \%$ power.

As noted above, billets can be heated in as little as $3 \mathrm{~min}$. It was also observed that a substantial gradient could not be produced from surface to center (approximately $20^{\circ} \mathrm{C}$ ) due to the high thermal conductivity and would equilibrate out in extremely short times. Therefore, one-sided heating was possible. Because most of the forgings at KomTeK and Queen City are in the range of 0.625 to 2.25 in., it was decided that the furnace would be designed with billets of these sizes as targets, though any size could be run.

Taking 2.25 in. as the largest billet diameter for furnace design, another set of experiments was run at ORNL to identify the fastest heating rate that would be easily reproducible in industrial settings. Figure 4.6 shows the heating profile for a 2.25 -in.diameter aluminum alloy 2618 billet. The figure shows a small thermal gradient from the surface to the center with a heating rate of $0.5^{\circ} \mathrm{C} / \mathrm{s}$. The thermal plot shows that a 2.25-in.-diameter, 6-in.-long billet could be heated to $425^{\circ} \mathrm{C}$ through the entire cross section in $16 \mathrm{~min}$. It was decided that once the entire cross section reached the forging temperature $\left(425^{\circ} \mathrm{C}\right.$ for this alloy), the billets would be forged immediately without any soaking.

To determine the effects of shorter preheating times on the metallurgy of this alloy, a comparative study with various preheating schedules was undertaken using conventional heating. The preheating experiments were performed in a Lindberg/blue furnace at

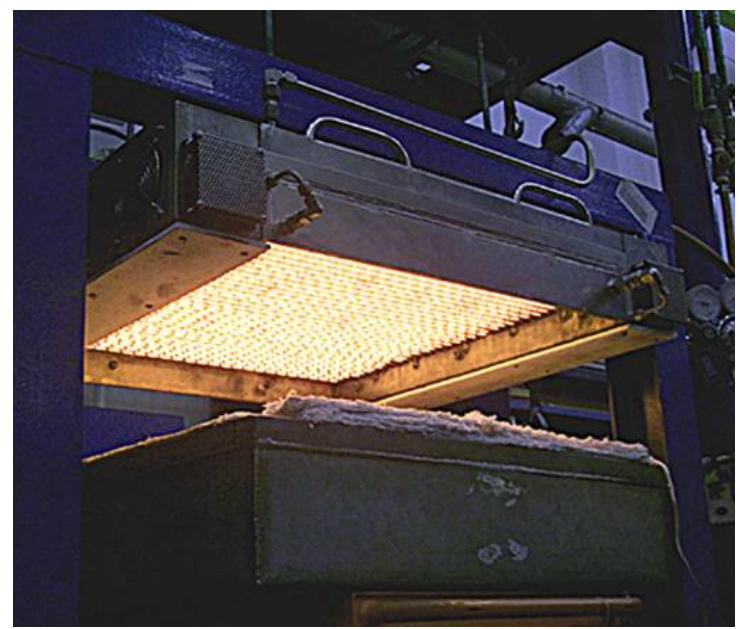

Fig. 4.4. ORNL's 88-kW batch-type drop-bottom IR furnace.

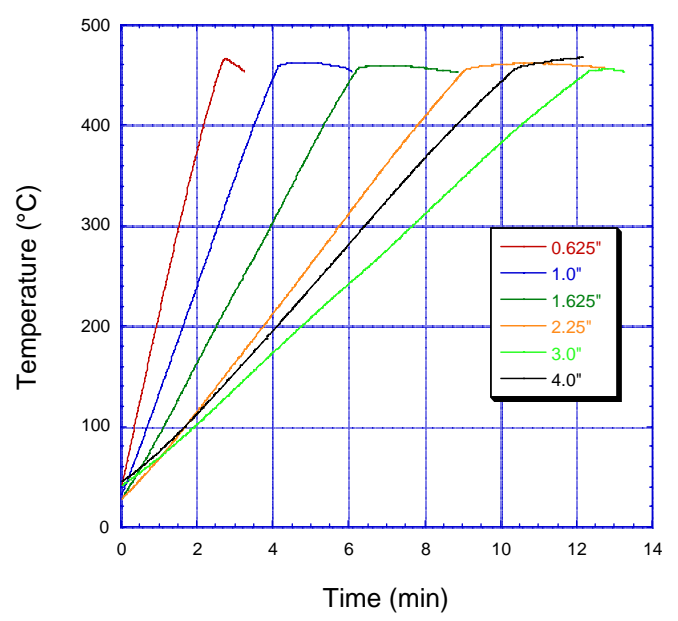

Fig. 4.5. Heating rate for various diameters of aluminum bars in the flat-bed IR furnace at $70 \%$ power. 
Northeastern University. Specimens 0.5 in. long were cut from the billets and placed in a preheated furnace. The preheating times studied were 15 and $30 \mathrm{~min}$ and 1, 2, 4, and $8 \mathrm{~h}$. Preheating time was calculated starting from the time when specimens were placed in a furnace at an initial temperature of $450^{\circ} \mathrm{C}$. As indicated in Fig. 4.7, the time required by the specimen to reach a preheating temperature of $450^{\circ} \mathrm{C}$ from room temperature was about $50 \mathrm{~min}$.

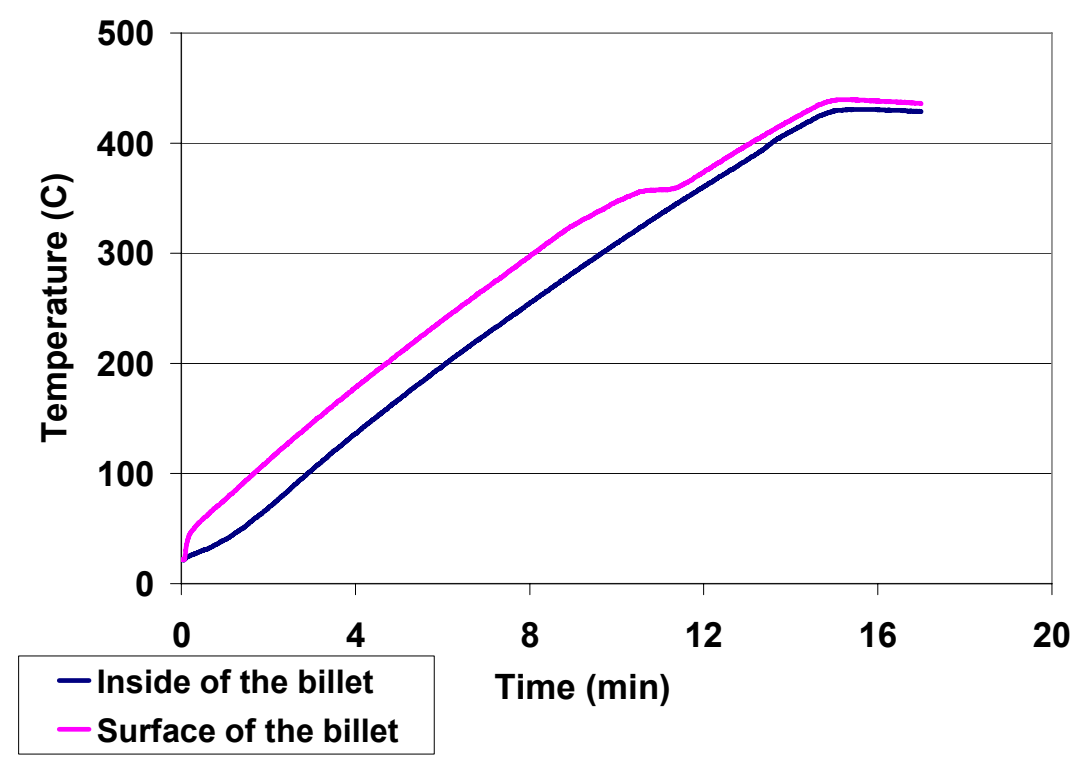

Fig. 4.6. Temperature profile for 2.25-in.-diameter, 6-in.-long aluminum alloy 2618 billet preheated using IR heating.

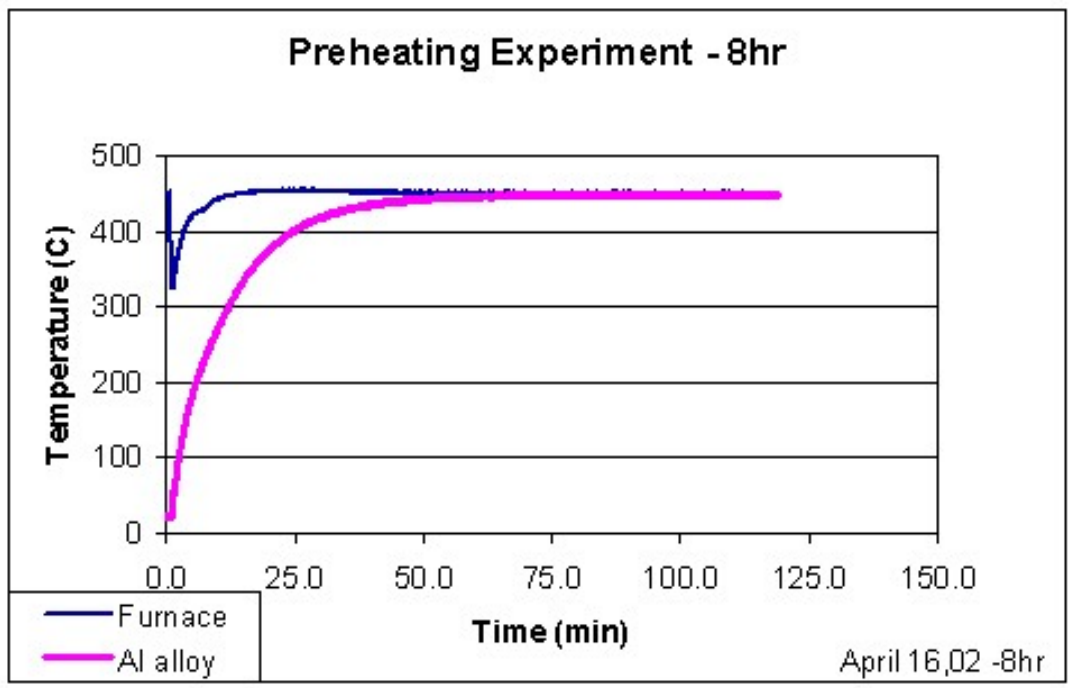

Fig. 4.7. Heating profile for 2.25-in.-diameter, 0.5-in.-long aluminum alloy 2618 billet preheated using an electric furnace. 
Specimens were immediately quenched after heating to "freeze" the microstructure. These specimens were cut and mounted for metallographic inspection. Keller's reagent and a mixture of $25 \mathrm{~mL} \mathrm{HNO}_{3}$ and $75 \mathrm{~mL} \mathrm{H}_{2} \mathrm{O}$ were used as the etchants to reveal the microstructure in the 2618 alloy specimens in the pre-heat-treated state. Figures 4.8 and 4.9 show optical micrographs at low, intermediate, and high magnifications representing transverse and longitudinal sections, respectively, for specimens prepared with shorter $(30 \mathrm{~min})$ and longer $(8 \mathrm{~h})$ preheating times at $450^{\circ} \mathrm{C}$.

As expected with this alloy, all micrographs show the presence of $\mathrm{Al}_{9} \mathrm{FeNi}$ and $\mathrm{CuMgAl}_{2}$ as gray and dark phases, respectively (Figs. 4.8-4.9). The $\mathrm{Al}_{9} \mathrm{FeNi}$ particles were somewhat elongated in the extrusion direction with an aspect ratio of 3 to 6 . None of etchants revealed grain boundaries; however, the second-phase particles appeared to have been coarsened considerably over the heat treatment time, implying that the matrix grains may also coarsen to similar degrees. Taking this into account, short preheating times were considered favorable in the design of the prototype system for industrial use.

\subsubsection{Fabrication of a Prototype System}

Based on the preliminary laboratory trial runs explained in the previous section, a continuous-belttype hybrid furnace with the design specifications shown in Table 4.2 was fabricated by one of the project industrial partners (IR Heating Technologies, Inc., Oak Ridge, TN).

\subsection{Materials Development}

To understand the microstructural evolution of these aluminum alloys and its effect on materials properties, it was necessary to isolate and study the effects of various parameters such as preheating time, forging, solution heat treatment time, and aging conditions independently on one of the aluminum alloy systems. In order to accomplish this, a series of aluminum alloy 2618 forgings with varying preheating and heat treating conditions, as shown in Table 4.3, were systematically produced at ORNL and characterized at Northeastern University. The grain sizes and hardness values corresponding to the various processing conditions are also summarized in Table 4.3. The starting billets were $2.5 \mathrm{in}$. in diameter and $6 \mathrm{in}$. long. The forging and solution heat treatment temperatures were in accordance with AMS 2772 specifications. The times required for the billets to reach the desired temperatures by the two heating methods were as follows:

$\begin{array}{lcc}\text { Heating method } & \text { Forging temperature } & \text { Solution heat treatment temperature } \\ & \left(425^{\circ} \mathrm{C}\right) & \left(530^{\circ} \mathrm{C}\right) \\ \text { IR heating } & 16 \mathrm{~min} & 21 \mathrm{~min} \\ \text { Conventional heating } & 2-2.5 \mathrm{~h} & 2-2.5 \mathrm{~h}\end{array}$

In cases where forgings were prepared, the dies were heated to $360-370^{\circ} \mathrm{C}$ using an IR insert heater prior to forging. Forging of billets was accomplished using a hydraulic press with an upset ratio of $2: 1$ and a strain rate of $0.5 \mathrm{~s}^{-1}$. Temperatures during rapid heating of the billets prior to forging and during solution heat treatment were monitored. Typical temperature profiles achieved during IR preheating were similar to those shown earlier in Fig. 4.6. Typical temperature profiles achieved during IR solution heat treatment are shown in Fig. 4.10.

The characterization of IR-processed and conventionally processed billets included phase identification and grain size measurement using optical microscopy and SEM, and age hardening behavior using hardness measurement and testing of tensile and fatigue properties. The following sections describe the results achieved during the characterization of the billets and forgings. 


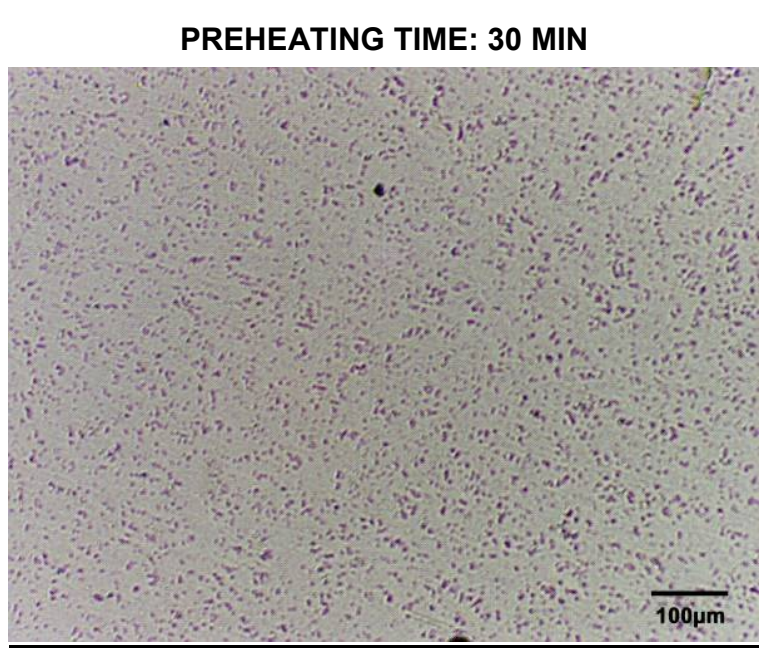

(a)



(b)

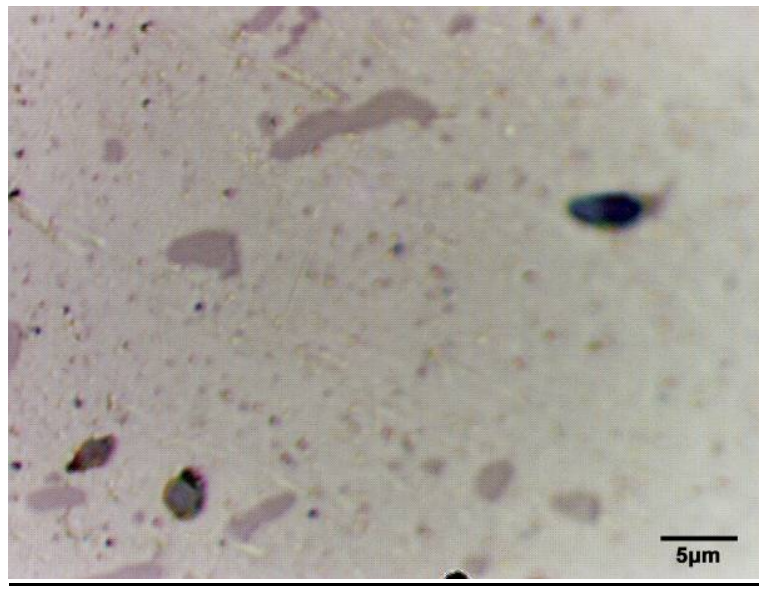

(c)

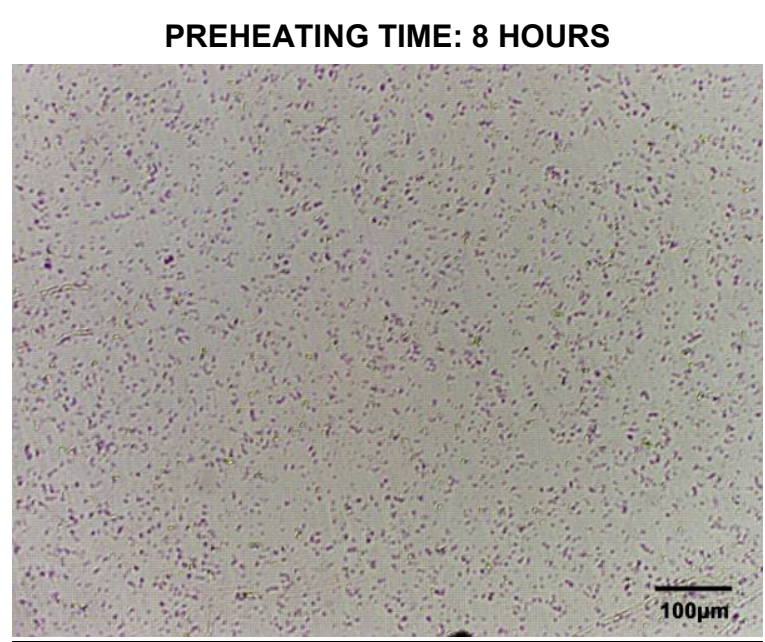

(d)

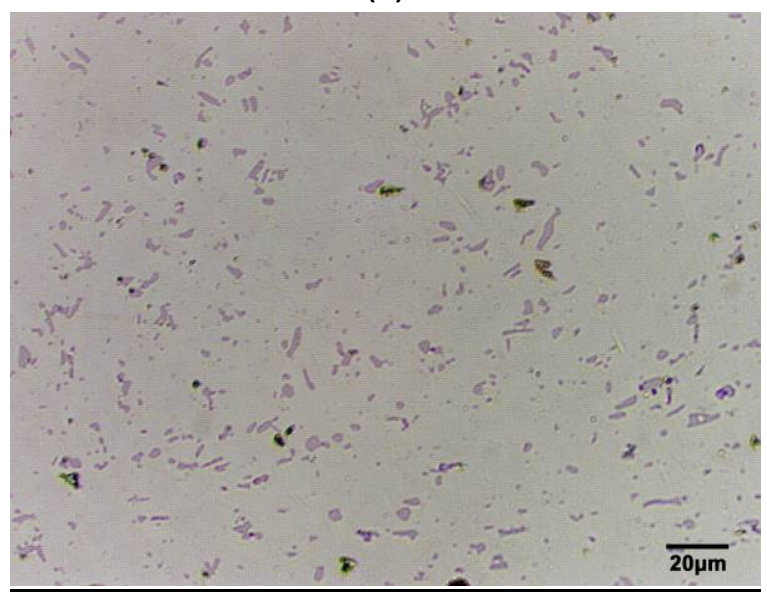

(e)

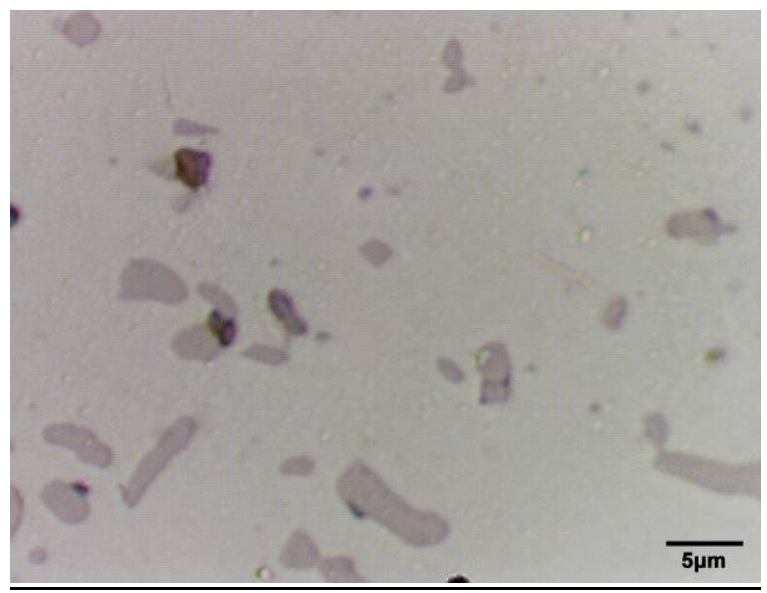

(f)

Fig. 4.8. Optical micrographs showing transverse cross sections of aluminum alloy 2618 billets preheated for $30 \mathrm{~min}$ and $8 \mathrm{~h}$ at $450^{\circ} \mathrm{C}$ (various magnifications). 


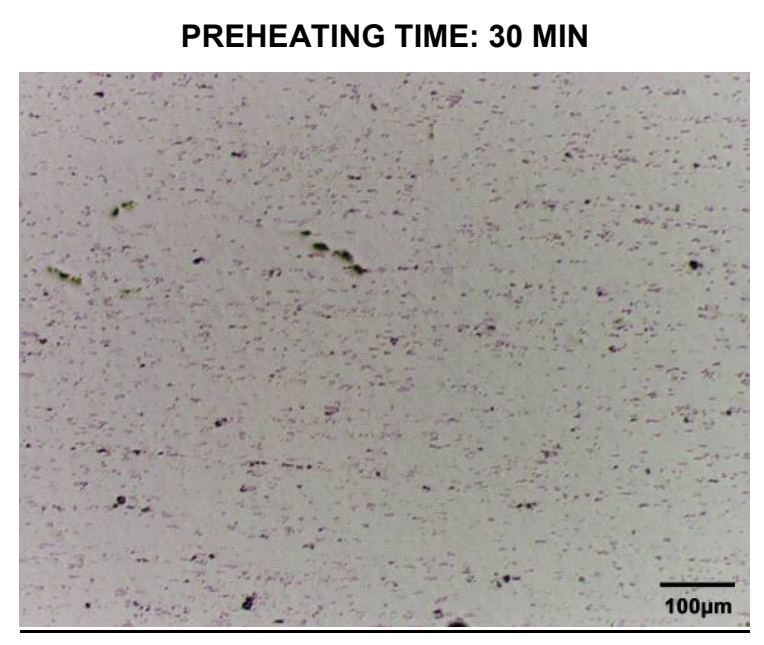

(a)

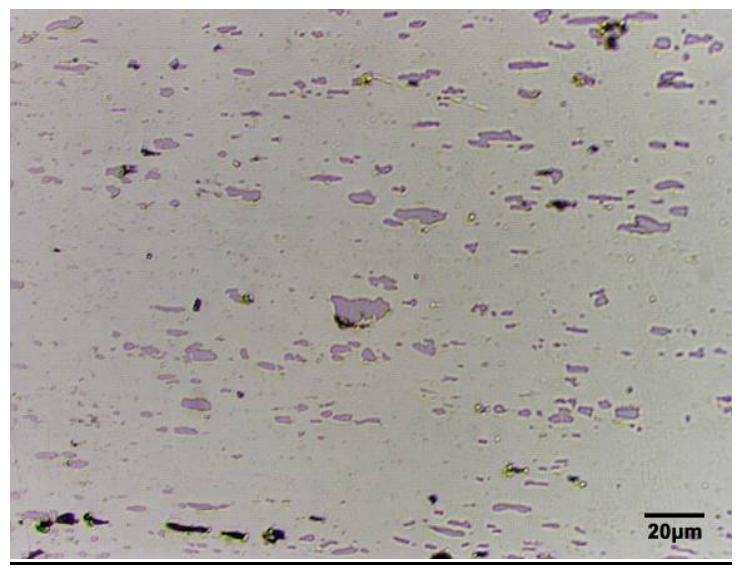

(b)



(c)
PREHEATING TIME: 8 HOURS

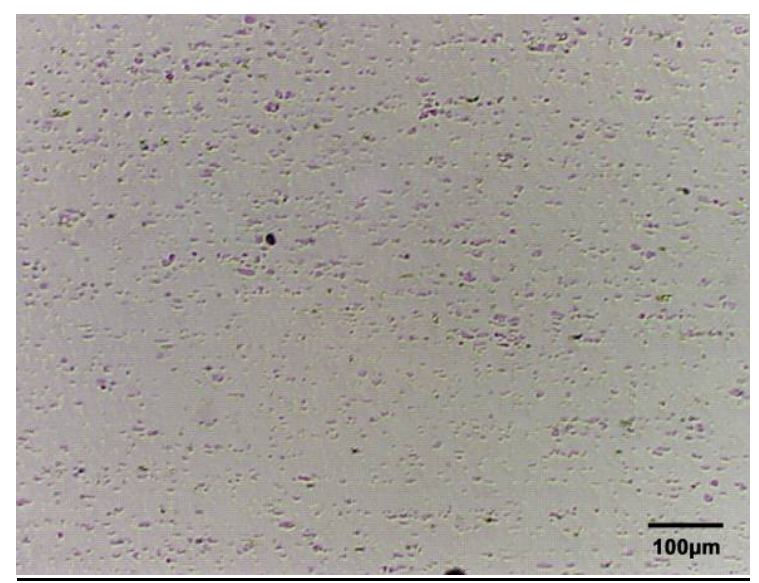

(d)

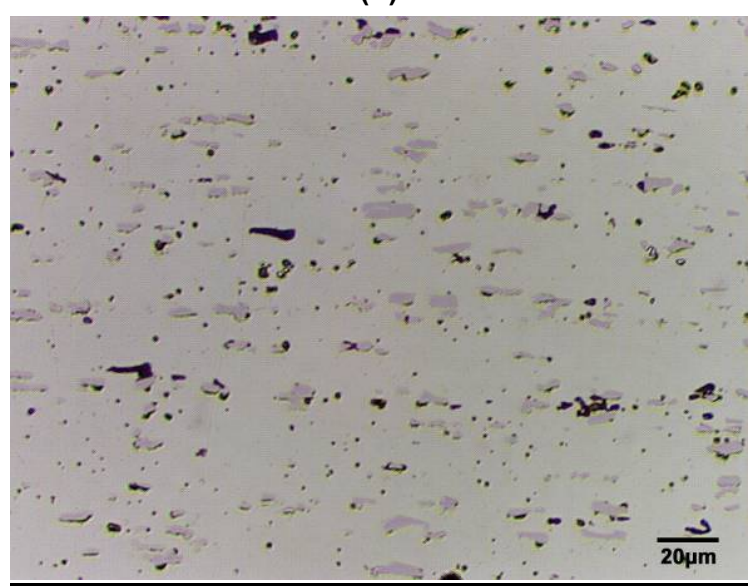

(e)

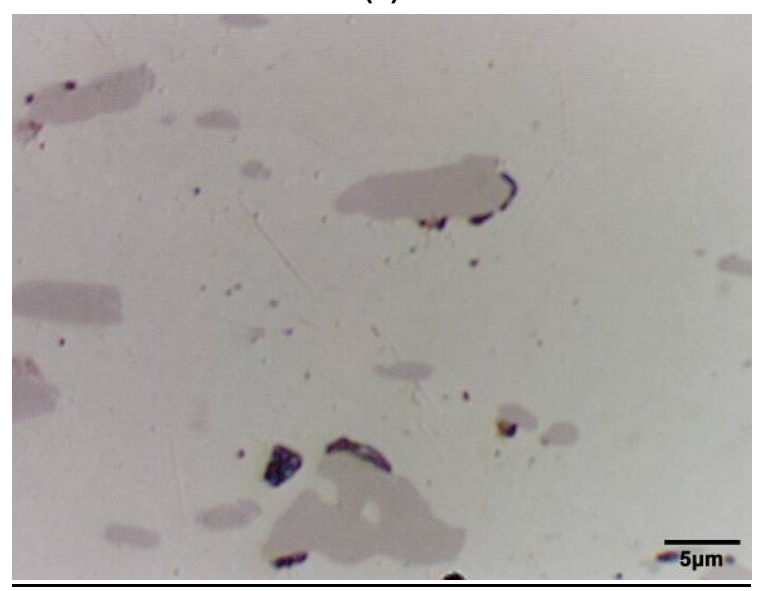

(f)

Fig. 4.9. Optical micrographs showing longitudinal cross sections of aluminum alloy 2618 billets preheated for $30 \mathrm{~min}$ and $8 \mathrm{~h}$ at $450^{\circ} \mathrm{C}$ (various magnifications). 
Table 4.2. Design specifications of IR conveyor oven system

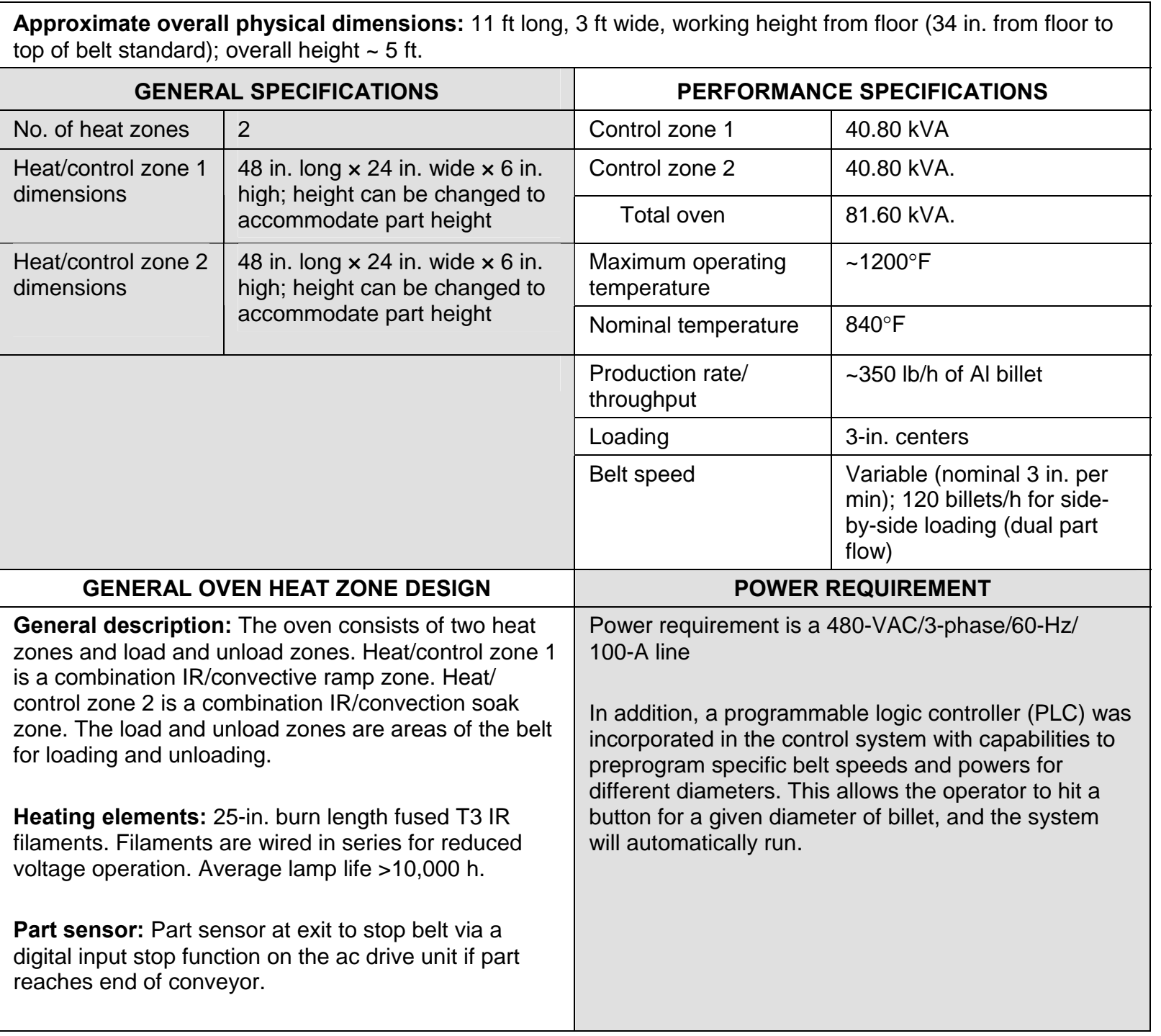


Table 4.3. Processing conditions for aluminum alloy 2618 specimens

\begin{tabular}{|c|c|c|c|}
\hline $\begin{array}{c}\text { Specimen } \\
\text { Identification }\end{array}$ & Preheating prior to forging & Solution heat treatment & Aging \\
\hline IR-1 & $\begin{array}{l}\text { Rapidly preheated to } 425^{\circ} \mathrm{C} \text {, } \\
\text { forged and air-cooled }\end{array}$ & $\begin{array}{l}\text { Rapidly heated to } 530^{\circ} \mathrm{C} \text {, soaked for } 1 \mathrm{~min} \text { and } \\
\text { quenched in agitating boiling water (Rapid Solution } \\
\text { Treatment) }\end{array}$ & $\begin{array}{l}\text { Precipitation hardened by heating the } \\
\text { quenched samples conventionally to } \\
200^{\circ} \mathrm{C} \text { and aged for } 20 \mathrm{~h} \text { (Conventional } \\
\text { Aging) - Temper T61 }\end{array}$ \\
\hline IR-40 & $\begin{array}{l}\text { Rapidly preheated to } 425^{\circ} \mathrm{C} \text {, } \\
\text { forged and air-cooled }\end{array}$ & Rapidly solution treated, but soaked for $40 \mathrm{~min}$ & Conventionally aged - Temper T61 \\
\hline IR-40 NA & $\begin{array}{l}\text { Rapidly preheated to } 425^{\circ} \mathrm{C} \text {, } \\
\text { forged and air-cooled }\end{array}$ & Rapidly solution treated, but soaked for $40 \mathrm{~min}$ & $\begin{array}{l}\text { Naturally aged ( } 1 \text { week) at room } \\
\text { temperature - Temper T4 }\end{array}$ \\
\hline IR-AC & $\begin{array}{l}\text { Rapidly preheated to } 425^{\circ} \mathrm{C} \text {, } \\
\text { forged and air-cooled }\end{array}$ & $N / A$ & $N / A$ \\
\hline IR-U-WQ & $\begin{array}{l}\text { Rapidly preheated to } 425^{\circ} \mathrm{C} \text {, } \\
\text { quenched in ambient water }\end{array}$ & $\mathrm{N} / \mathrm{A}$ & $\mathrm{N} / \mathrm{A}$ \\
\hline IR-WQ & $\begin{array}{l}\text { Rapidly preheated to } 425^{\circ} \mathrm{C} \text {, } \\
\text { forged and quenched in } \\
\text { ambient water }\end{array}$ & $N / A$ & $N / A$ \\
\hline IR-C & $\begin{array}{l}\text { Rapidly preheated to } 425^{\circ} \mathrm{C} \text {, } \\
\text { forged and air-cooled }\end{array}$ & $\begin{array}{l}\text { Conventionally heated to } 530^{\circ} \mathrm{C} \text {, soaked for } \\
2-2.5 \mathrm{~h} \text { and quenched in agitating boiling water } \\
\text { (Conventional Solution Treatment) }\end{array}$ & Conventionally aged - Temper T61 \\
\hline C-C & $\begin{array}{l}\text { Conventionally preheated to } \\
425^{\circ} \mathrm{C} \text {, forged and air-cooled }\end{array}$ & $\begin{array}{l}\text { Conventionally heated to } 530^{\circ} \mathrm{C} \text {, soaked for } \\
2-2.5 \mathrm{~h} \text { and quenched in agitating boiling water } \\
\text { (Conventional Solution Treatment) }\end{array}$ & Conventionally aged - Temper T61 \\
\hline C-AC & $\begin{array}{l}\text { Conventionally preheated to } \\
425^{\circ} \mathrm{C} \text {, forged and air-cooled }\end{array}$ & $N / A$ & $\mathrm{~N} / \mathrm{A}$ \\
\hline C-U-WQ & $\begin{array}{l}\text { Conventionally preheated to } \\
425^{\circ} \mathrm{C} \text {, quenched in ambient } \\
\text { water }\end{array}$ & $N / A$ & $N / A$ \\
\hline C-WQ & $\begin{array}{l}\text { Conventionally preheated to } \\
425^{\circ} \mathrm{C} \text {, forged and quenched } \\
\text { in ambient water }\end{array}$ & $N / A$ & $N / A$ \\
\hline
\end{tabular}




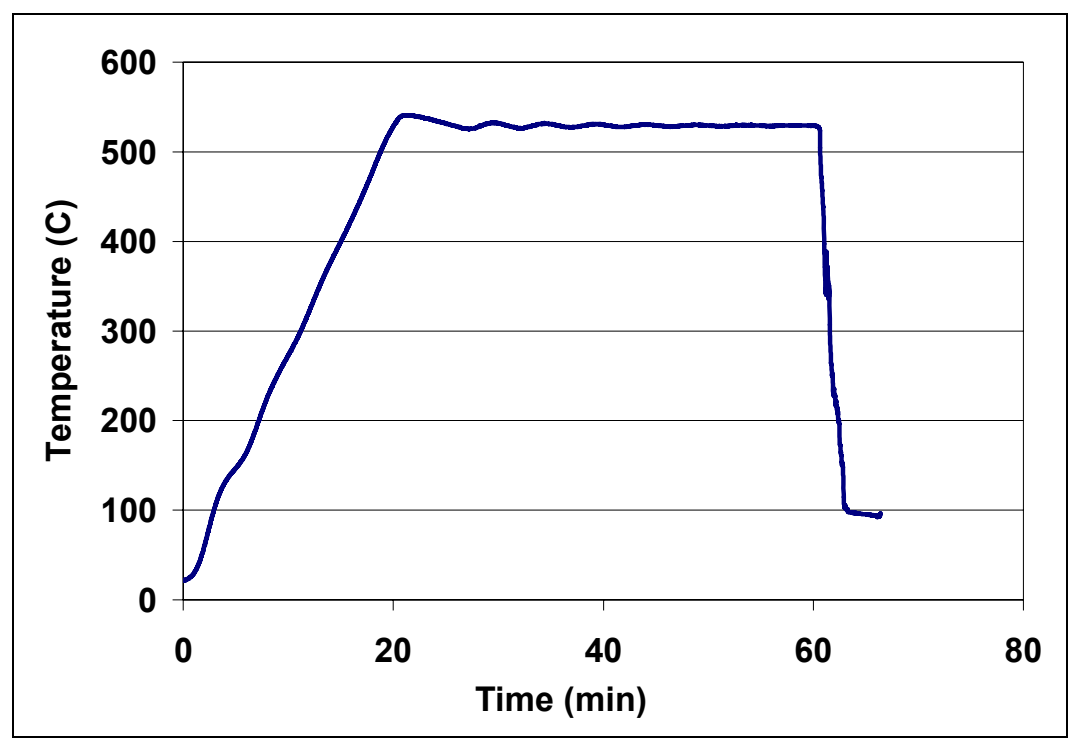

Fig. 4.10. Temperature profile from the center of the billet during IR solution heat treatment (soaking time $=\mathbf{4 0} \mathrm{min}$ ).

\subsubsection{Effects of Preheating}

The effects of rapid preheating on the microstructure just before forging were investigated by comparing specimens IR-U-WQ and C-U-WQ. These specimens were preheated under the following conditions:

IR-U-WQ: Rapidly preheated to $425^{\circ} \mathrm{C}$ and quenched in water

CU-WQ: Conventionally preheated to $425^{\circ} \mathrm{C}$ and quenched in water*

Metallographic characterization was performed at the center of transverse cross sections of the forgings using an Olympus VANOX-T optical microscope. Micrographs (a) and (b) of Fig. 4.11 were taken at low and high magnifications on transverse sections of specimen IR-U-WQ; micrographs (c) and (d) show specimen C-U-WQ at two magnifications. The specimens were etched with a mixture of $2 \mathrm{~g}$ of $\mathrm{NaOH}, 4 \mathrm{~g}$ of $\mathrm{Na}_{2} \mathrm{CO}_{3}$, and $94 \mathrm{~mL}$ of water. Both specimens exhibit similar microstructures, characterized by intermetallic particles distributed in a recovered polycrystalline $\alpha$ matrix. The etching technique employed did not reveal the grain boundaries or sub-boundaries in the recovered $\alpha$ matrix in either of the specimens. Recrystallization did not take place during the preheating at $425^{\circ} \mathrm{C}$, probably because there was insufficient prior cold work left, and also because of the presence of fine intermetallic particles in the matrix, which suppresses recrystallization. Specimen IR-U-WQ, rapidly heated to the preheating temperature, appear to have a slightly higher volume fraction of intermetallic particles, as can be seen by comparing micrographs (a) and (c) in Fig. 4.11. The higher-magnification micrographs [Figs. 4.11(b) and 4.11(d)] show that the intermetallic particles are somewhat larger and more irregularly shaped in the rapidly preheated specimen than in the conventionally preheated specimen on both longitudinal and transverse sections. The intermetallic phase particles in the conventionally preheated specimen had more time to spheroidize, partially dissolve, and possibly undergo some Ostwald ripening as well.

\footnotetext{
* In the following discussion the terms "rapidly" or "IR" indicate the faster heating rates using IR heating, and the terms "conventionally" or " $\mathrm{C}$ " indicate the slower heating rates using a conventional convection furnace.
} 
Specimen IR-U-WQ — Rapid preheating

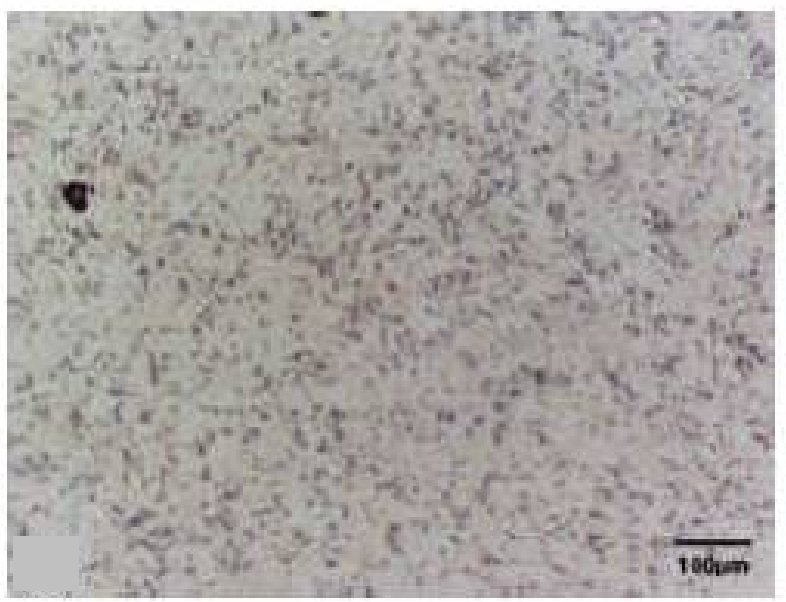

(a)

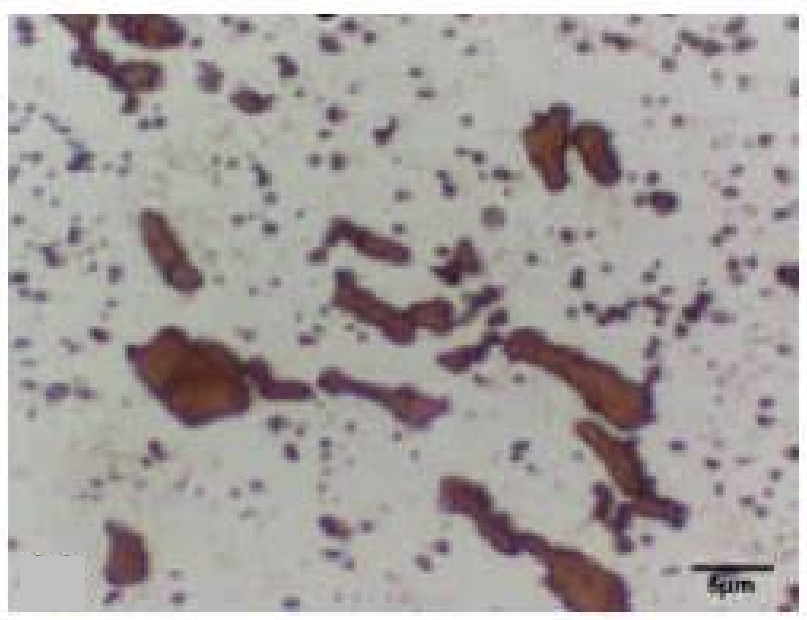

(b)
Specimen C-U-WQ - Conventional preheating

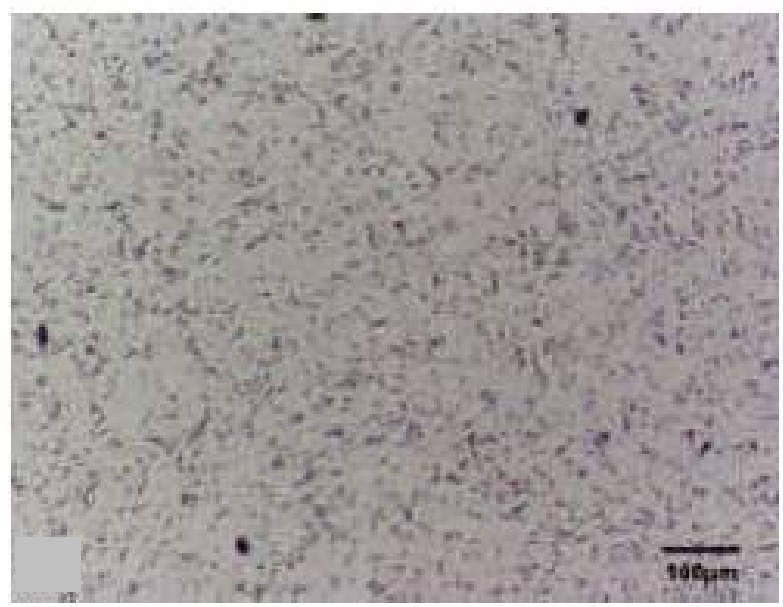

(c)

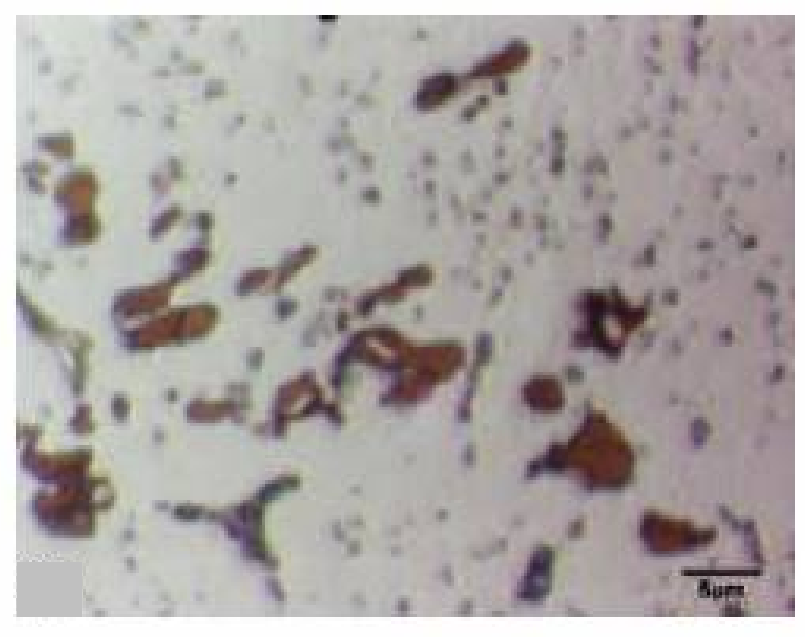

(d)

Fig. 4.11. Optical micrographs of specimens with rapid vs conventional preheating, under two different magnifications.

\subsubsection{Forging and Cooling Conditions}

The effects of rapid preheating on aluminum alloy microstructure just after forging were investigated by comparing specimens IR-AC, C-AC, IR-WQ, and IR-WQ, which were preheated under the conditions below:

IR-AC: $\quad$ Rapidly preheated, forged at $425^{\circ} \mathrm{C}$, and air-cooled

C-AC: $\quad$ Conventionally preheated, forged at $425^{\circ} \mathrm{C}$, and air-cooled

IR-WQ: Rapidly preheated, forged at $425^{\circ} \mathrm{C}$, and water-quenched

C-WQ: $\quad$ Conventionally preheated, forged at $425^{\circ} \mathrm{C}$, and water-quenched 
Metallographic characterization was done on transverse sections. Figure 4.12 shows highmagnification micrographs taken at the center of the four specimens. The metallography was conducted on samples electro-etched with Barker's reagent at a current density of 14-18 A/DM2, immersed for $30 \mathrm{~s}$. All of these specimens exhibited similar microstructures, characterized by intermetallic particles distributed in a deformed (and partially recovered) $\alpha$ matrix. There was no indication of recrystallization observed in either of the specimens. Reflecting the additional deformation, the intermetallic particles in these specimens were rounder and more uniformly distributed in the matrix than in the as-extruded specimens. The rapidly preheated specimens (IR-AC and IR-WQ) appeared to have slightly more intermetallic particles than the conventionally preheated billets (C-AC and C-WQ). There was no noticeable microstructural difference between the air-cooled and water-quenched specimens.

RAPIDLY PREHEATED SPECIMENS

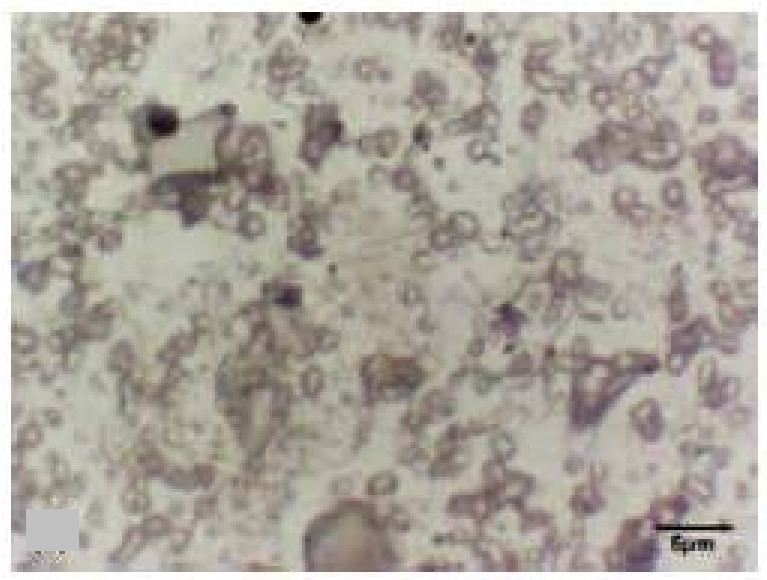

IR-AC

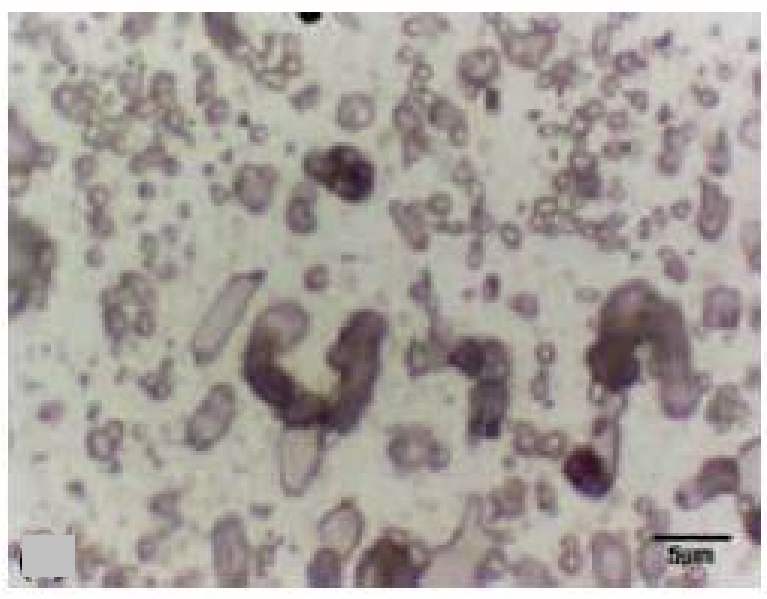

IR-WQ

\section{CONVENTIONALLY PREHEATED SPECIMENS}

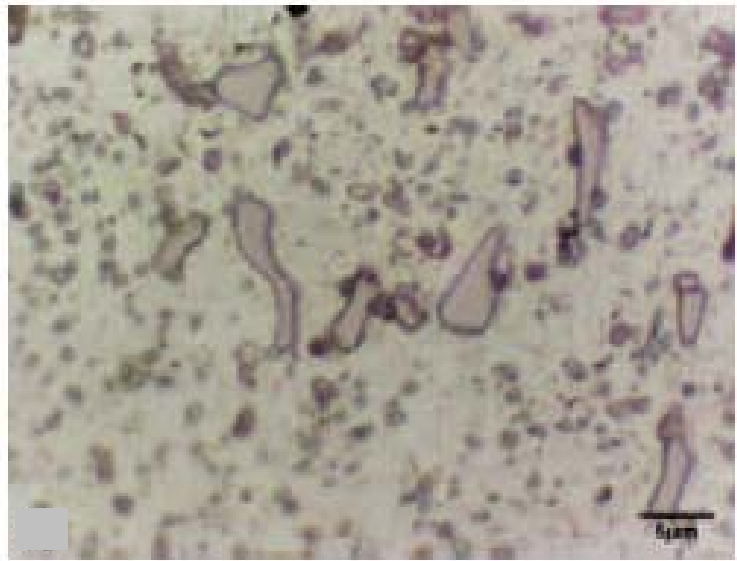

C-AC

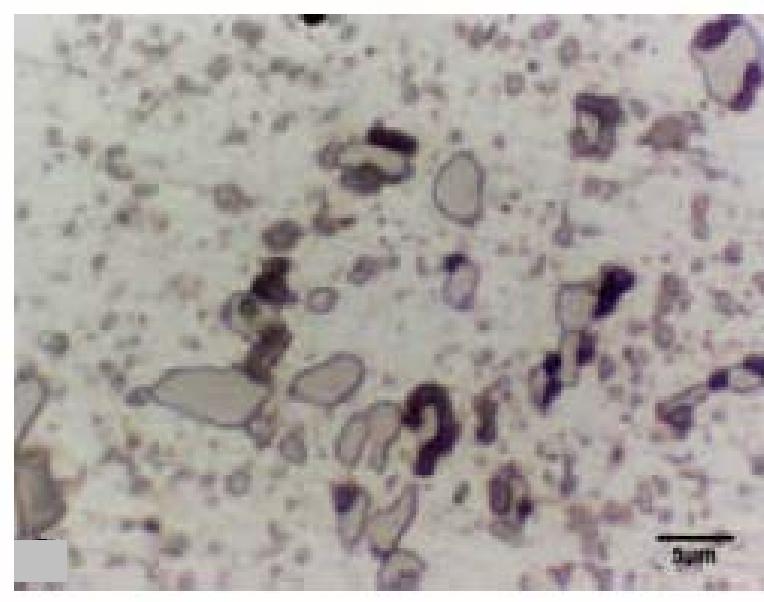

C-WQ

Fig. 4.12. Optical micrographs of rapidly preheated and conventionally preheated specimens with different cooling conditions after forging 


\subsubsection{Effects of Heat Treatment}

The effects of rapid heating on the preheating and solutionizing temperatures on the final Temper T61 (T61) microstructure and hardness were studied with specimens IR-40 and C-C, which were processed as follows:

IR-40: $\quad$ Rapidly preheated, forged, air-cooled, rapidly solution heat treated (soaked at $530^{\circ} \mathrm{C}$ for $40 \mathrm{~min}$ ) and conventionally aged (at $200^{\circ} \mathrm{C}$ for $20 \mathrm{~h}$ )

C-C: $\quad$ Conventionally preheated, forged, air-cooled, conventionally solution heat treated (soaked at $530^{\circ} \mathrm{C}$ for $2-2.5 \mathrm{~h}$ ) and conventionally aged (at $200^{\circ} \mathrm{C}$ for $20 \mathrm{~h}$ )

Figure 4.13 shows micrographs taken on longitudinal and transverse sections at the center of the specimens. Barker's reagent was used to reveal the grain boundaries. Both specimens exhibited equiaxed spheroidal grains indicative of full recrystallization during the solution treatment. The specimen processed with IR rapid heating (IR-40) clearly exhibits much smaller grains than the conventionally processed specimen (C-C). The average grain size of specimen IR-40 was determined by the linear-intercept method (ASTM standard E112-96) to be $27 \mu \mathrm{m}$, and that of C-C was $40 \mu \mathrm{m}$. The finer grain size of the HDI-processed specimen could be due to the greater grain boundary pinning effects of intermetallic particles. This resulted because the shorter exposure to high temperature of this specimen left more intermetallic particles with less particle coarsening in the $\alpha$ matrix. Figure 4.14 shows a high-magnification SEM micrograph of IR-40, showing intermetallic particles at the grain boundaries. Energy-dispersive X-ray spectroscopy (EDX) indicated that the primary pinning phase is $\mathrm{Al}_{9} \mathrm{FeNi}$.

Hardness tests showed that the IR-processed specimen (IR-40) has higher ultimate tensile strength (UTS) and hardness values (370 MPa and HRB 67.7) than those of the conventionally processed specimen (C-C), which have values of $345 \mathrm{MPa}$ and HRB 59.5 (Fig. 4.15 and Table 4.4). Hardness tests were conducted at the center of transverse cross section of the forgings, on the HRB Rockwell scale, by a Wilson/Rockwell Hardness Tester Series 500 with a 1/16-in. steel ball penetrator, a minor load of $10 \mathrm{~kg}$ and a major load of $100 \mathrm{~kg}$. Tensile test specimens were cut longitudinally from the center of the forgings; their shape and dimensions are shown in Fig. 4.16. The tests were performed on an Instron 5582 testing machine at a crosshead speed of $0.02 \mathrm{~mm} / \mathrm{s}$. A $12.7-\mathrm{mm}$ extensometer was attached to the gage portion of the tensile test specimens during the tests.

Table 4.4. Properties of heat-treated aluminum alloy 2618 specimens

\begin{tabular}{lcccc}
\hline Specimen & $\begin{array}{c}\text { Grain size } \\
(\mu \mathrm{m})\end{array}$ & $\begin{array}{c}\text { Yield } \\
\text { Hardness }\end{array}$ & $\begin{array}{c}\text { (HRB) } \\
\text { strength } \\
(\mathrm{MPa})\end{array}$ & $\begin{array}{c}\text { Elongation } \\
(\%)\end{array}$ \\
\hline IR-1 & 28 & 60.0 & 268 & 9.3 \\
IR-40 & 27 & 67.7 & 270 & 13.3 \\
IR-40NA & 32 & 62.1 & 222 & 24.2 \\
IR-C & 27 & 58.9 & 260 & 13.7 \\
C-C & 40 & 59.5 & 266 & 13 \\
\hline
\end{tabular}




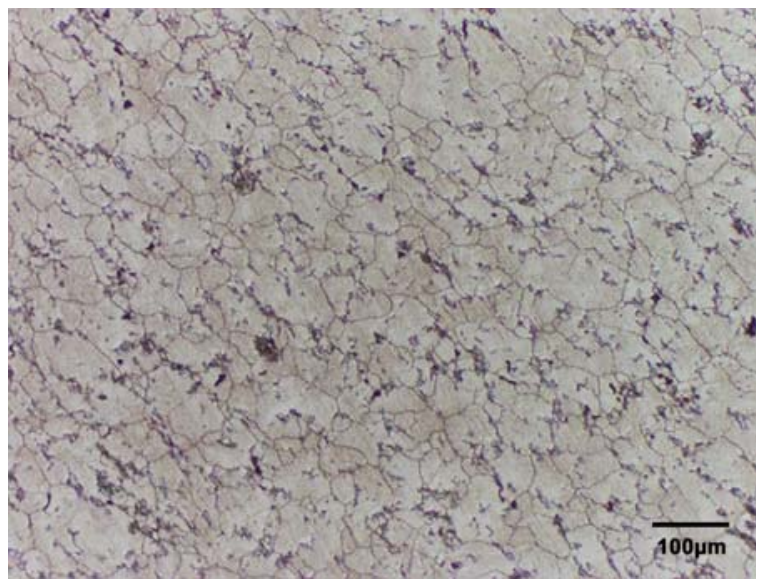

C-C: Longitudinal

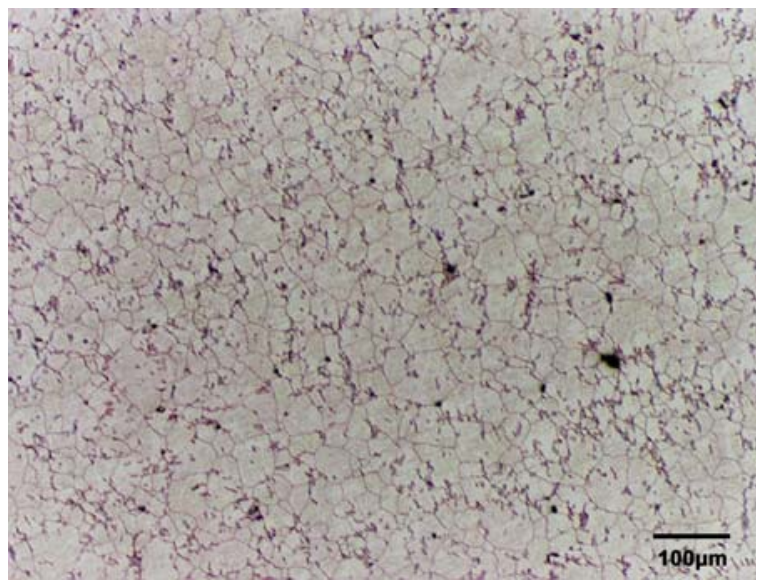

IR-40: Longitudinal

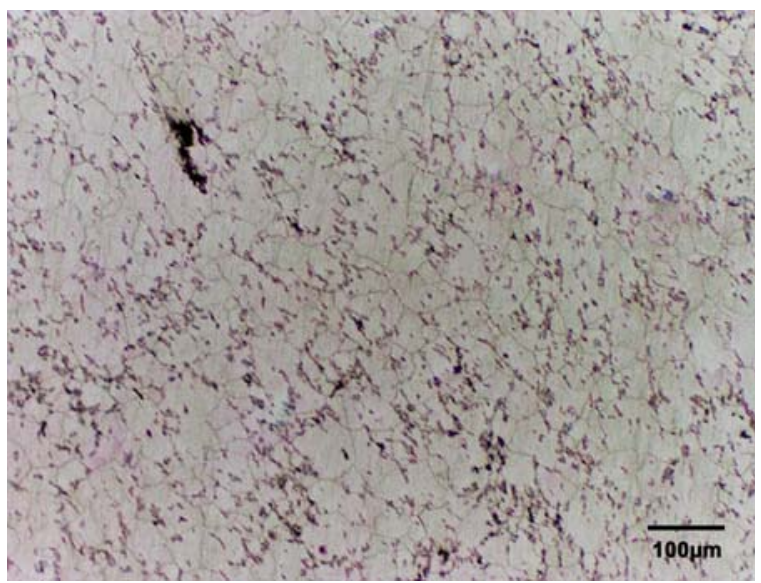

C-C: Transverse

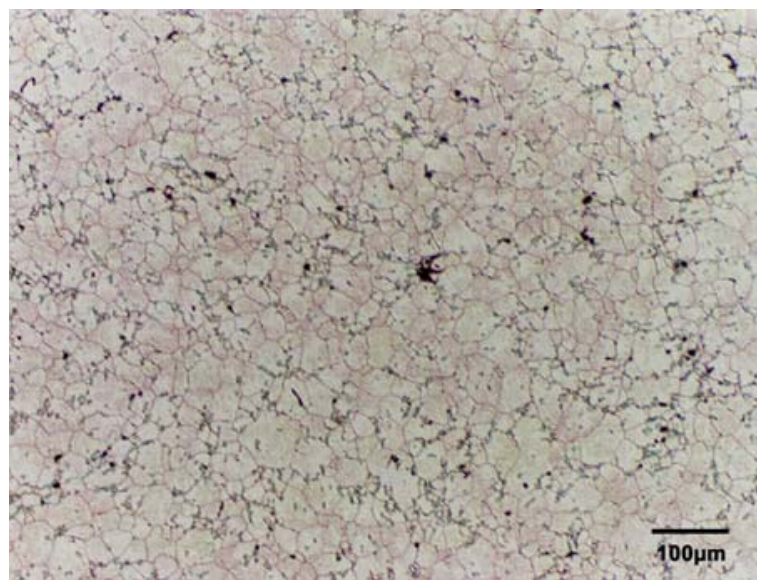

IR-40: Transverse

Fig. 4.13. Grain sizes of a conventionally processed specimen (C-C) versus those of a specimen processed with IR rapid heating (IR-40).

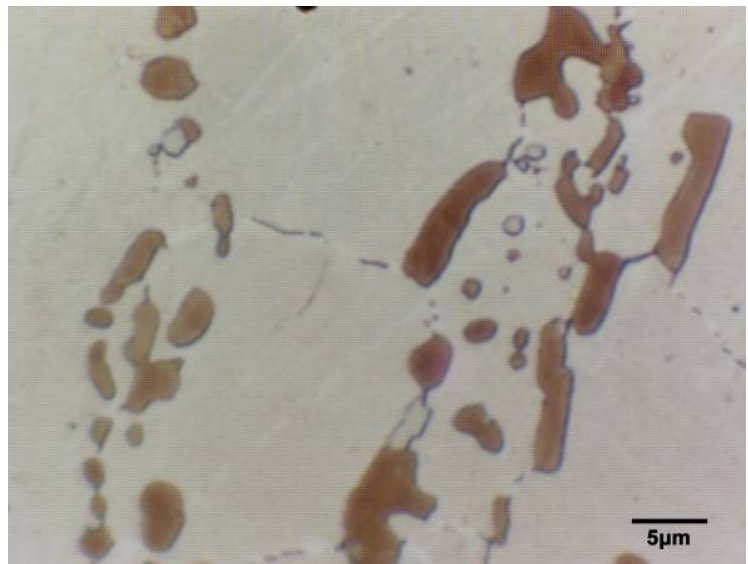

(a)



(b)

Fig. 4.14. (a) High-resolution SEM micrograph of specimen IR-40 showing intermetallic particles at the grain boundaries. (b) Energy-dispersive $\mathrm{X}$-ray spectroscopy analysis showing that the particles could be $\mathrm{Al}_{9} \mathrm{FeNi}$ 


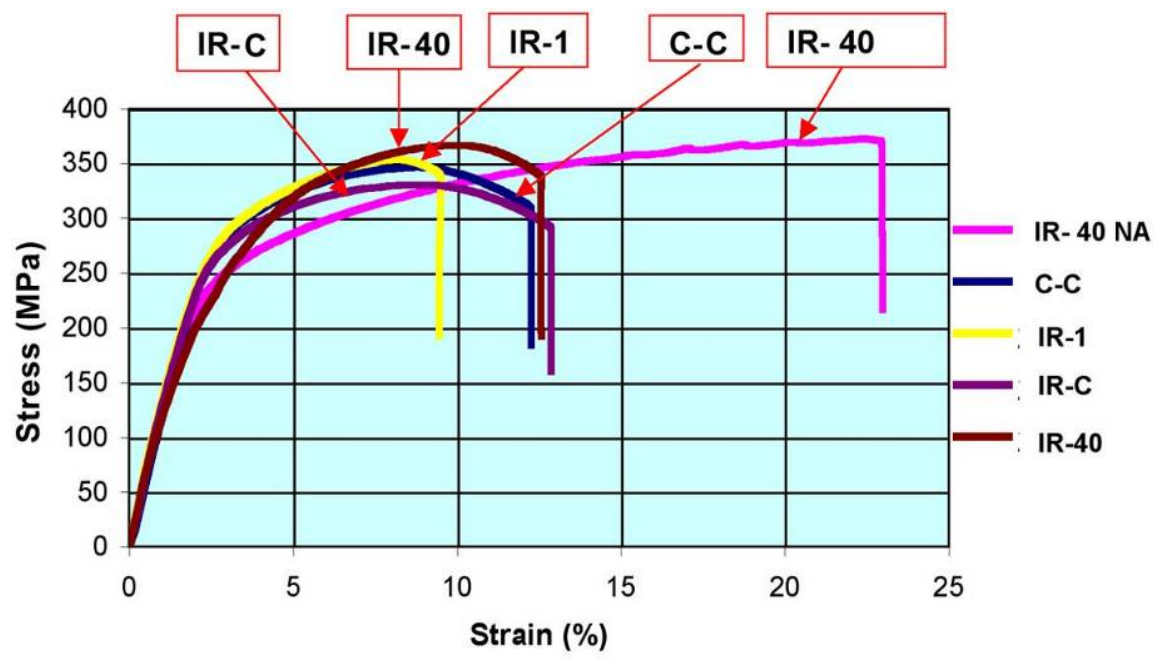

Fig. 4.15. Stress-strain curves for heat-treated specimens.
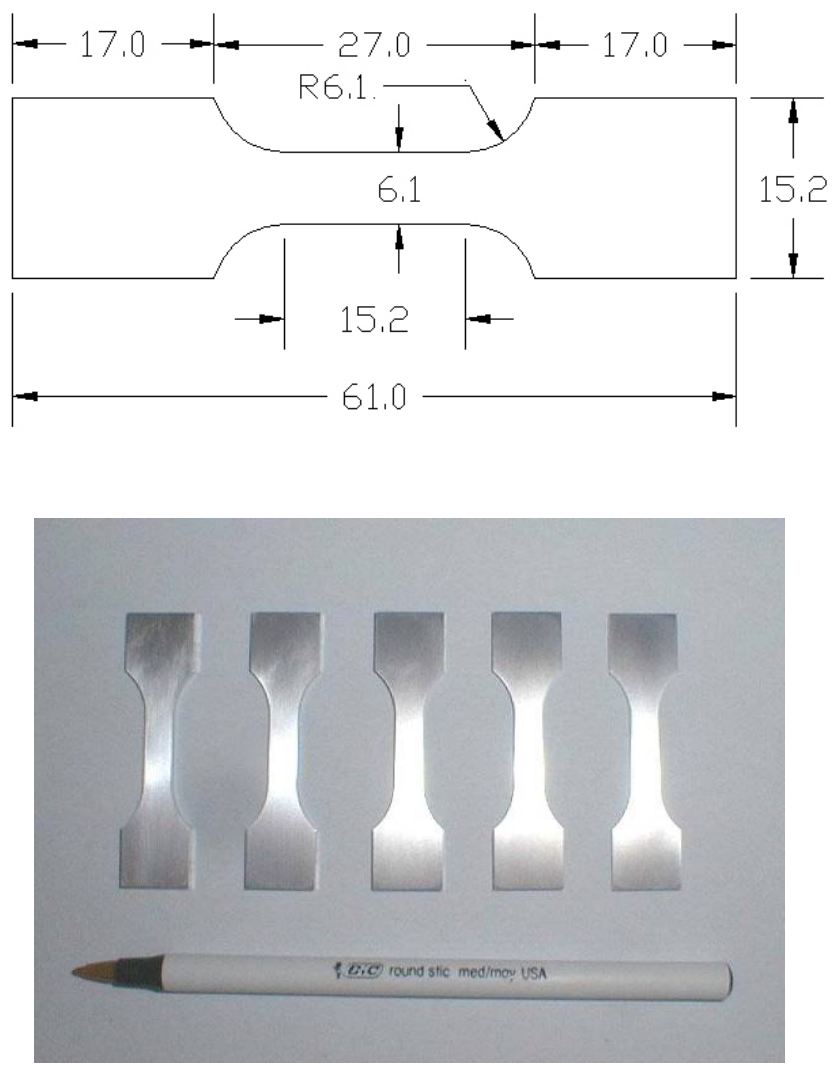

Fig. 4.16. Schematic (top) and picture (bottom) of the tensile and fatigue test specimens. Specimens were $2.54 \mathrm{~mm}$ thick. (All dimensions in $\mathrm{mm}$.) 


\subsubsection{Effects of Soaking Time}

The effects of soaking time after rapid heating to the solutionizing temperature $\left(530^{\circ} \mathrm{C}\right)$ on the final T61 microstructure and hardness were studied with specimens IR-1, IR-40 and IR-C. These specimens were processed under the conditions summarized below.

IR-1: $\quad$ Rapidly preheated, forged, air-cooled, rapidly solution heat treated (soaked at $530^{\circ} \mathrm{C}$ for $1 \mathrm{~min}$ ), and conventionally aged (at $200^{\circ} \mathrm{C}$ for $20 \mathrm{~h}$ )

IR-40: $\quad$ Rapidly preheated, forged, air-cooled, rapidly solution heat treated (soaked at $530^{\circ} \mathrm{C}$ for $40 \mathrm{~min}$ ), and conventionally aged (at $200^{\circ} \mathrm{C}$ for $20 \mathrm{~h}$ )

IR-C: $\quad$ Rapidly preheated, forged, air-cooled, conventionally solution heat treated (soaked at $530^{\circ} \mathrm{C}$ for $2-2.5 \mathrm{~h}$ ), and conventionally aged (at $200^{\circ} \mathrm{C}$ for $20 \mathrm{~h}$ )

Figure 4.17 compares micrographs of the three specimens taken at the center (core) on transverse sections. The micrograph of specimen IR-40 is the same as the one shown in Fig. 4.13. All three specimens show fully recrystallized equiaxed grains $\sim 27-28 \mu \mathrm{m}$ in diameter. An obvious interpretation of this observation is that recrystallization in these specimens took place within $1 \mathrm{~min}$ of soaking time and that the recrystallized grains did not coarsen for at least $2-2.5 \mathrm{~h}$ at the solutionizing temperature of $530^{\circ} \mathrm{C}$. This absence of grain coarsening is characteristic of grain boundary pinning by particles. In addition, since specimen IR-C was rapidly preheated for forging but conventionally heated to the solutionizing temperature, one can deduce that the enhanced grain boundary pinning effects come from the rapid heating to the preheating temperature.

The average hardness values of the specimens IR-1, IR-40, and IR-C are HRB 60.0, 67.7, and 58.9, respectively (Table 4.4). The hardness values parallel the UTS values. Therefore, the soaking time of $1 \mathrm{~min}$ after rapid heating did not produce full age-hardening. It is peculiar that despite the long (and supposedly sufficient) soaking time of $2-2.5 \mathrm{~h}$, specimen IR-C did not age-harden as much as did IR-1 and IR-40. Assuming that the soaking temperature was indeed controlled at $530^{\circ} \mathrm{C}$ for all three specimens, we may speculate that slow heating and/or long soaking time may have impaired the agehardening ability of this rapidly preheated and forged 2618 specimen. More evidence supporting this speculation is provided in Sect. 4.3.6, which discusses the fatigue results of the heat-treated specimens.

\subsubsection{Effects of Aging Temperature}

The effects of aging temperature were studied by comparing specimens IR-40 and IR-40NA that were heat treated to T61 and Temper T4 (T4) conditions, respectively, under the conditions shown below.

IR-40: Rapidly preheated, forged, air-cooled, rapidly solution heat treated (soaked at $530^{\circ} \mathrm{C}$ for $40 \mathrm{~min}$ ), and conventionally aged (at $200^{\circ} \mathrm{C}$ for $20 \mathrm{~h}$ )

IR-40NA: Rapidly preheated, forged, air-cooled, rapidly solution heat treated (soaked at $530^{\circ} \mathrm{C}$ for $40 \mathrm{~min}$ ), and naturally aged

Figure 4.17 compares micrographs of the two specimens taken at the center on transverse sections. The micrograph of specimen IR-40 is the same as the one in Fig. 4.13. Both specimens exhibit fully recrystallized equiaxed grains with small gain sizes characteristic of IR-processed specimens. 


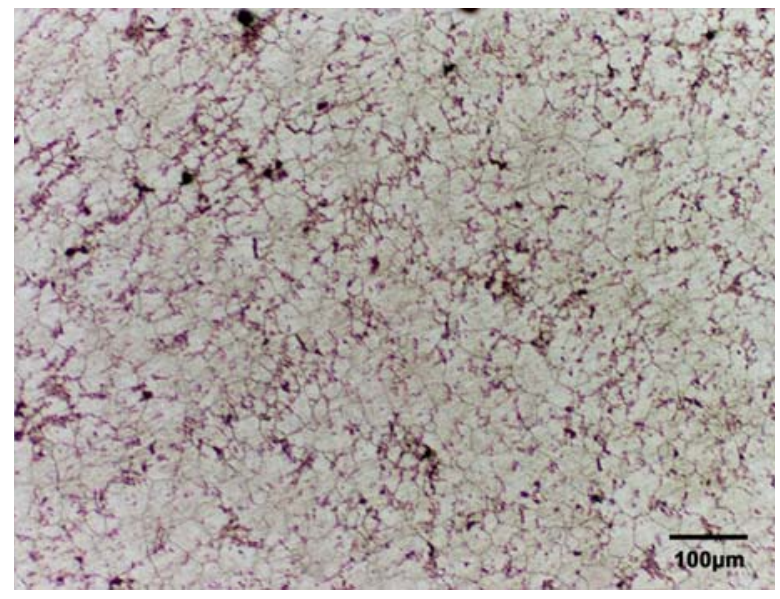

IR-1

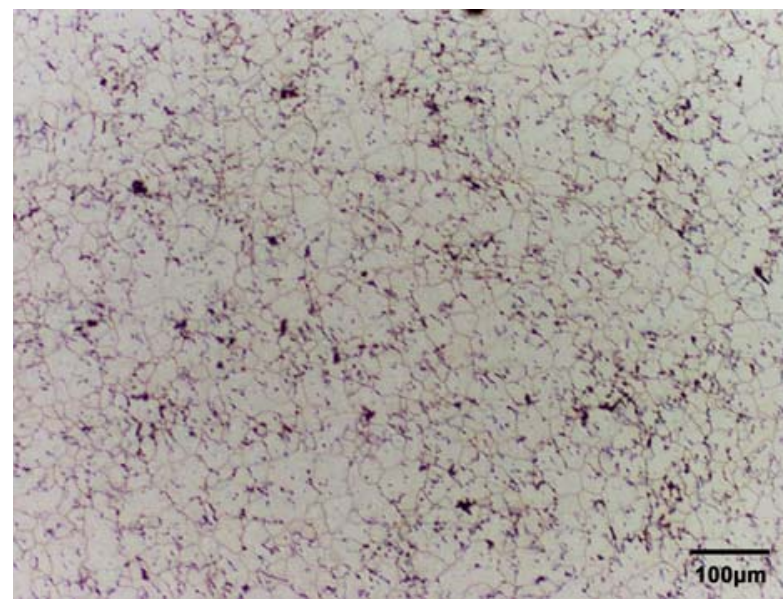

IR-C
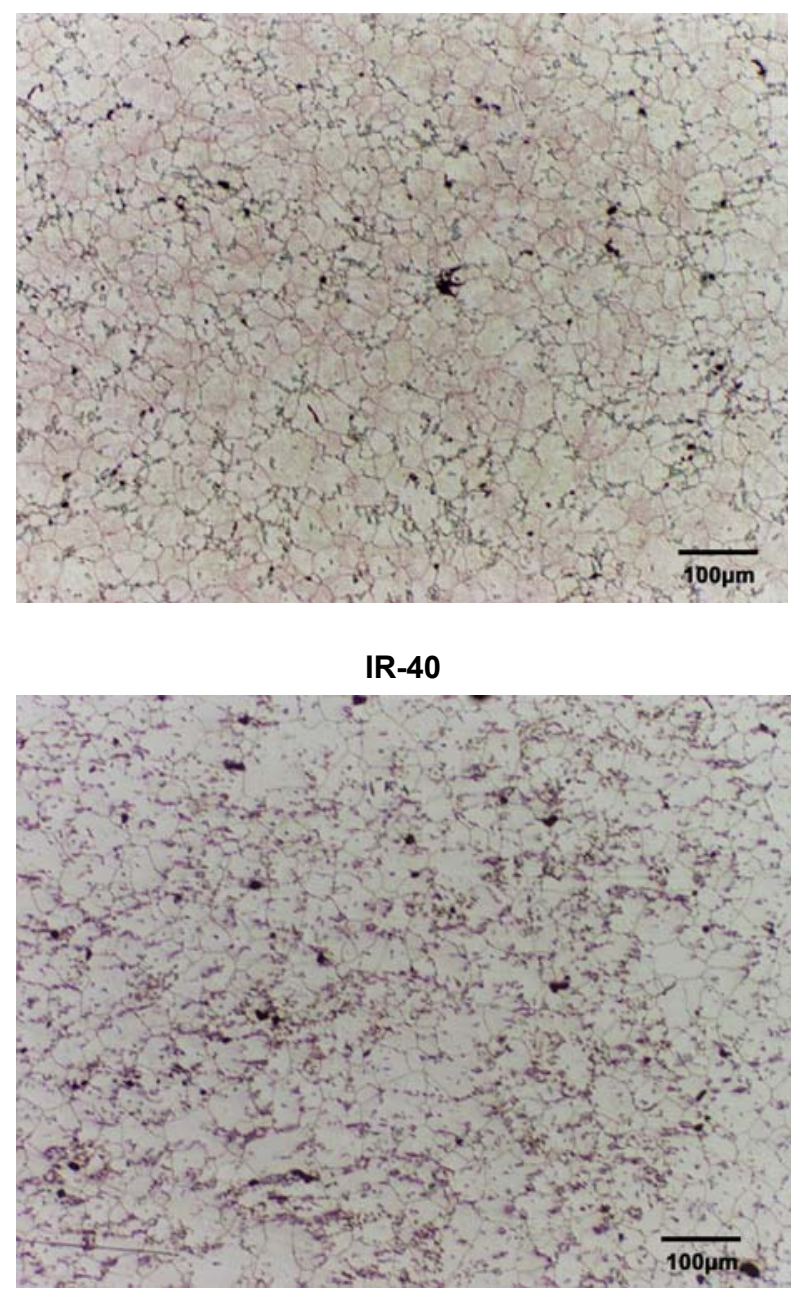

IR-40NA

Fig. 4.17. Optical micrographs showing effects of different soaking times (1 $\mathrm{min}, 40 \mathrm{~min}$ and $2-2.5 \mathrm{~h})$ and different aging temperatures (artificial aging at $200^{\circ} \mathrm{C}$ and room temperature natural aging) on microstructure.

Specimen IR-40NA, subjected to T4 treatment (natural aging), has a lower hardness (HRB 62.1) than the T61-treated IR-40 specimen, which has HRB 67.7, indicating an underaged condition in IR-40NA (Table 4.4). The two specimens have similar UTS values (370-375 MPa), as shown in Fig. 4.15. Specimen IR-40NA, rapidly preheated for forging and rapidly heated to and held for $40 \mathrm{~min}$ at the solutionizing temperature, continued to strain-harden, exhibiting a serrated strain-strain curve, until it fractured at an elongation of $23 \%$, where a flow stress of $375 \mathrm{MPa}$ was recorded. The serrated stressstrain curve was caused by dynamic strain aging (the Portevin-LeChatelier effect). 


\subsubsection{Fatigue Testing}

High-cycle fatigue tests were conducted to investigate the effects of grain size refinement and stronger tensile strength due to IR processing on the fatigue properties of aluminum alloy 2618 processed under the following conditions:

IR-40: IR-preheated and forged, IR-solutionized for $40 \mathrm{~min}$, and artificially aged at $200^{\circ} \mathrm{C}$ for $20 \mathrm{~h}$

IR-40NA: IR-preheated and forged, IR-solutionized for $40 \mathrm{~min}$, and naturally aged

IR-C: $\quad$ IR-preheated and forged, conventionally solutionized for $2-2.5 \mathrm{~h}$, and artificially aged at $200^{\circ} \mathrm{C}$ for $20 \mathrm{~h}$

IR-1: IR-preheated and forged, IR-solutionized for $1 \mathrm{~min}$, and artificially aged at $200^{\circ} \mathrm{C}$ for $20 \mathrm{~h}$

C-C: $\quad$ Conventionally preheated and forged, conventionally solutionized for 2-2.5 hours, and artificially aged at $200^{\circ} \mathrm{C}$ for $20 \mathrm{~h}$

Flat fatigue specimens were sectioned in the longitudinal direction from the center of the subject materials. All specimens were machined to the same dimensions as those of tensile test specimens; dimensions are shown in Fig. 4.16. The surfaces of the specimens were given a final polish with a 1500 grit emery paper. The fatigue tests were conducted on an Instron 8800 testing machine at room temperature in accordance with ASTM standard E466-96. Tension-tension loading with a minimumto-maximum stress ratio (R) of 0.1 and a sinusoidal waveform was employed. All the specimens were tested at a frequency of $20 \mathrm{~Hz}$. Tests were terminated at 10 million cycles if failure (defined as full sample separation) did not occur.

Figure 4.18(a) compares the fatigue data for specimens IR-40 and C-C. The IR-40 specimens had significantly higher fatigue resistance than the $\mathrm{C}-\mathrm{C}$ specimens at all the stress amplitudes tested (except for specimen 2). The improved fatigue resistance of the IR-40 specimens is attributed in part to the finer grain size $(\sim 30 \mu \mathrm{m})$ produced by the IR processing (see Table 4.4). Conventional processing produced courser grains $(\sim 40 \mu \mathrm{m})$ in the $\mathrm{C}$-C specimens. It should also be noted that the IR-40 specimens had a higher hardness value than the $\mathrm{C}-\mathrm{C}$ specimens (as also shown in Table 4.4).

Figure 4.18(b) summarizes the fatigue data for all five processing conditions (IR-40, IR- 40NA, IR-C, IR-1, and C-C). The IR-C specimens failed faster than the C-C specimens at high stress amplitudes, but both sets of specimens showed similar fatigue life at low stress amplitudes. Comparison of the IR-40 and IR-C fatigue data implies that conventional solution treatment nullifies the advantage of the prior RI-preheating. The hardness of the IR-C specimens (HRB 58.9) is significantly lower than that of the IR-40 specimens (HRB 67.7) but is comparable to that of the C-C specimens (HRB 59.5). However, the IR-C specimens, despite their longer exposure to the solutionizing temperature, retained a grain size $(27 \mu \mathrm{m})$ comparable to that of the IR-40 specimens $(27 \mu \mathrm{m})$, indicating that regardless of the solutionizing conditions, IR preheating is the primary determinant of grain size. These results also imply that the longer fatigue life of the IR-40 specimens may not be explainable solely on the basis of the grain refinement produced by IR preheating. The naturally aged specimens, IR-40NA, showed shorter fatigue life than the artificially aged specimens, primarily because of their low hardness. The RI-1 specimens, which were solution heat treated for $1 \mathrm{~min}$, have a short fatigue life at high stress amplitude and a relatively high fatigue life at low stress amplitude due to their small grain size $(28 \mu \mathrm{m})$. 


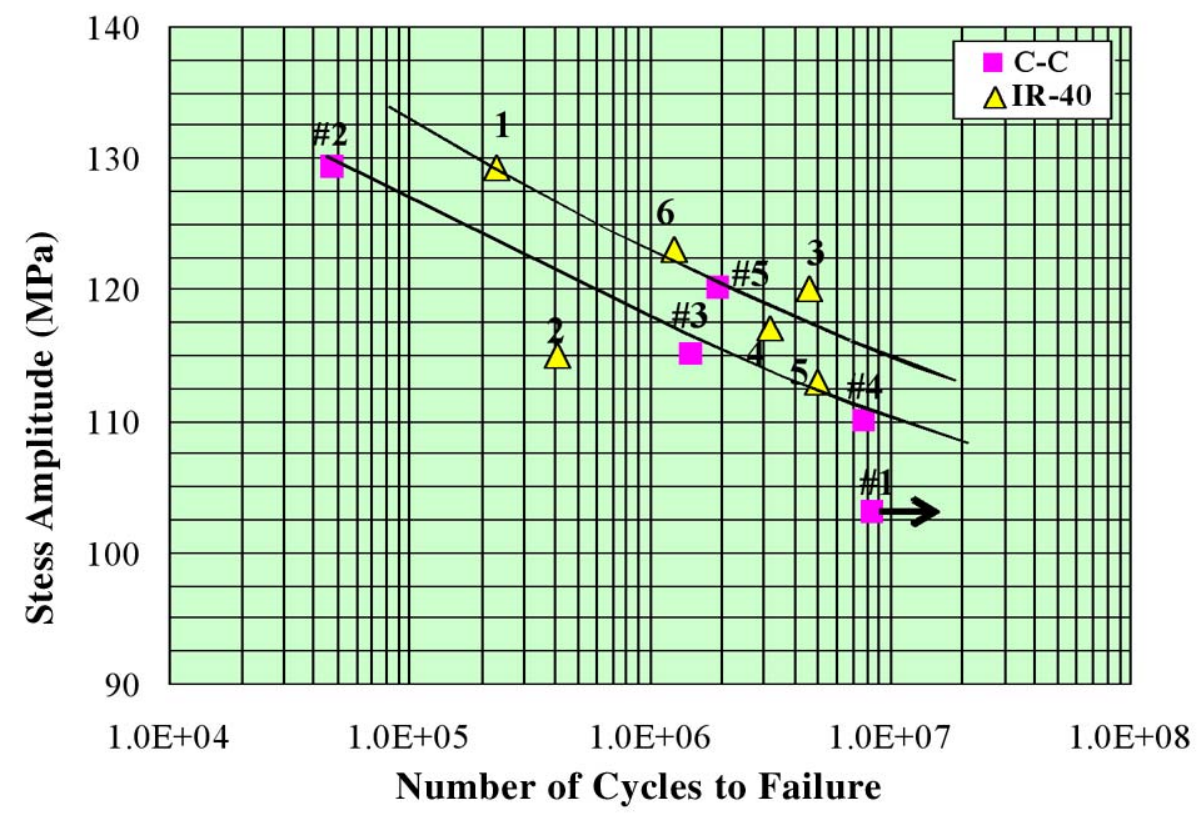

(a)

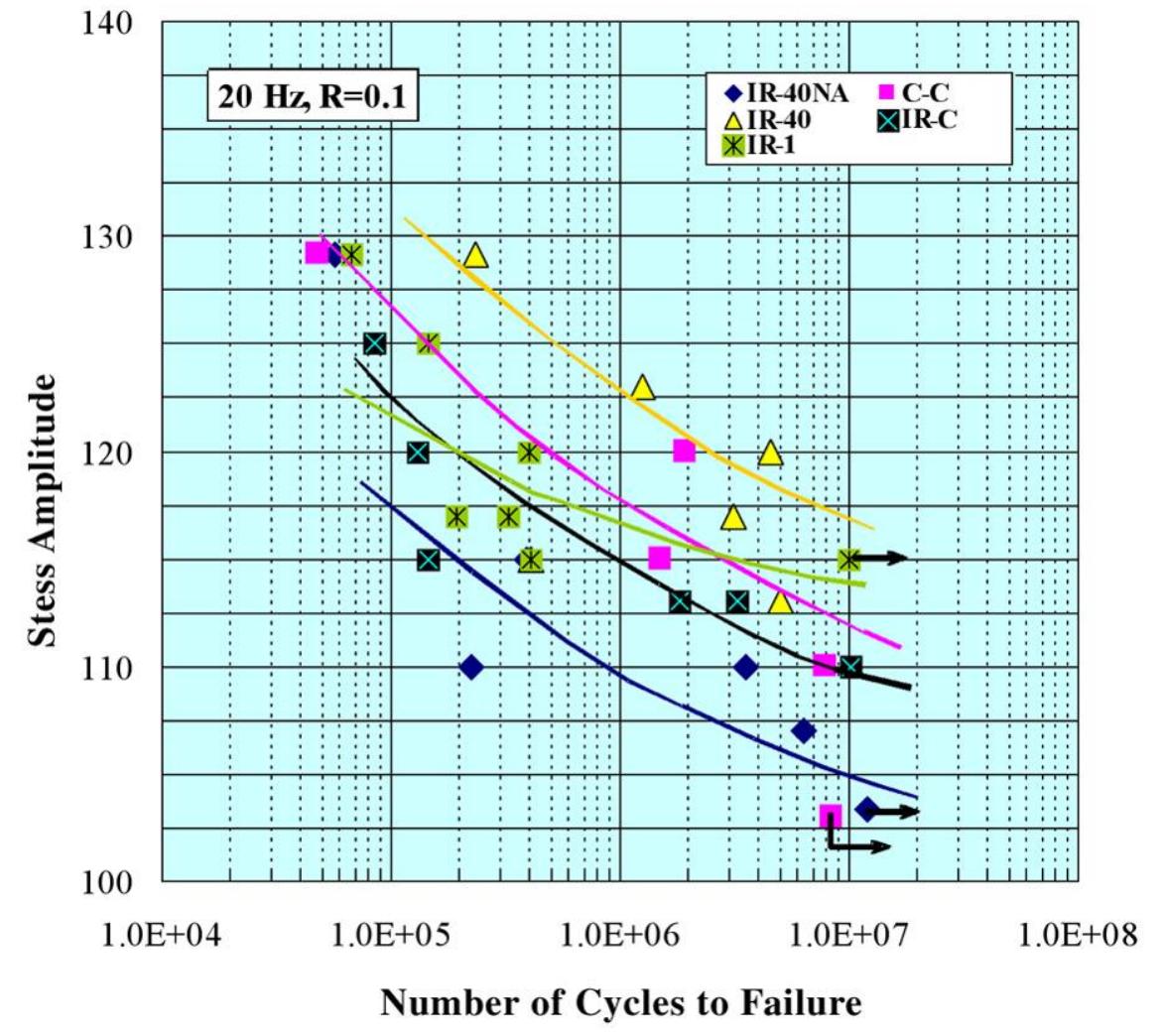

(b)

Fig. 4.18. Results of fatigue testing: (a) Comparison of fatigue properties for the IR treated and conventionally processed forgings; $(b) \mathrm{S}-\mathrm{N}$ curves for various heat treating conditions. 
The fracture surfaces of the fatigue test specimens were investigated with SEM to study the exact fracture mechanisms in these specimens. The crack initiation sites of the $\mathrm{C}-\mathrm{C}$ specimens were all near the surface, and the cracks propagated in a transgranular manner, as shown in Fig. 4.19. The crack initiation sites of the IR-40 specimens were also found near the surface. For specimens 3-5, the fracture mode appears to have been intergranular at the initiation site but turned transgranular as the cracks propagated. Figure 4.20 show SEM fractographs of the IR-40 fatigue specimens. Small pores were noted in the specimens that were solution treated by IR heating (IR-1, IR-40, and IR-40NA); these pores acted as crack initiation sites, as shown in a typical fracture surface in Fig. 4.21(a). No pores were noted on the fracture surface of the specimens that received conventional solution heat treatment (IR-C and C-C), as shown in Fig. 4.21(b). The porosity of the specimens that received rapid solution heat treatment, as estimated from density measurements, is $\sim 0.1-0.2 \%$. In general, porosity has deleterious effects on mechanical properties, such as fatigue resistance and ductility. Pores may evolve in this alloy by eutectic melting during the rapid solution heat treatment. Eutectic melting porosity (EMP) [10] occurs by overheating above the eutectic temperature. Round cavities with smooth surfaces are created, preferentially at grain boundaries by resolidification and dissolution of solute enriched liquid.

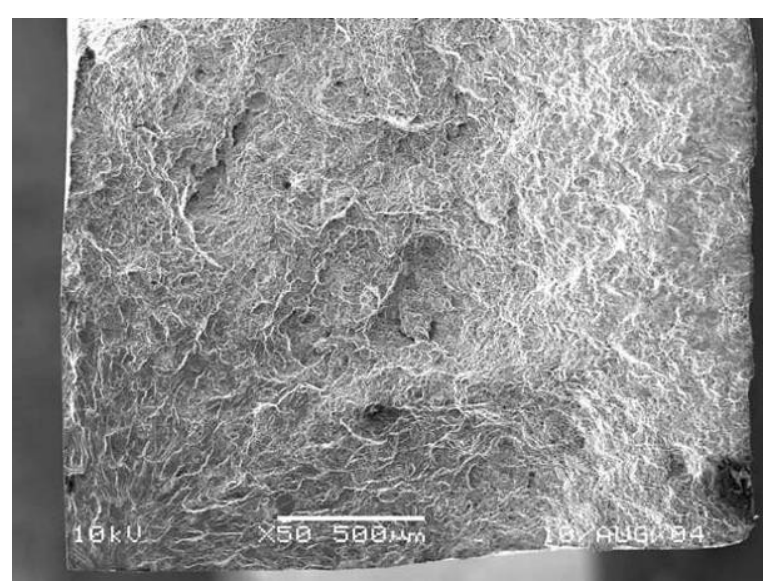

$50 X$

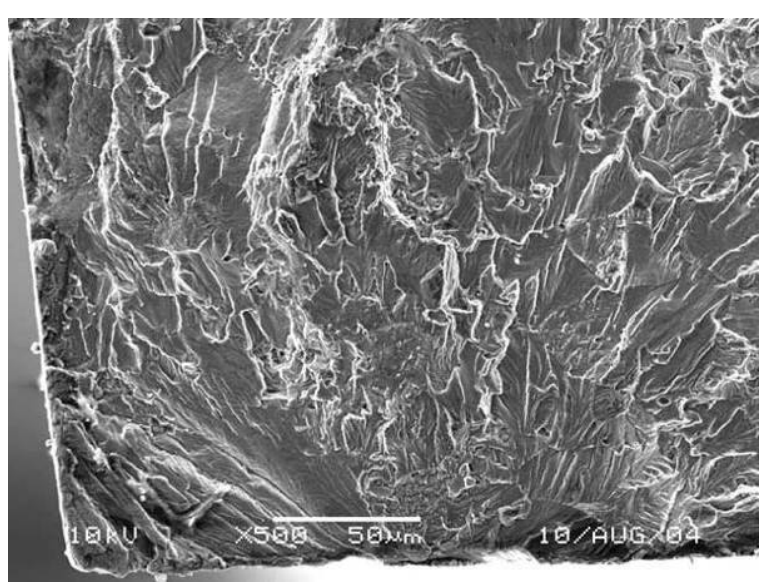

$500 X$

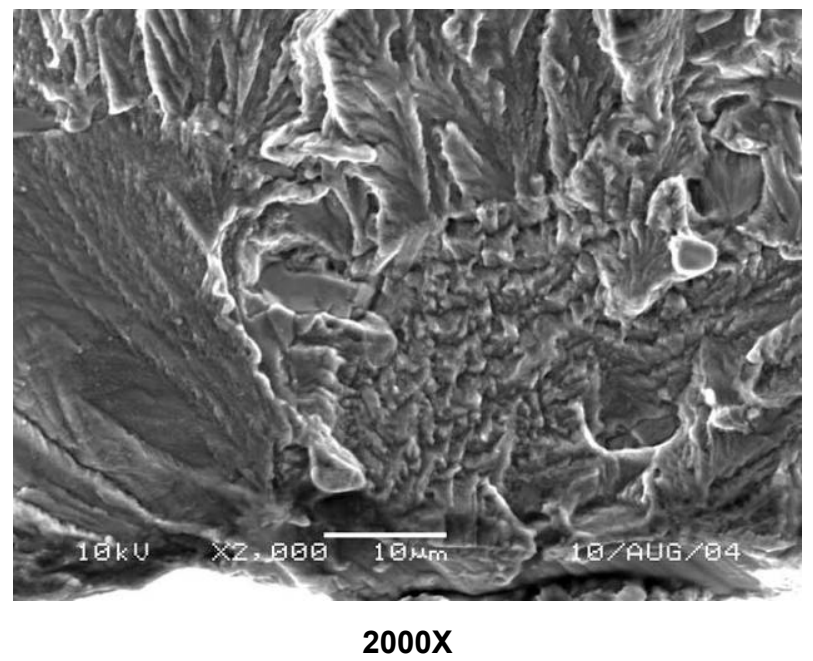

Fig. 4.19. SEM fractographs of C-C no. 2 fatigue specimen at a stress amplitude of $129 \mathrm{MPa}$. The micrographs are arranged with an increasing order of magnification. 


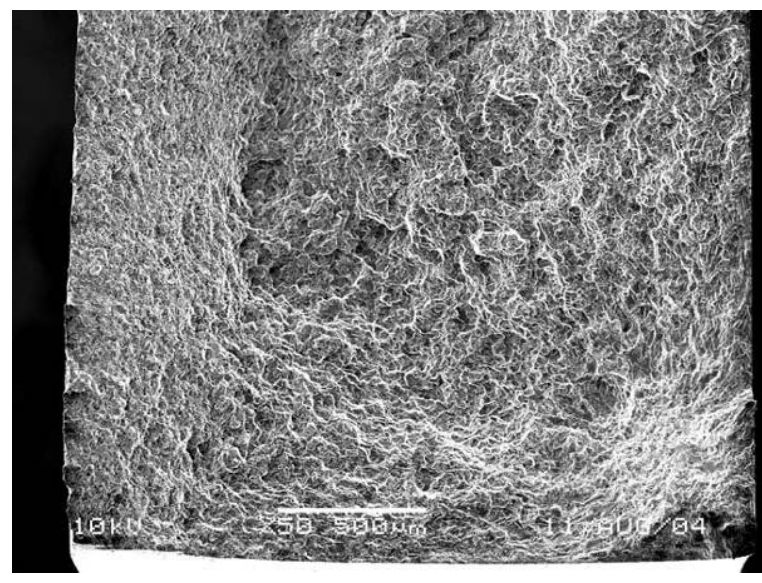

$50 \mathrm{X}$

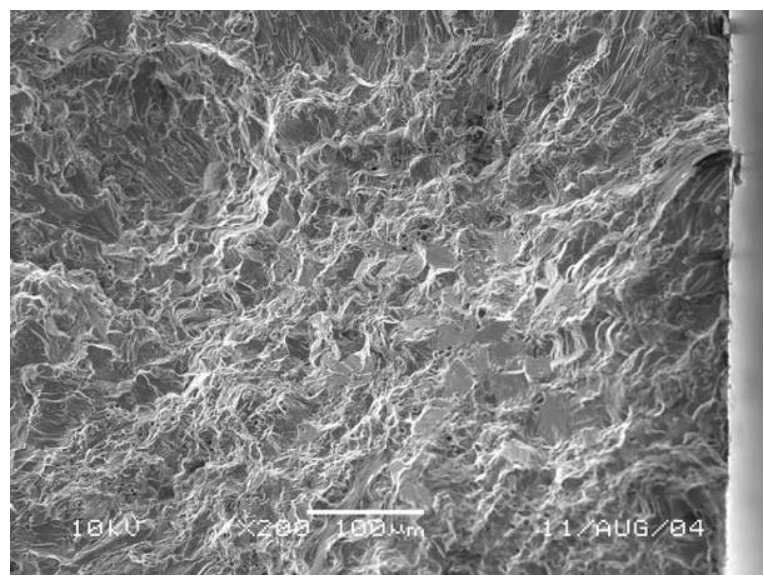

$200 X$

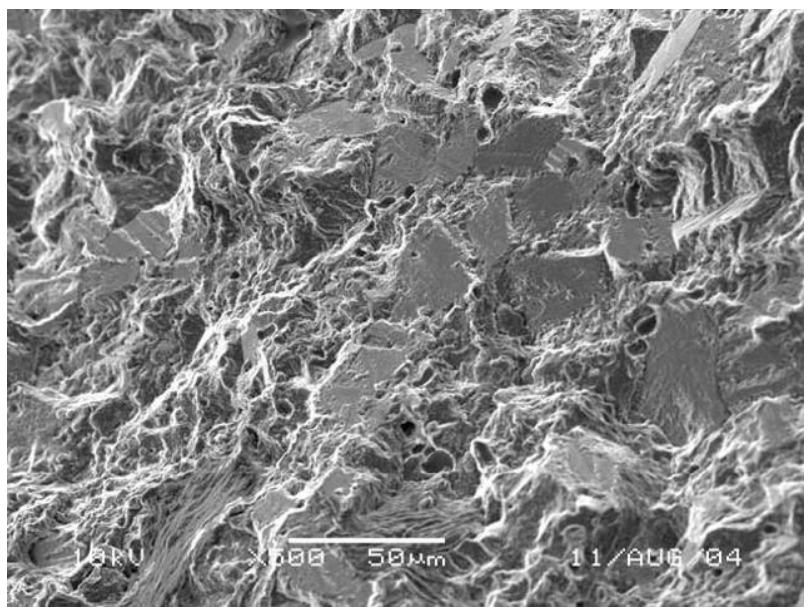

$500 \mathrm{X}$

Fig. 4.20. SEM fractographs of IR-40 no. 3 fatigue specimen at a stress amplitude of $120 \mathrm{MPa}$. The micrographs are arranged with an increasing order of magnification.

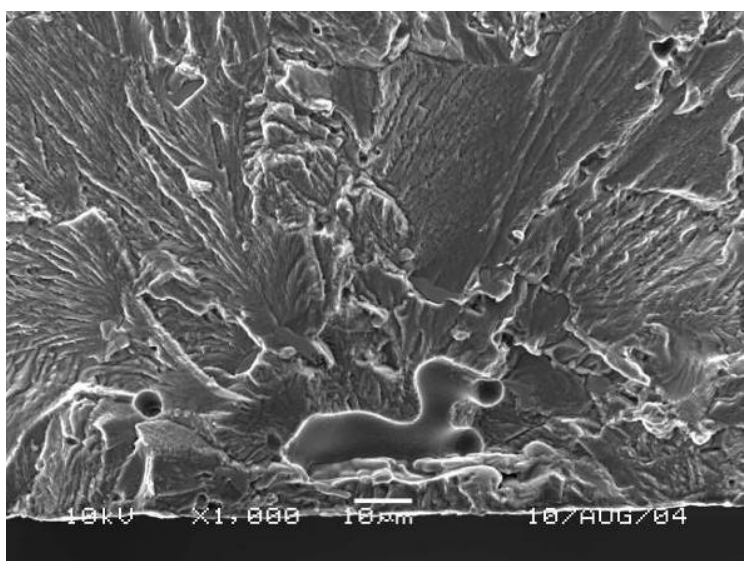

(a) IR-40

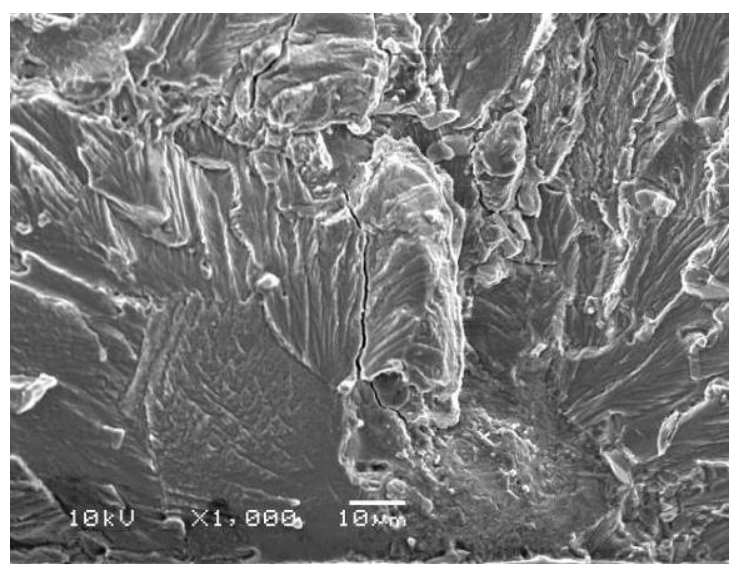

(b) C-C

Fig. 4.21. Crack initiation started from pores in rapidly preheated specimens: (a) RI-40 after fatigue testing at stress amplitude of $129 \mathrm{MPa}$; (b) C-C after fatigue testing at stress amplitude of $120 \mathrm{MPa}$. 
Another possible mechanism of pore formation is dissolution microvoid formation (DMF) [10]. DMF occurs when large intermetallic particles dissolve into the matrix under high heating-rates, giving insufficient time for aluminum to diffuse back into the volume formerly occupied by the low-density particles, thereby leaving microvoids. Despite the presence of pores in rapidly solutionized IR-40 specimens, they still maintained superior fatigue resistance to the conventionally processed C-C specimens at all stress levels tested. Even better fatigue properties would be obtained if porosity formation were prevented.

\subsubsection{Mechanism of Grain Refinement}

As explained in Section 4.3.6, the hardness of the IR-C specimens (HRB 58.9) is significantly lower than that of the IR-40 specimens (HRB 67.7) but is comparable to that of the C-C specimens (HRB 59.5). Also, despite the longer exposure to the solutionizing temperature, IR-C specimens retained a grain size comparable to that of the IR-40 specimens (both $27 \mu \mathrm{m}$ ). This implies that IR preheating, regardless of the solutionizing conditions, is the primary determinant of grain size. The rate of grain growth (or increase in grain size) with time in a single-phase metal depends on the grain boundary mobility (M) and the driving force for boundary migration velocity. Once the material nucleates strain-free grains, the driving force for grain boundary migration is thermal activation or thermal input [11]. Since there was not enough strain in the billet prior to forging, new grains are assumed to have recrystallized within the forgings during the ramp-up to the solutionizing temperature. In the case of the IR-processed forgings, it is likely that the rapid heating to the solutionizing temperature and the short soak times lead to lower thermal activation energies and therefore lower velocities for the migrating grain boundary as compared with the conventionally processed forgings. Excessive or abnormal grain growth during the long soak times ( $2-2.5$ hours) is prevented by the uniform distribution of intermetallic particles, which apply a pinning effect on the migrating grain boundaries. Image analysis performed on the optical micrographs (Fig. 4.13) shows that the intermetallic particles distributed in the $\alpha$-matrix are $\sim 5-10 \mu \mathrm{m}$ in size with a volume fraction of $\sim 8-10 \%$. Substituting these values for the size, $r$, and distribution, $f$, of the second-phase particles in the Zener model [12],

$$
D / r=4 / 3 f^{-1}
$$

it was found that the mean final grain size, $D$, in aluminum alloy 2618 alloy heat-treated specimens was indeed controlled by the inhibiting effects of the intermetallic particles.

\subsubsection{Strengthening Mechanism in Forgings}

Although the contribution to strengthening from grain refinement (as a Hall-Petch effect) cannot be completely ruled out, comparison of the hardness, tensile, and fatigue strengths of IR-1, IR-40 and $\mathrm{C}-\mathrm{C}$ specimens clearly indicates that the improved strength is largely due to stronger age hardening in the IR-processed specimens. It has been hypothesized that during prolonged heating using conventional techniques, $\mathrm{Al}_{9} \mathrm{FeNi}$, the primary intermetallic phase in aluminum alloy 2618, might pick up some of the copper from the matrix [13], possibly releasing some iron and/or nickel into the matrix. This could decrease the potential for age hardening that occurs by the precipitation of the $(\mathrm{Cu}$, $\mathrm{Mg}$ )-rich Guinier-Preston (GP) zones and $\left(\mathrm{Al}_{2} \mathrm{CuMg}\right)$ [14]. Besides the incorporation of copper in $\mathrm{Al}_{9} \mathrm{FeNi}$, the released nickel and iron may form stable compounds containing copper, such as $(\mathrm{CuFe}) \mathrm{Al}_{3}$ and $\mathrm{AlCuNi}$ in $\mathrm{Al}-\mathrm{Cu}-\mathrm{Mg}$ alloys [13], further depleting the copper in the matrix. In an effort to study the distribution of copper and magnesium within the matrix and understand their effect on age-hardening behavior, comparative studies of specimens IR-40 and C-C using transmission electron microscopy (TEM), differential scanning calorimetry (DSC), and atom probe field ion microscope were carried out as described in the following sections. 


\section{Precipitation aging in aluminum alloy 2618}

According to Silcock [14] and Bagaryatsky [15], strengthening of Al-Cu-Mg alloys is associated with the coherent Guinier-Preston-Bagaryatsky (GPB) zones; the finely dispersed metastable precipitates $\mathrm{S}^{\prime \prime}\left(\mathrm{Al}_{2} \mathrm{CuMg}\right)$ and $\mathrm{S}^{\prime}\left(\mathrm{Al}_{2} \mathrm{CuMg}\right)$ : and the equilibrium precipitate phase $\mathrm{S}\left(\mathrm{Al}_{2} \mathrm{CuMg}\right)$. The possible precipitation sequence during the aging of an $\mathrm{Al}-\mathrm{Cu}-\mathrm{Mg}$ alloy with a $\mathrm{Cu}: \mathrm{Mg}$ weight ratio of 2.2:1.0 has been reported to be [15]

$$
\text { SSS (supersaturated solid solution) } \rightarrow \text { GPB zones } \rightarrow \mathrm{S}^{\prime \prime}+\mathrm{S}^{\prime} \rightarrow \mathrm{S}^{\prime}+\mathrm{S} \rightarrow \mathrm{S} \text {. }
$$

Although the crystallographic structure, orientation, and evolution of these precipitating phases is still controversial, there is broad agreement that these phases occur as rods of laths extended in the $<001>_{\alpha}$ direction. GPB zones are reported to be cylindrical, 1-2 nm in diameter , and $4 \mathrm{~nm}$ long [14] and are considered to have nucleated on coherent atomic co-clusters such as $\mathrm{Mg}-\mathrm{Mg}, \mathrm{Cu}-\mathrm{Cu}$, and $\mathrm{Cu}-\mathrm{Mg}$ that form during the early stages of the decomposition process [16]. S" is a partially ordered version of the GPB zones, and its nucleation is believed to set in situ on these GPB zones during the heating of this alloy. The $S^{\prime \prime}$ phase is proposed to be the precursor to the semicoherent $S^{\prime}$ phase [17]. The $\mathrm{S}^{\prime}$ phase has an orthorhombic structure similar to that of the $\mathrm{S}$ phase but with slightly different lattice parameters $(\mathrm{a}=0.404, \mathrm{~b}=0.925$, and $\mathrm{c}=0.718 \mathrm{~nm})$ [18]. The equilibrium $\mathrm{S}-\mathrm{Al}_{2} \mathrm{CuMg}$ phase has a face-centered orthorhombic structure with lattice parameters $\mathrm{a}=0.404, \mathrm{~b}=0.923$, and $\mathrm{c}=$ $0.714 \mathrm{~nm}$ and a $\mathrm{CmCm}$ space group. The $\mathrm{S}$ phase grows with the following orientation relationship with the matrix [19]:

$$
\begin{aligned}
& {[100]_{\mathrm{S}} / /[100]_{\alpha}} \\
& {[010]_{\mathrm{S}} / /[021]_{\alpha}} \\
& {[001]_{\mathrm{S}} / /[0 \overline{2} 1]_{\alpha}}
\end{aligned}
$$

Strengthening of the alloy occurs when these precipitating phases act as barriers to the movement of dislocations. The degree of strengthening depends largely on the shape, volume fraction, size, and distribution of these phases within the matrix. Changing the heat treatment parameters, such as the soak time at solutionizing temperature (i.e., similar to specimens IR-40 and C-C), can alter the saturation of solute in the matrix, thereby affecting the formation kinetics of atomic clusters and GPB zones. As explained above, these clusters and GPB zones are potential nucleation sites for the subsequent precipitates, and understanding the evolution of these phases is essential to understanding the resultant alloy properties.

The precipitation of strengthening phases in heat-treatable aluminum alloys is sensitive to subtle room-temperature structural changes that may take place in as-solutionized alloys before artificial aging. For this reason, the dwell time between solution treatment and artificial aging is an important process parameter in the heat treatment of aluminum alloys. In the present study, the roomtemperature structural changes in solutionized aluminum alloy 2618 were investigated by microhardness measurements and XRD. The effects of natural aging on subsequent artificial aging were also investigated.

\section{Natural aging}

Specimens $10 \times 10 \times 1.3-1.5 \mathrm{~mm}$ were cut from the forged billet representing the IR-AC condition with their broad surfaces perpendicular to the longitude of the billets. The cut specimens were solution-treated at Northeastern University using an electric air furnace to simulate an RI 
solutionizing condition - i.e., rapid heating to, and holding at, $530^{\circ} \mathrm{C}$ for $40 \mathrm{~min}$. The specimen temperature was monitored with a thermocouple attached to the specimen, which showed a ramp-up time of $20 \mathrm{~min}$. The solutionized specimens were water-quenched to room temperature and refrigerated immediately in liquid nitrogen before hardness measurement and XRD. These specimens were designated as IR-AC-R40.

2-AC-R40: $\quad$ RI-preheated to $425^{\circ} \mathrm{C}$, forged (air-cooled), and solutionized in an electric furnace at $530^{\circ} \mathrm{C}$ for $40 \mathrm{~min}$

The Vickers hardness measurements were carried out at different stages of heat treatment using a Shimadzu HMV microhardness tester with a 1-kg load applied for $30 \mathrm{~s}$. The XRD analysis was carried out in a continuous mode on a Philips X'pert instrument, using $\mathrm{CuK} \alpha$. The XRD specimens were ground to $<0.25 \mathrm{~mm}$ in thickness to minimize residual stresses caused by water quenching that significantly affected the lattice parameter of the aluminum matrix. The lattice parameter of the $\alpha-\mathrm{Al}$ matrix was determined from the high-angle (420) and (422) reflections [20].

Figure 4.22 shows the changes in hardness and lattice parameter of the IR-AC-R40 specimens as a function of time at room temperature. The hardness increased monotonically and reached full hardness after about 10 days. The lattice parameter increased from an initial value of $4.0529 \AA$ to a peak value of $4.0539 \AA$ in about $20 \mathrm{~h}$ and then decreased to $4.0533 \AA$ in one day. In determining the values of the lattice parameter by XRD, care was taken to eliminate the effects of residual stress from the prior heat treatment. The compressive residual stress of the surface [21] increases the apparent lattice parameter as determined by XRD, since a compressive surface stress elongates the lattice in the direction normal to the specimen. The use of thin $(0.25-\mathrm{mm})$ specimens permitted determining the lattice parameter in the absence of residual stresses caused by the prior heat treatment, as shown in Figure 4.23.

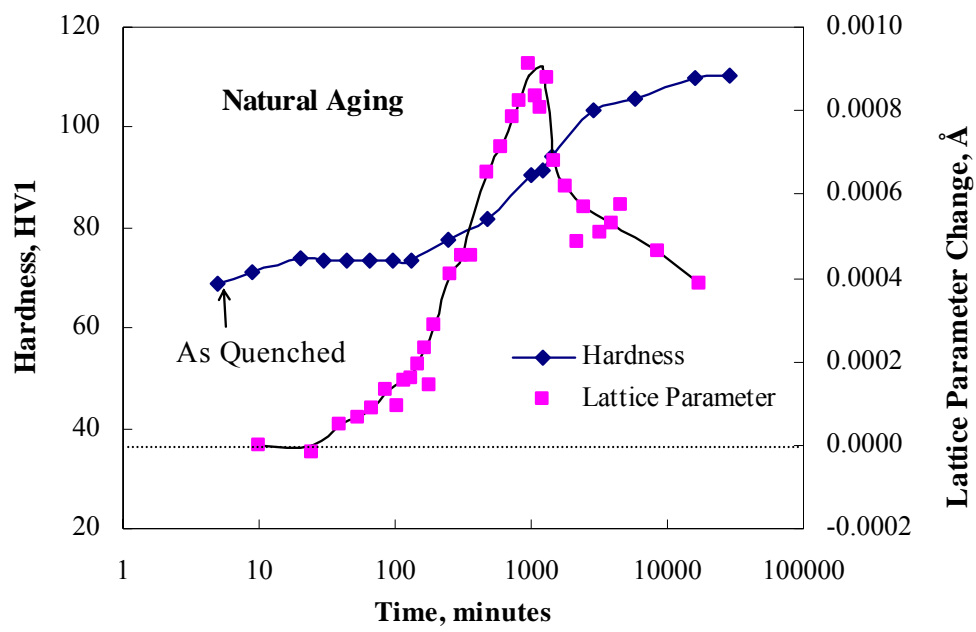

Fig. 4.22. Vickers hardness and lattice parameter variations of solutionized specimens as a function of natural aging. 


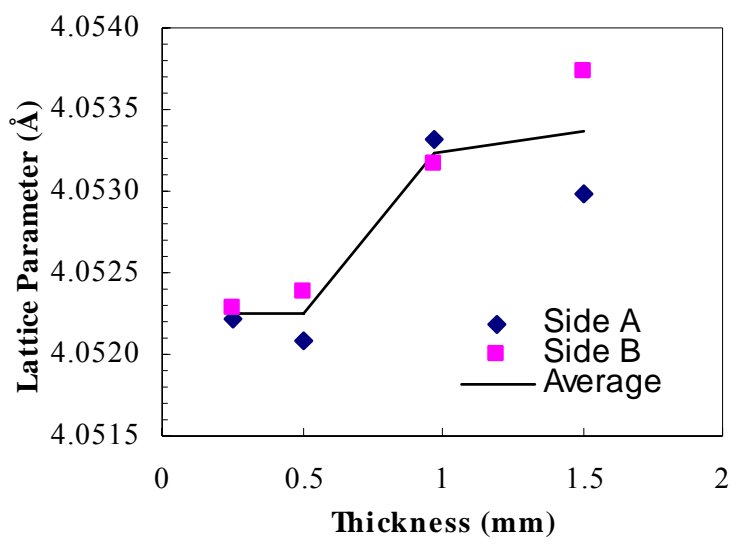

Fig. 4.23. Effects of specimen thickness on the lattice parameter of specimen aged at $200^{\circ} \mathrm{C}$ for $80 \mathrm{~h}$. Both sides of the specimens were measured.

The initial increase in the lattice parameter is indicative of copper depletion from the matrix, which should increase the lattice parameter at a rate of $0.0049 \AA / \mathrm{at} . \% \mathrm{Cu}$ [22]. Therefore, the hardening during the initial $20 \mathrm{~h}$ is considered to result primarily from the formation of copper-enriched clusters. The decrease in the lattice parameter after $20 \mathrm{~h}$ is considered to have resulted by the formation of magnesium-containing clusters [23], which depletes the magnesium from the matrix, causing the lattice parameter to decrease at a rate of $-0.0044 \AA /$ at.\% $\mathrm{Mg}[22]$.

\section{Artificial aging}

Specimens subjected to IR preheating and then forged, and IR solutionized for 40 min were artificially aged with no natural aging or after $24 \mathrm{~h}$ of natural aging at $150,180,200$, or $230^{\circ} \mathrm{C}$ in an air furnace for various times up to $80 \mathrm{~d}$, with a 10-min ramp-up time to artificial aging temperatures.

Figure 4.24 shows the variations of hardness during aging for specimens artificially aged without natural aging (designated D0) and those artificially aged after $24 \mathrm{~h}$ of natural aging (designated D24) at $150,180,200$, and $230^{\circ} \mathrm{C}$. At $150^{\circ} \mathrm{C}$, the D0 specimen initially had a lower hardness than the D24 specimen (Fig. 4.24) because of the hardening during the prior 24-h natural aging. After about 8 min, however, both the D0 and the D24 specimens exhibited identical hardening to the peak hardness, which was reached in $40 \mathrm{~d}$. Thus, prior natural aging had no effect on the final hardness reached through artificial aging at $150^{\circ} \mathrm{C}$.

At the three higher temperatures, the hardness of the D0 specimens was also initially lower than that of the D24 specimens. However, the hardness of the D0 specimens quickly caught up with that of the D24 specimens and reached a peak value that was consistently higher than that of the D24 specimens. While the peak hardness of the specimens aged at $180^{\circ} \mathrm{C}$ and $200^{\circ} \mathrm{C}$ occurred at aging times of 48 and $20 \mathrm{~h}$, respectively, that of the specimens aged at $230^{\circ} \mathrm{C}$ occurred at $2 \mathrm{~h}$.

Figure 4.25 shows the change in artificial age-hardening as a function of prior natural aging time, for specimens artificially aged at 150,180 , and $200^{\circ} \mathrm{C}$ for $20 \mathrm{~h}$. While the age hardening at 180 and $200^{\circ} \mathrm{C}$ weakened with increase in prior natural aging time, the age hardening at $150^{\circ} \mathrm{C}$ was not affected by prior natural aging. This implies that the clusters that form during the prior natural aging are large enough to survive at $150^{\circ} \mathrm{C}$, but they must dissolve into the matrix at the higher aging 


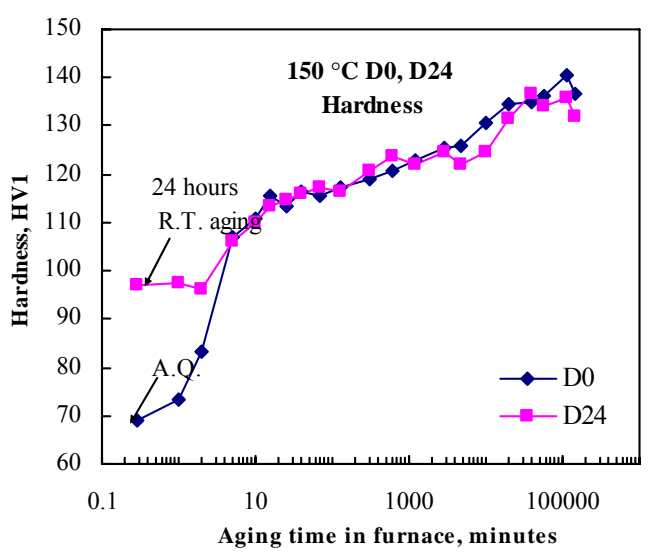

$150^{\circ} \mathrm{C}$

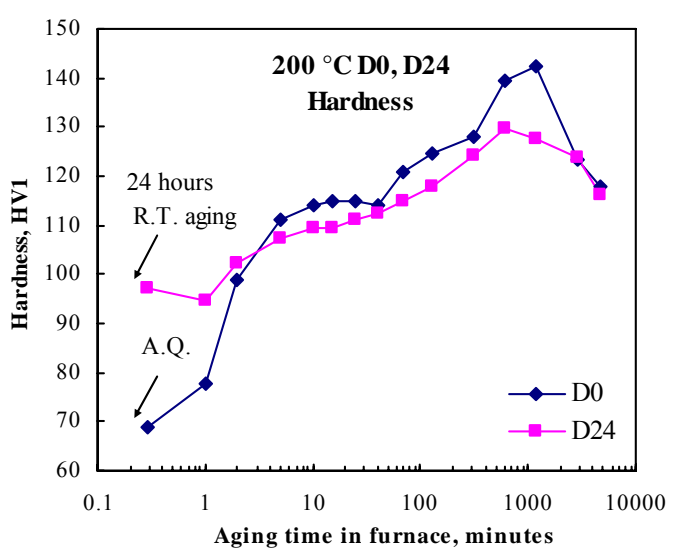

$200^{\circ} \mathrm{C}$

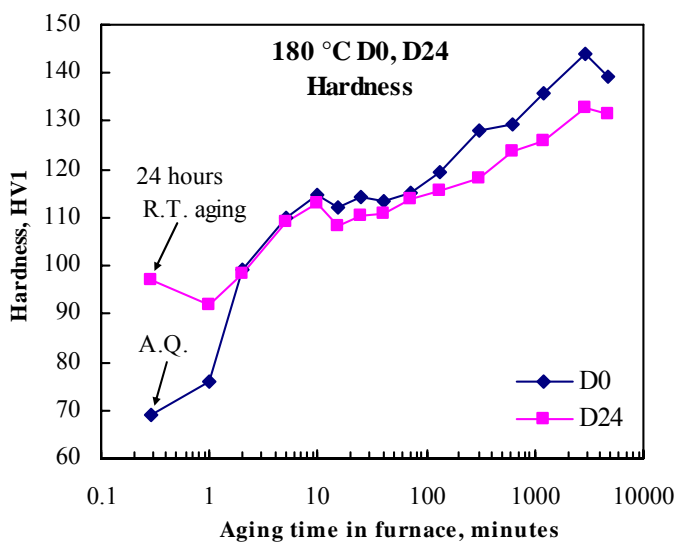

$180^{\circ} \mathrm{C}$

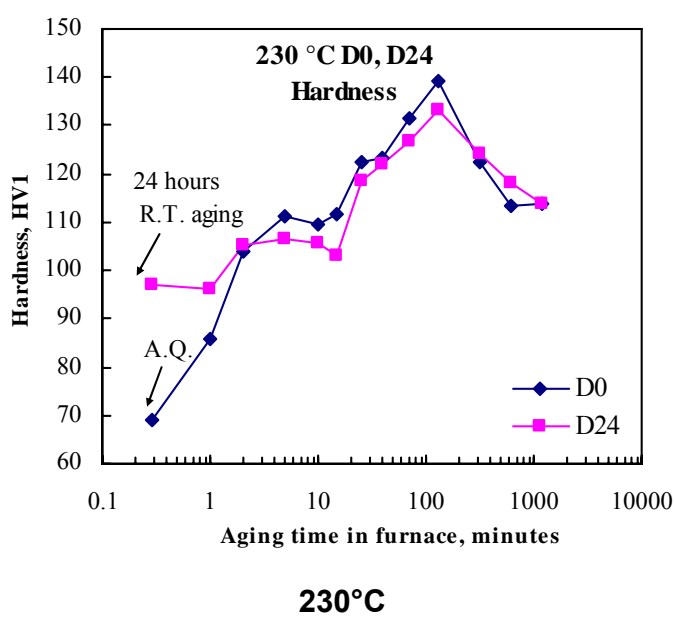

Fig. 4.24. Variations in hardness for specimens artificially aged under varying conditions and temperatures. D0 = no prior natural aging; D24 = with prior $24 \mathrm{~h}$ of natural aging.

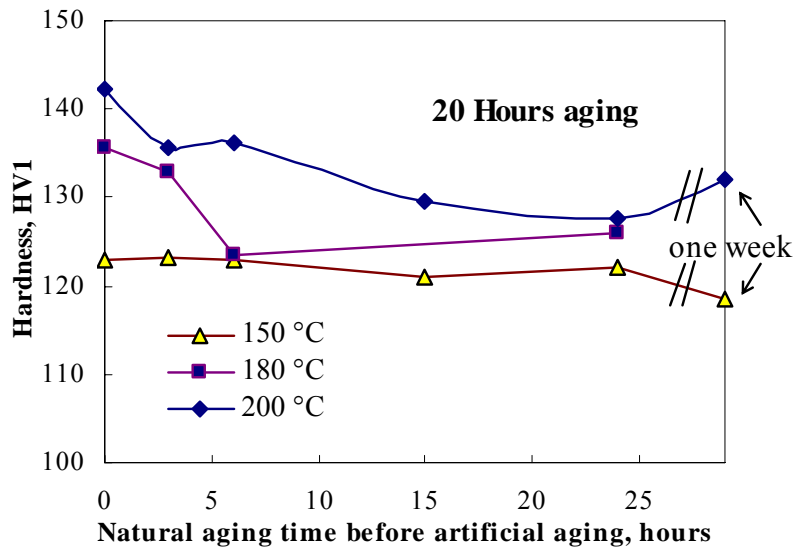

Fig. 4.25. Effects of natural aging time on age hardening at 150,180 and $200^{\circ} \mathrm{C}$. 
temperatures. The reversion of the clusters delays the subsequent age hardening. Shorter prior natural aging, however, produces smaller clusters in smaller amounts, causing less delay.

Figure 4.26 shows the changes of lattice parameters during artificial aging at $150-230^{\circ} \mathrm{C}$ for the D0 and D24 specimens. In all specimens, the lattice parameter varied erratically with aging time, indicating that a complex sequence of structural changes occurred while hardening proceeded monotonically during the artificial aging. Although understanding the exact sequence of events in detail may not be possible immediately, the variations of lattice parameter of the D0 specimens aged at $150-230^{\circ} \mathrm{C}$ all appear to exhibit a common sequence. Figure 4.27 schematically shows this sequence, which is characterized by an initial increase in the lattice parameter and alternating decreases and increases following the initial increase. Similar trends are noted for the D24 specimens as well, except in early stages, where their lattice parameter variations do not match the D0 pattern shown in Fig. 4.26.

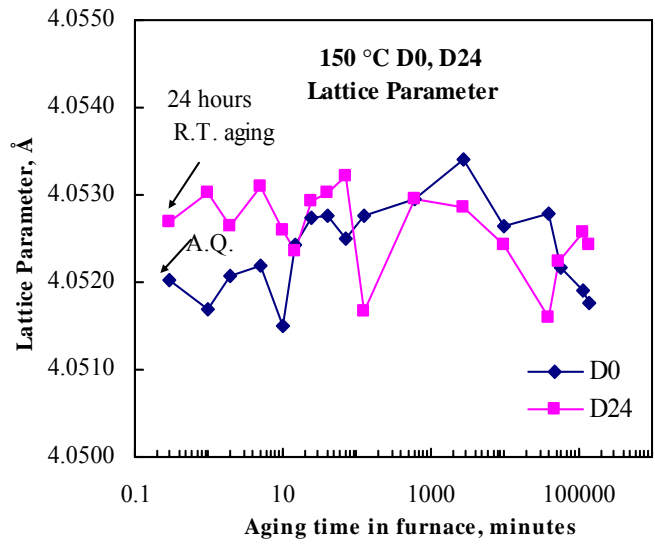

$150^{\circ} \mathrm{C}$

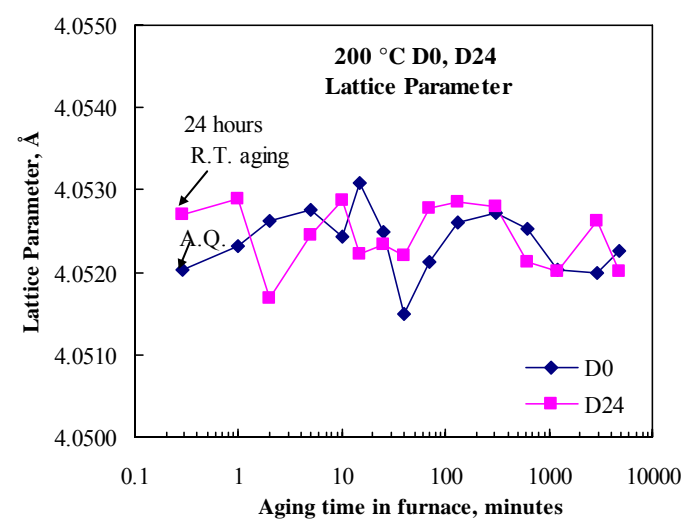

$200^{\circ} \mathrm{C}$
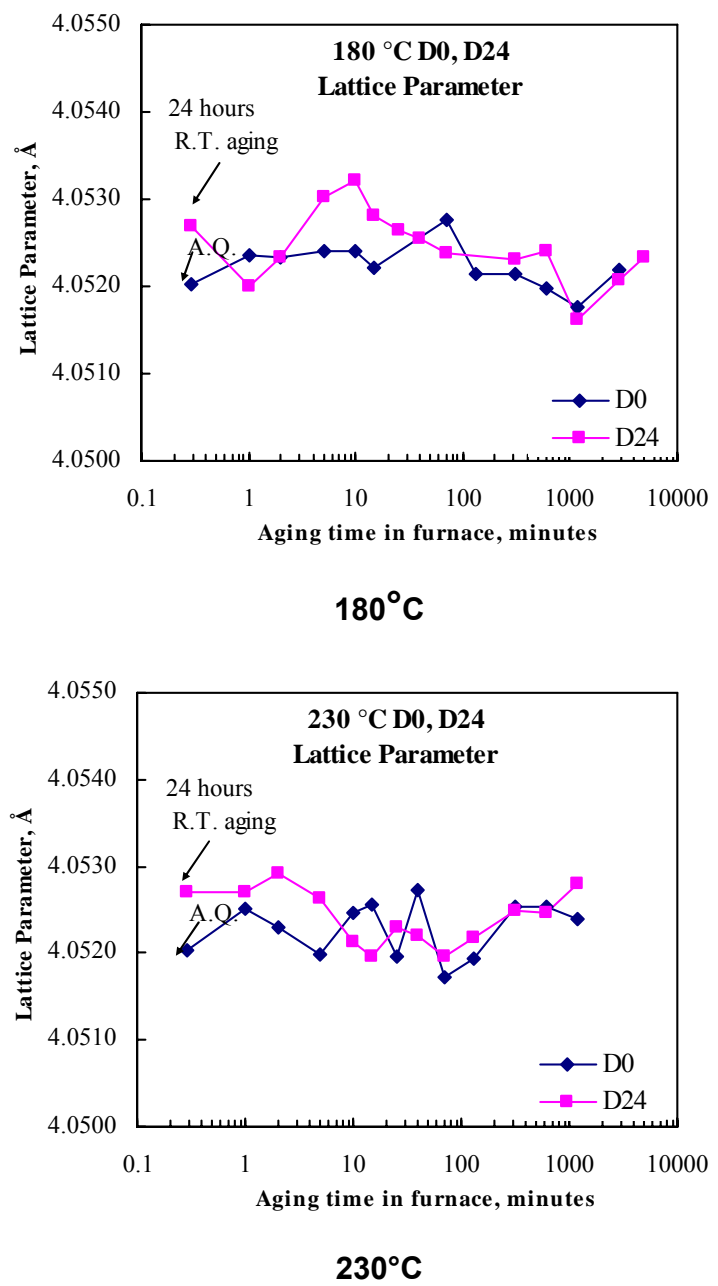

Fig. 4.26. Variations in lattice parameter for specimens artificially aged under varying conditions and temperatures. D0 = specimen had no prior natural aging; D24 = specimen with prior $24 \mathrm{~h}$ of natural aging. 


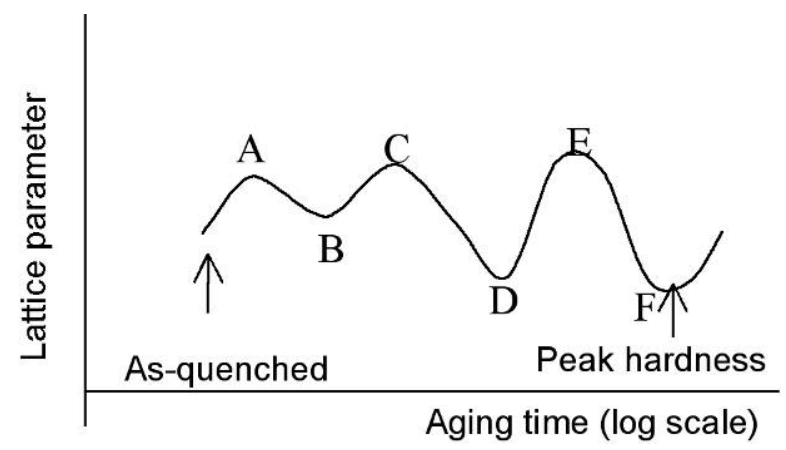

Fig. 4.27. Schematic of the sequence of the lattice parameter changes vs artificial aging time.

\section{Differential scanning calorimetry}

To determine the correlation between age hardening and the sequence of phase formation and dissolution during aging that caused the lattice parameter variation in Fig. 4.27, additional specimens (discs $5 \mathrm{~mm}$ in diameter and $1-1.2 \mathrm{~mm}$ in thickness), as-solutionized at $530^{\circ} \mathrm{C}$ for $1 \mathrm{~h}$ or solutionized at $530^{\circ} \mathrm{C}$ for $1 \mathrm{~h}$ and aged at $200^{\circ} \mathrm{C}$ to conditions corresponding to the states $\mathrm{A}(5 \mathrm{~min}), \mathrm{B}(10 \mathrm{~min})$, $\mathrm{C}$ (20 min), D (40 min), E (5 h), and F (20 h) and immediately refrigerated in liquid nitrogen, were subjected to differential scanning calorimetry (DSC). The DSC scans were obtained at a heating rate of $20^{\circ} \mathrm{C}$ per min over a temperature range from 40 to $520^{\circ} \mathrm{C}$ using a Perkin Elmer Diamond DSC with nitrogen flowing at a rate of $20 \mathrm{~mL} / \mathrm{min}$. Figures 4.28 and 4.29 compare the DSC thermograms of an as-quenched specimen and aged specimens after subtracting the baseline.

The DSC thermogram of the as-quenched specimen in Fig. 4.28 exhibited two exothermic peaks and two endothermic peaks. The first exothermic peak was attributed to the formation of GPB zones characteristic of Al-Cu-Mg alloys [24, 25, 26]. GPB2 may also form, perhaps in situ on GPB [24], during DSC runs although no separate exothermic peak was noted. The first endothermic peak of the thermogram of the as-solutionized specimen, occurring over the broad temperature range between 160 and $270^{\circ} \mathrm{C}$, was attributed to the dissolution of GPB and GPB2 zones. The second exothermic peak also is broad, indicating that $\mathrm{S}^{\prime}$ and $\mathrm{S}$ phases precipitated in sequence over the temperature range during the DSC run. Upon further heating, the $\mathrm{S}^{\prime}$ and $\mathrm{S}$ phases dissolved, producing the broad endothermic peak between 350 and $470^{\circ} \mathrm{C}$.

None of the aged specimens produced the first exothermic peak (Figs. 4.28 and 4.29), indicating that GPB zones had already formed during the pre-aging treatment. Their DSC thermograms show only the two endothermic peaks and the second exothermic peak. The position, shape, and magnitude of the three peaks, however, vary with the aging time. The first endothermic peak, corresponding to the dissolution of GPB and GPB2 zones formed during the artificial aging, starts at progressively higher temperatures with increasing aging time at $200^{\circ} \mathrm{C}$. Thus, longer prior aging leaves smaller amounts of zones to dissolve during DSC. Prolonged prior aging, however, eliminated much of the GPB zones, leaving mainly GPB2 zones to dissolve during subsequent DSC run. The first endothermic peaks of the specimens pre-aged for 5 and $20 \mathrm{~h}$ are therefore narrower than those of the specimens pre-aged for shorter times and occurred only between 200 and $270^{\circ} \mathrm{C}$.

The second exothermic peak was caused by the precipitation of $\mathrm{S}^{\prime}$ and $\mathrm{S}$ phases. It was broad since it consists of the two peaks for the precipitation of $\mathrm{S}^{\prime}$ and $\mathrm{S}$. The specimens pre-aged for $\leq 5 \mathrm{~h}$ all produced a similar broad second exothermic peak, indicating that both $\mathrm{S}^{\prime}$ and $\mathrm{S}$ precipitated during DSC run regardless of the pre-aging time. It follows that the precipitation of $\mathrm{S}^{\prime}$ during isothermal 


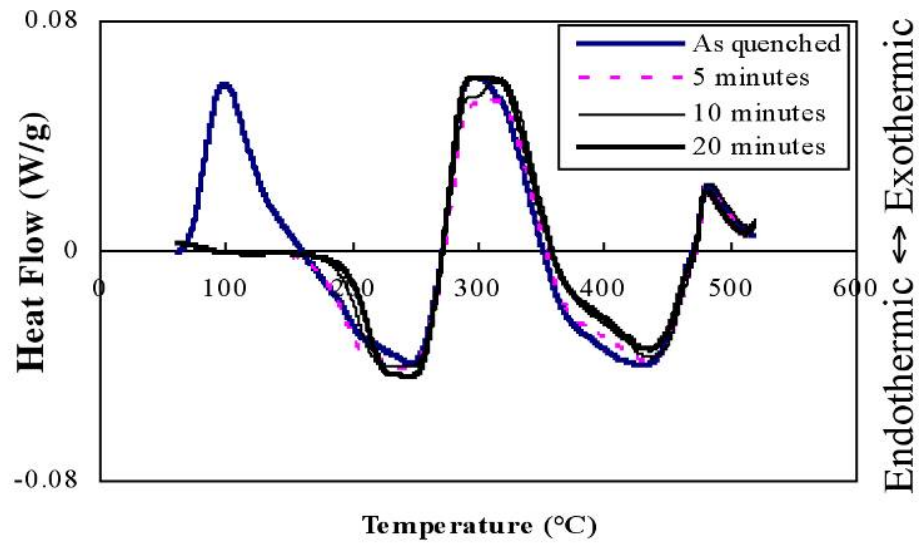

Fig. 4.28. DSC thermograms of aluminum alloy 2618 at $20^{\circ} \mathrm{C} / \mathrm{min}$, as-quenched and artificially aged at $200^{\circ} \mathrm{C}$ for 5 , 10 , and $20 \mathrm{~min}$.

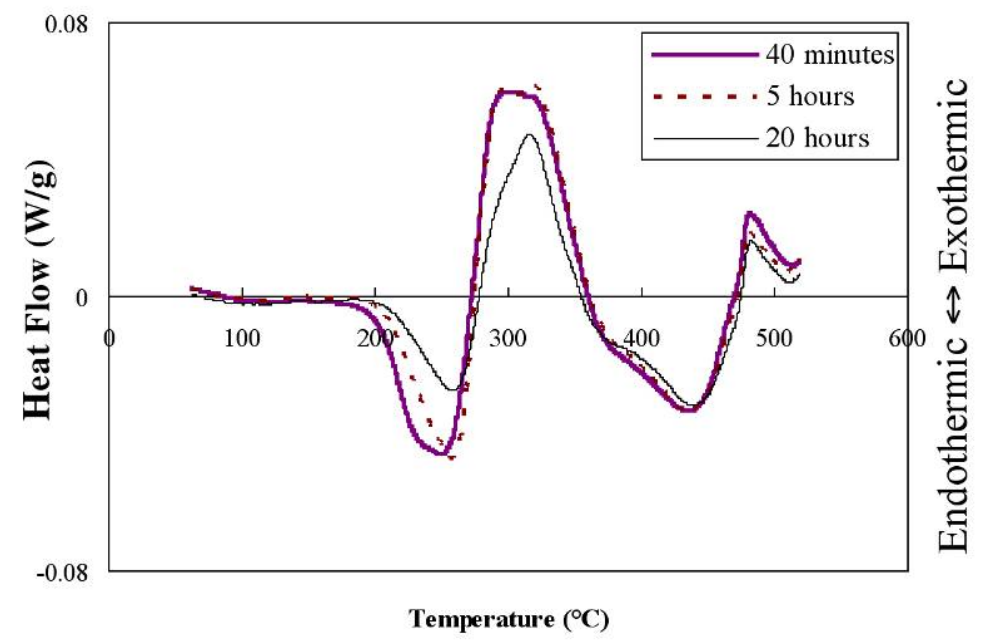

Fig. 4.29. DSC thermograms of aluminum alloy 2618 at $20^{\circ} \mathrm{C} / \mathrm{min}$ artificially aged at $200^{\circ} \mathrm{C}$ for $40 \mathrm{~min}, 5 \mathrm{~h}$, and $20 \mathrm{~h}$.

aging at $200^{\circ} \mathrm{C}$ requires more than $5 \mathrm{~h}$ of holding. The second exothermic peak of the specimen preaged for $20 \mathrm{~h}$ is much smaller, however, and has a sharper head around $320^{\circ} \mathrm{C}$, indicating that $\mathrm{S}^{\prime}$, and probably some $\mathrm{S}$, had precipitated during the long pre-aging. This is also reflected by the first endothermic peak of this specimen, which is much shallower than those of the specimens pre-aged for shorter times (Fig. 4.29), indicating that the GPB2 zones that formed in early stages of prior aging had been replaced with $\mathrm{S}^{\prime}$ precipitates during the later stages between 5 and $20 \mathrm{~h}$ at $200^{\circ} \mathrm{C}$.

The changes in lattice parameter during isothermal aging (Fig. 4.27) may be understood with the aid of the above discussion on the DSC curves. Although the exact compositions of the zones and other precipitates involved in the artificial aging of aluminum alloy 2618 are not known, it would be reasonable to assume that all of these phases have a composition approximately represented by that of 
the equilibrium phase $\mathrm{S}$, or $\mathrm{Al}_{2} \mathrm{CuMg}$. Given the rates of lattice parameter change $(-0.0049 \AA /$ at. \% $\mathrm{Cu}$ and $0.0044 \AA /$ at. $\% \mathrm{Mg}$ ), it can be deduced that formation of any such phase will increase the lattice parameter of the matrix, while its dissolution will decrease the lattice parameter.

It follows that the initial increase in lattice parameter - up to A (5 min) in Fig. 4.27-was caused by the formation of clusters and GBP zones during the initial period of artificial aging. The monitored specimen temperature indicates that the GPB zones formed while the specimen was still heating up to the aging temperature. The decrease in lattice parameter between $\mathrm{A}$ and $\mathrm{B}$ during isothermal aging (Fig. 4.27) resulted from the dissolution of GPB zones that were smaller than the critical size at $200^{\circ} \mathrm{C}$. This is also reflected by the increase in start temperature of the first endothermic peak when the pre-aging time is increased from 5 to $10 \mathrm{~min}$ (Fig. 4.28). The increase in lattice parameter between $\mathrm{B}$ and $\mathrm{C}$ resulted from continued growth of the remaining coarser GPB zones. The subsequent decrease in lattice parameter between $\mathrm{C}$ and $\mathrm{D}$ is considered to have resulted from additional dissolution of the GPB zones. The lattice parameter increased again between $\mathrm{D}$ and $\mathrm{E}$ due to the formation of GPB2 zones, probably by the in situ GPB to GPB2 transformation. Beyond E, the GPB2 zones partially dissolved while some $S^{\prime}$ precipitated. Thus, the peak age-hardening condition $\left(20 \mathrm{~h}\right.$ at $\left.200^{\circ} \mathrm{C}\right)$ produced a mixture of GPB2 zones and $\mathrm{S}^{\prime}$ precipitates in the alloy.

These observations confirm the overall sequence of precipitation during the artificial aging of aluminum alloy 2618 reported by Shih et al. [24]:

$$
\text { Supersaturated Solid Solution } \rightarrow \text { clusters }+\mathrm{GPB} \rightarrow \mathrm{GPB}+\mathrm{GPB} 2 \rightarrow \mathrm{GPB} 2+\mathrm{S}^{\prime} \rightarrow \mathrm{S}^{\prime}+\mathrm{S} \text {. }
$$

\section{Transmission electron microscopy and atom probe field ion microscope}

Although TEM and APFIM studies to verify the development of phases explained using DSC and $\mathrm{X}$-ray studies were out of the scope of this project, such studies were performed on two peak-aged specimens $\left(20 \mathrm{~h}\right.$ at $\left.200^{\circ} \mathrm{C}\right)$, IR-40 and C-C, which were heat-treated as follows. The objective was to determine whether a correlation between the phases predicted in the hardness, X-ray, and DSC studies and the observed final properties of the forgings existed.

IR-40: $\quad$ IR-preheated and forged, IR-solutionized for $40 \mathrm{~min}$, and artificially aged at $200^{\circ} \mathrm{C}$ for $20 \mathrm{~h}$

C-C: $\quad$ Conventionally preheated and forged, conventionally solutionized for $2-2.5 \mathrm{~h}$ and artificially aged at $200^{\circ} \mathrm{C}$ for $20 \mathrm{~h}$.

TEM specimens were prepared by cutting small slices $10 \times 10 \times 0.2 \mathrm{~mm}$ from the center of the forgings. Small discs, $3 \mathrm{~mm}$ in diameter, where punched out of these slices and were hand-ground to a thickness of about $6 \mu \mathrm{m}$. These discs were further thinned for transparency by electropolishing using a methanol/nitric acid electrolyte, $13 \mathrm{~V}$, and $0.13 \mathrm{~A}$. The temperature during electropolishing was maintained at $-20^{\circ} \mathrm{C}$. TEM studies were performed using a conventional $200-\mathrm{kV}$ Philips Tecnai 20 TEM with high-resolution TV-rate video for real-time imaging.

Figures 4.30 and 4.31 represent bright-field (BF) images and selected area diffraction (SAD) patterns corresponding to the $\mathrm{C}-\mathrm{C}$ and IR-40 specimens, respectively. Figures $4.31 \mathrm{a}-\mathrm{b}$ and $4.32 \mathrm{a}-\mathrm{b}$ both show a fine distribution of lathlike structures typical of the $S$ (or $S^{\prime}$ ) phase aligned along the $[100]_{\alpha}$ matrix planes. There was no noticeable difference between the distributions of these precipitates, although the laths in the C-C specimen appear to be larger than those in the IR-40 specimen [Figs. 4.30(c) and 4.31(c)]. There was no evidence of GPB zones or $\mathrm{Cu} / \mathrm{Mg}$ clusters in either specimen; this is consistent with the results observed in the DSC studies, where $S$ (or $\mathrm{S}^{\prime}$ ) phases were assumed to have formed in 
the peak-aged condition. Figures 4.30(d) and 4.31(d) show the SAD patterns corresponding to the $[100]_{\alpha}$ BF images in the two parts (c) of these figures that verify the presence of $S$ (or $S^{\prime}$ ). Indexing of the diffraction spots by the scheme proposed by D. G. Eskin [27] (Fig. 4.32) reveals the existence of the $[100]_{\mathrm{S}} / /[100]_{\alpha}$ orientation relationship between the $\mathrm{S}$ and the matrix.

In addition to the precipitate distribution, both specimens also show precipitate-free zones (PFZs) along the grain boundaries. The formation of PFZs suggests higher diffusion and insufficient vacancy saturation along grain boundaries occurring during quenching. The widths of the PFZs in the two specimens appear to be same, indicating that the vacancy concentration within the grain boundary region for the two heat-treating conditions could be the same [11]. Close examination of the PFZs also shows the presence of fine inclusions along the grain boundaries in the two specimens. Phase analysis of these inclusions has not yet been undertaken.

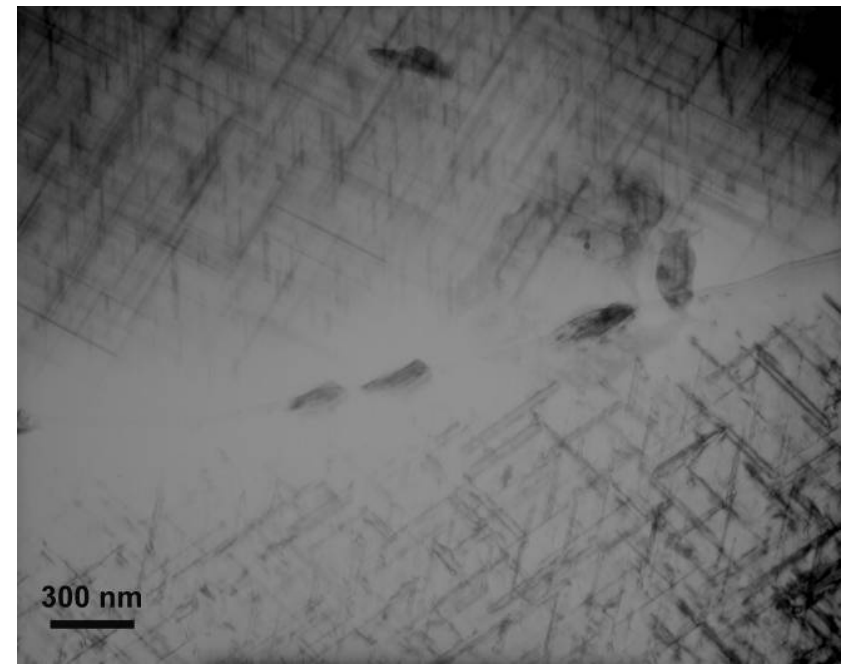

(a)

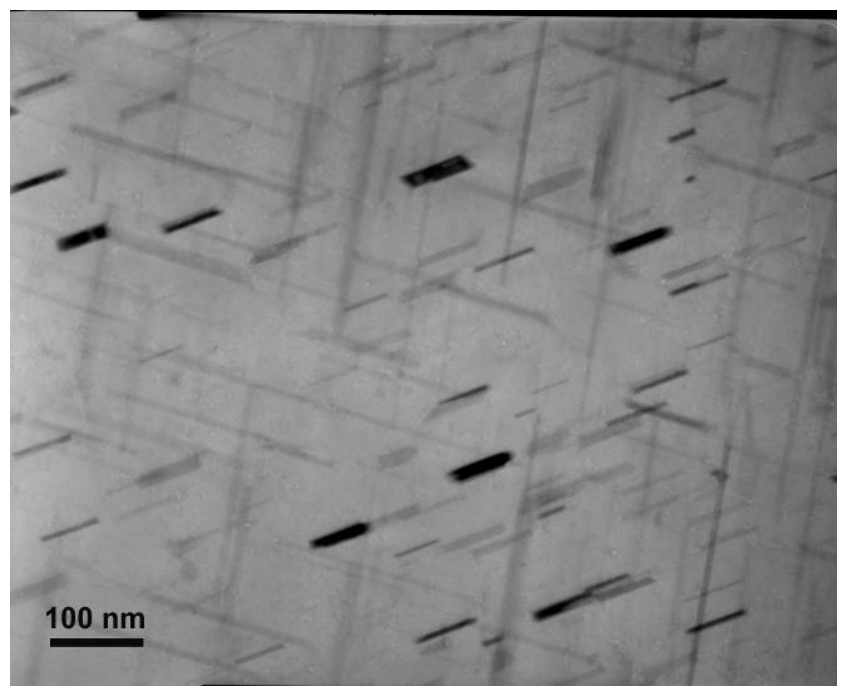

(c)

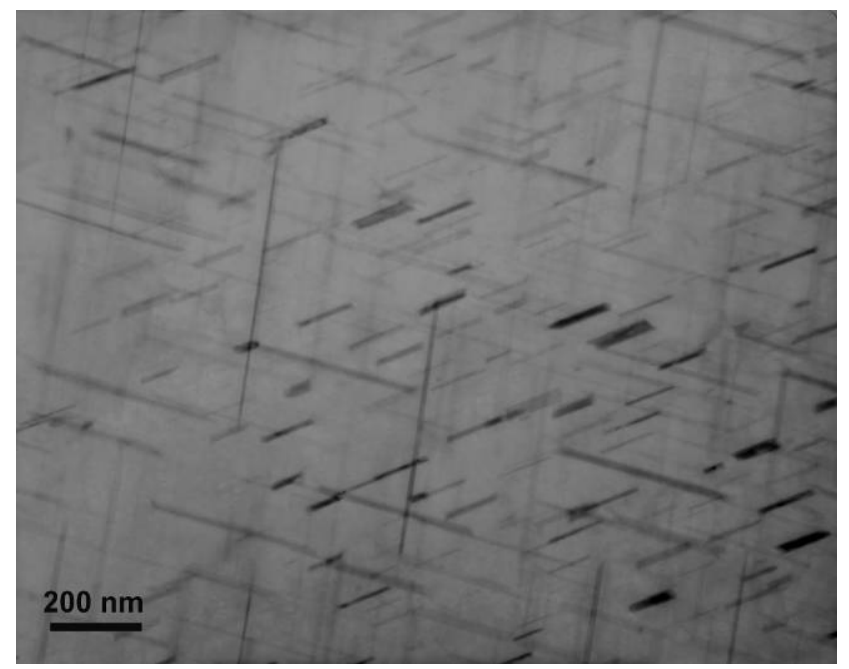

(b)

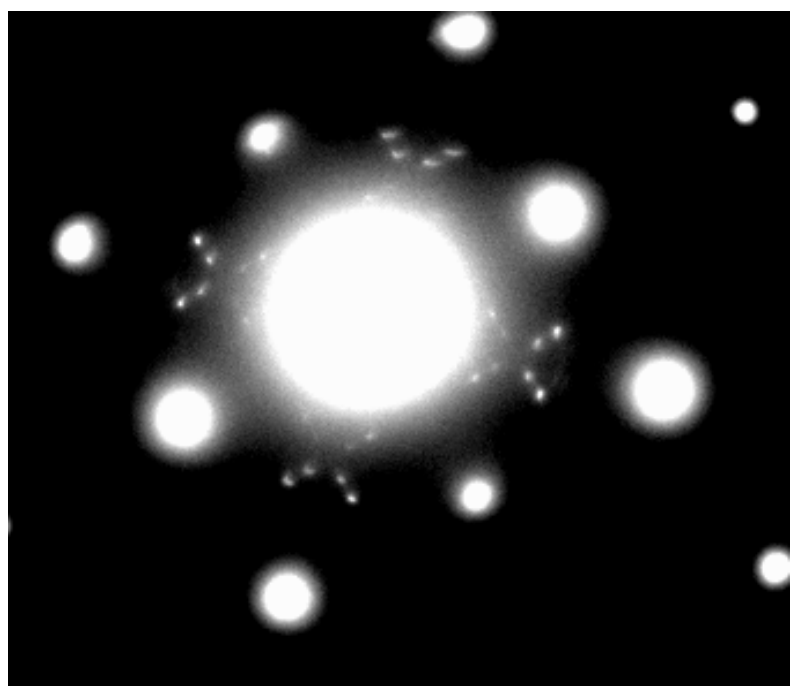

(d)

Fig. 4.30. TEM Bright-field images and SAD pattern for C-C specimen. (a) Low-magnification BF image corresponding to C-C specimen showing precipitate-free grain boundaries; $(b)$ and (c) high-magnification BF image showing $S$ (or $S^{\prime}$ ) precipitates aligned along [100] $\alpha$ matrix plane; (d) selected area diffraction (SAD) pattern corresponding to $(c)$ showing $S$ (or $\left.S^{\prime}\right)$ as the major precipitating phase in the peak-aged condition $\left(20 \mathrm{~h}\right.$ at $\left.200^{\circ} \mathrm{C}\right)$. 


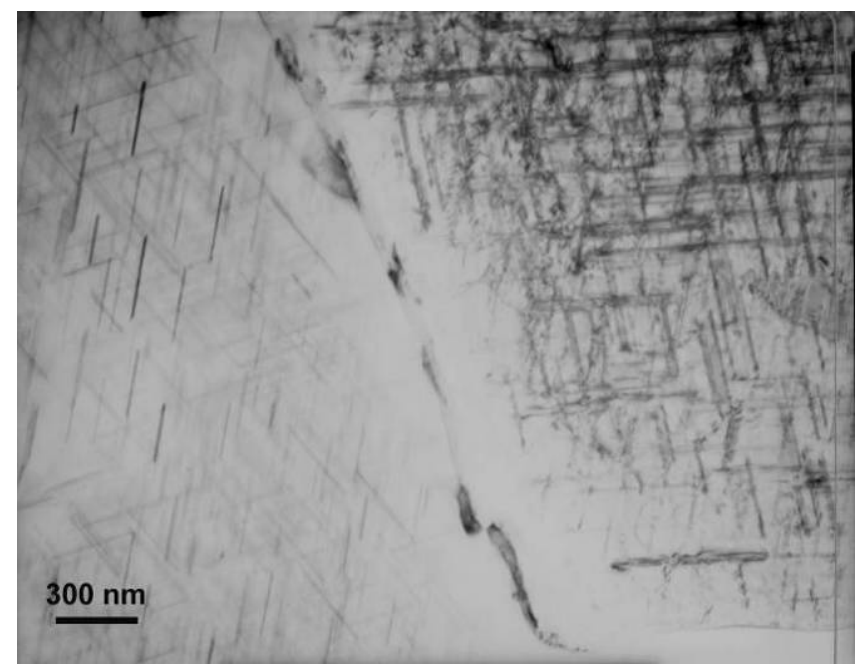

(a)



(c)

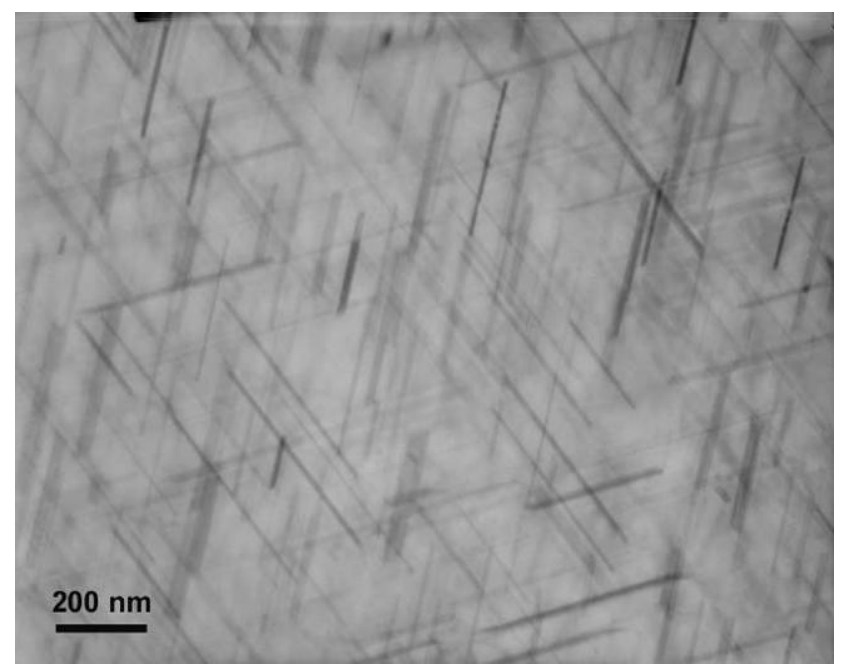

(b)

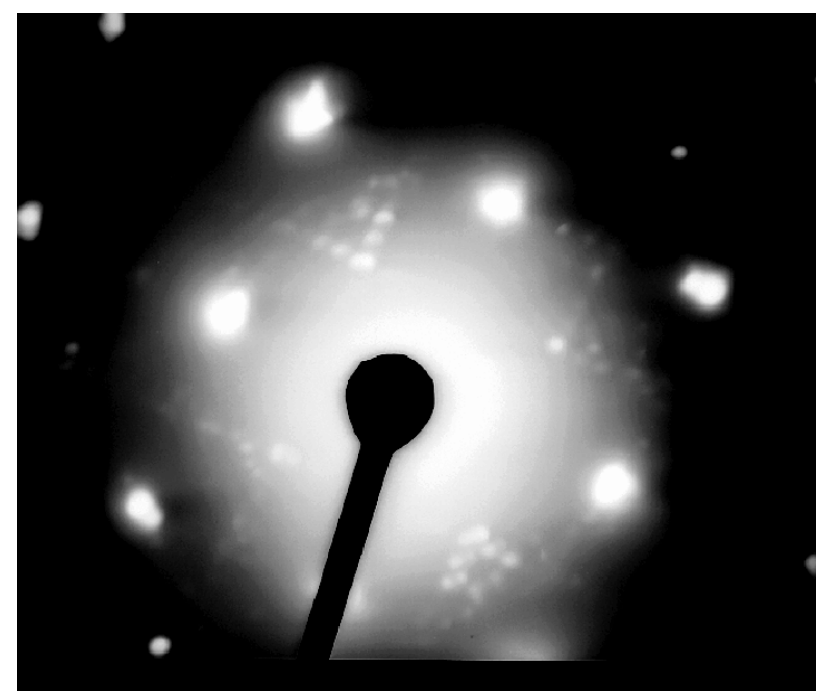

(d)

Fig. 4.31. TEM Bright-field images and SAD pattern for IR-40 specimen. (a) Low-magnification BF image corresponding to IR-40 specimen showing precipitate-free grain boundaries; $(b)$ and (c) high-magnification BF image showing $S$ (or $S^{\prime}$ ) precipitates aligned along [100] $\alpha$ matrix planes; (d) selected area diffraction (SAD) pattern corresponding to $(c)$ showing $S\left(\right.$ or $\left.S^{\prime}\right)$ as the major precipitating phase in the peak-aged condition $(20 \mathrm{~h}$ at $200^{\circ} \mathrm{C}$ )

To perform quantitative analysis at an atomic resolution and to investigate the presence of even finer features (such as GPB zones and $\mathrm{Cu} / \mathrm{Mg}$ clusters) that the TEM images failed to reveal, three dimensional atom probe (3DAP) analyses of C-C and IR-40 specimens was undertaken. APFIM is a microscopic tool used to characterize the solute distribution in the microstructure at the atomic level by field evaporating atoms from the specimen and determining their spatial coordinates and mass-tocharge ratios. Detailed information about this microscopy can be found in reference [28]. For APFIM samples, rods $0.3 \times 0.3 \times 10 \mathrm{~mm}$ were cut from small slices $\sim 200 \mu \mathrm{m}$ thick using a diamondimpregnated wire saw. The rod specimens were electropolished in a solution of $75 \%$ acetic acid and $25 \%$ perchloric acid at $10 \mathrm{~V}$ dc. Microanalysis was performed using an Imago LEAP3000 microscope under ultrahigh vacuum at $\sim 25 \mathrm{~K}$ with a pulse repetition rate of $200 \mathrm{kHz}$ and a pulse fraction of $20 \%$. 


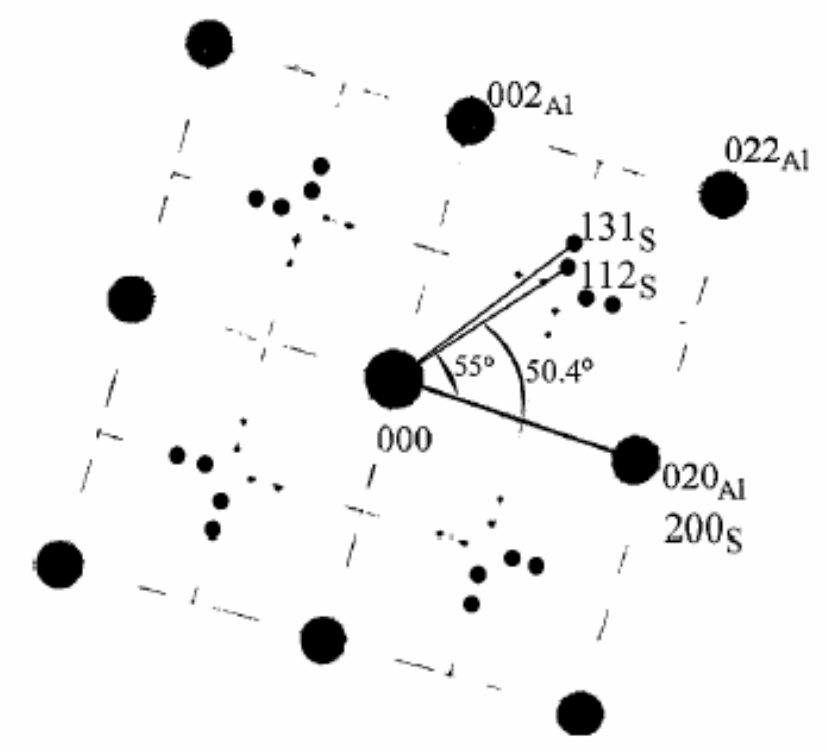

Fig. 4.32. Electron diffraction indexed scheme characteristic of the S' phase.

For statistically reliable measurements, more than 1,000,000 atoms were probed from each specimen. The data analysis was carried out using the Imago Visualization Analysis Software (IVAS).

Figure 4.33(a-b) shows 3DAP reconstructions of an element of the $87 \times 84 \times 38 \mathrm{~nm} \mathrm{C}$-C specimen with spatial mapping of magnesium and copper atoms. Similarly, Fig. 4.34(a-c) shows 3DAP reconstructions of an element of the IR-40 specimen $80 \times 79 \times 140 \mathrm{~nm}$ in size. The aluminum atoms were subtracted from the reconstruction to achieve better resolution for the magnesium and copper atoms. Figure 4.33 indicates only one large $\mathrm{Cu}-\mathrm{Mg}$-containing precipitate at the corner of the element, whereas Fig. 4.34 shows a mixture of large and fine $\mathrm{Cu}-\mathrm{Mg}$-containing precipitates. Based on the TEM analysis described above, these $\mathrm{Cu}-\mathrm{Mg}$-containing precipitates can be considered to be $\mathrm{S}$ (or $\mathrm{S}^{\prime}$ ) phases with a composition similar to that of $\mathrm{Al}_{2} \mathrm{CuMg}$. Taking into account that both specimens were treated under similar peak-aged conditions, the difference in the distribution of the precipitates can be attributed to a higher density of precipitate nucleation sites in case of IR-40 specimen. This can be proposed only with the assumption that the area probed by the atom probe is away from the PFZ grain boundaries exhibited in the TEM analysis. The increased nucleation density can be linked to retention of higher amounts of copper and magnesium in the short soak times during the solution heat treatment of IR-processed specimens. Higher amounts of copper and magnesium can form large number of $\mathrm{Cu}-$ $\mathrm{Mg}$ atomic clusters that form effective nucleation sites for the subsequent precipitates. However, since these specimens represent peak-aged conditions, such clusters or atomic segregates may not be available in the microstructure [17, 29]. The absence of such clusters in the C-C and IR-40 specimens is confirmed by the atom probe one-dimensional (1DAP) concentration-depth profiles within the precipitate and matrix regions, as shown in Figure 4.33(c) and 4.34(d), respectively. Additional atomprobe studies with specimens prepared using IR-40 and C-C heat-treating conditions but representing early stages of aging would be necessary to resolve and compare the density of clusters and GPB formation as a function of the different soak times. 


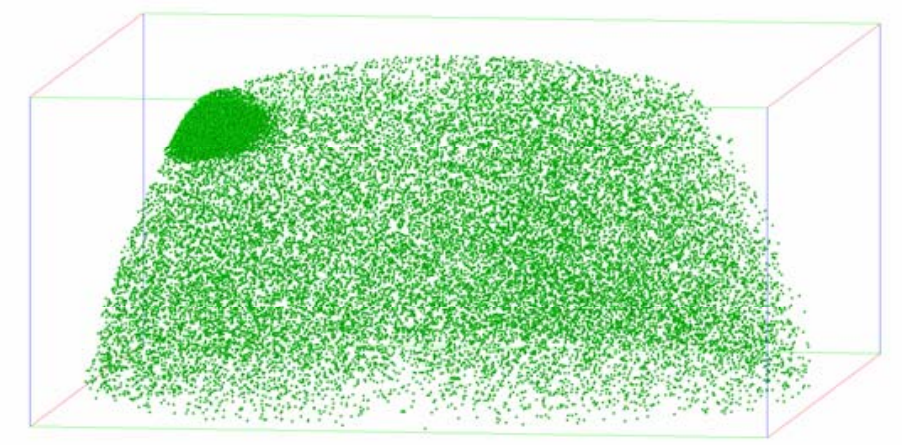

(a) Magnesium

$\vec{b}$

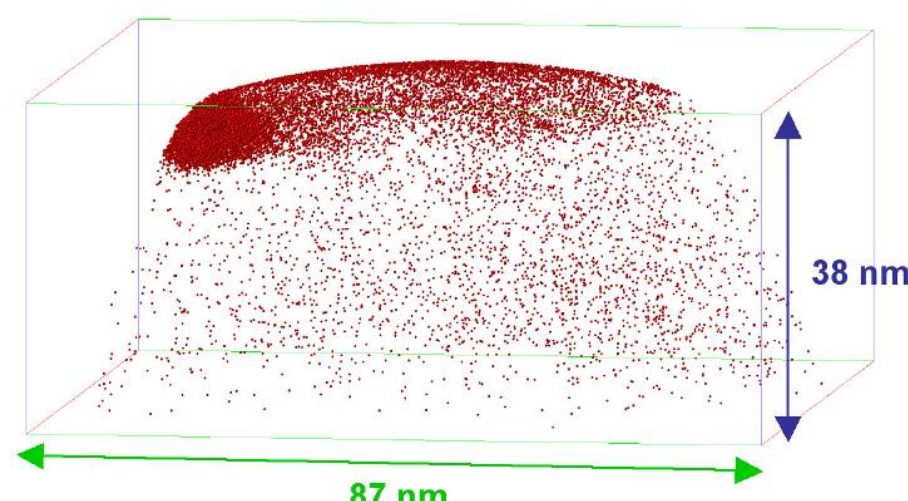

(b) Copper



(c) Concentration-depth profile

Fig. 4.33. APFIM results for C-C specimen heat-treated to the peak-aged condition (a-b) Three-dimensional reconstruction (3DAP) of magnesium and copper distribution in aluminum; (c) concentration-depth profile (1DAP) within precipitate and matrix region. There is no indication of cluster or zone formation within the matrix region. 


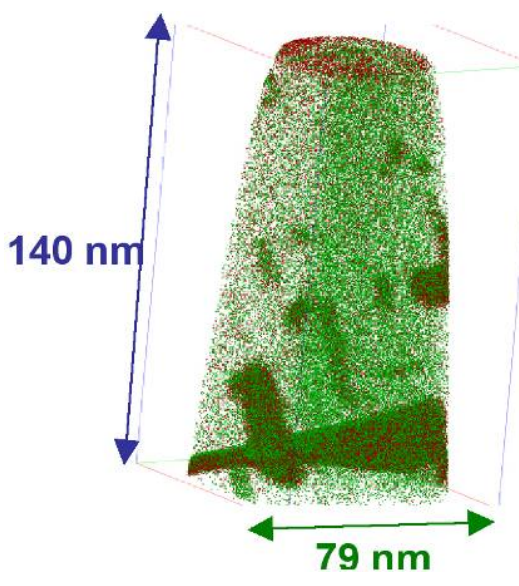

(a) Magnesium and copper

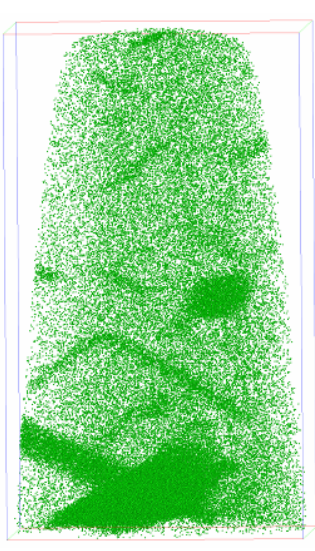

(b) Magnesium

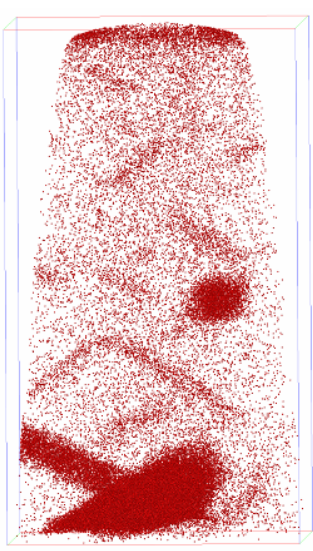

(c) Copper
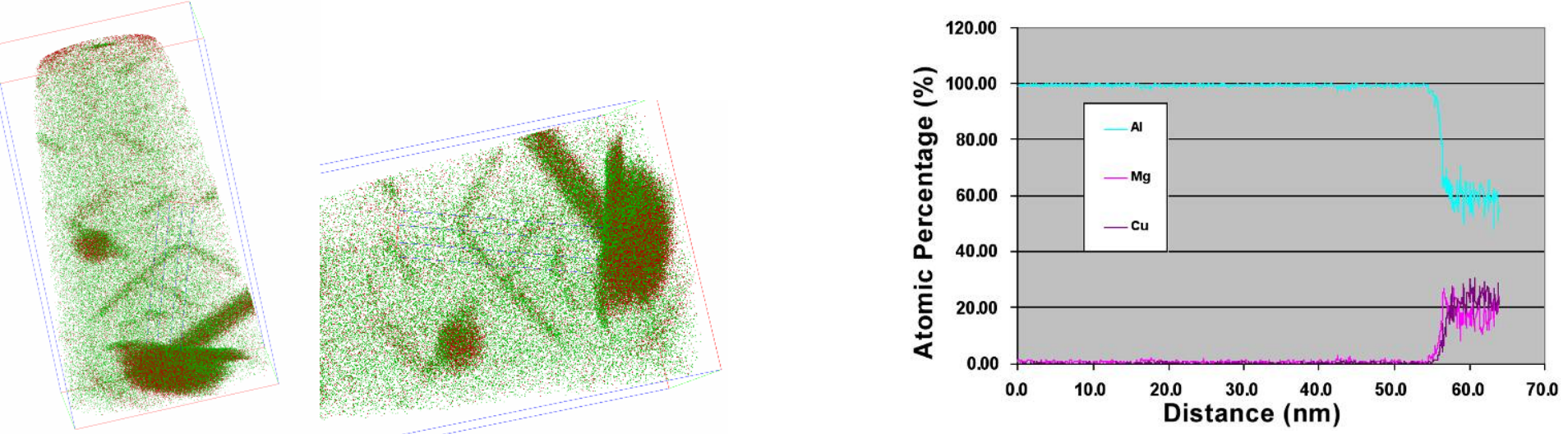

(d) Concentration-depth profile

Fig. 4.34. APFIM results for IR-40 specimen heat-treated to the peak-aged condition (a-c) Three-dimensional reconstruction (3DAP) of magnesium and copper, magnesium, and copper distribution in aluminum; (d) concentration-depth profile (1DAP) within the precipitate and matrix region. There is no indication of cluster or zone formation within the matrix region. 


\subsection{Field Testing}

Prior to the field testing, the continuous-belt IR furnace, installed at Queen City Forging as shown in Fig. 4.35, was calibrated to preheat 2.25-in.-diameter aluminum alloy 2618 billets. An attempt was made to reproduce the preheating temperatures and times, achieved at ORNL with these billets by adjusting the belt speed and the temperature setpoints in zones 1 and 2 of the furnace. The temperature of the billets while they traversed through the furnace was measured and recorded. The final temperature profile for the billets after the furnace was calibrated is shown in Fig. 4.36(a). After the furnace was calibrated, a full production run of 1200 billets was preheated and forged. During the continuous run, temperature data was acquired from the billets every $2-3 \mathrm{~h}$ [Fig. $4.36(\mathrm{~b})$ ] to check the consistency of the furnace in preheating such large sets of billets.

In addition to the furnace calibration and the full production run of billets, four upsets of IRpreheated 2.25-in.-diameter aluminum alloy 2618 billets were produced using the continuous-belt setup at Queen City Forging for microstructural evaluation. A PLC-controlled 650-ton National Maxi Mechanical Press with the capability to vary the deformation rates during forging operation was used to produce these upsets. Two of these four upsets were

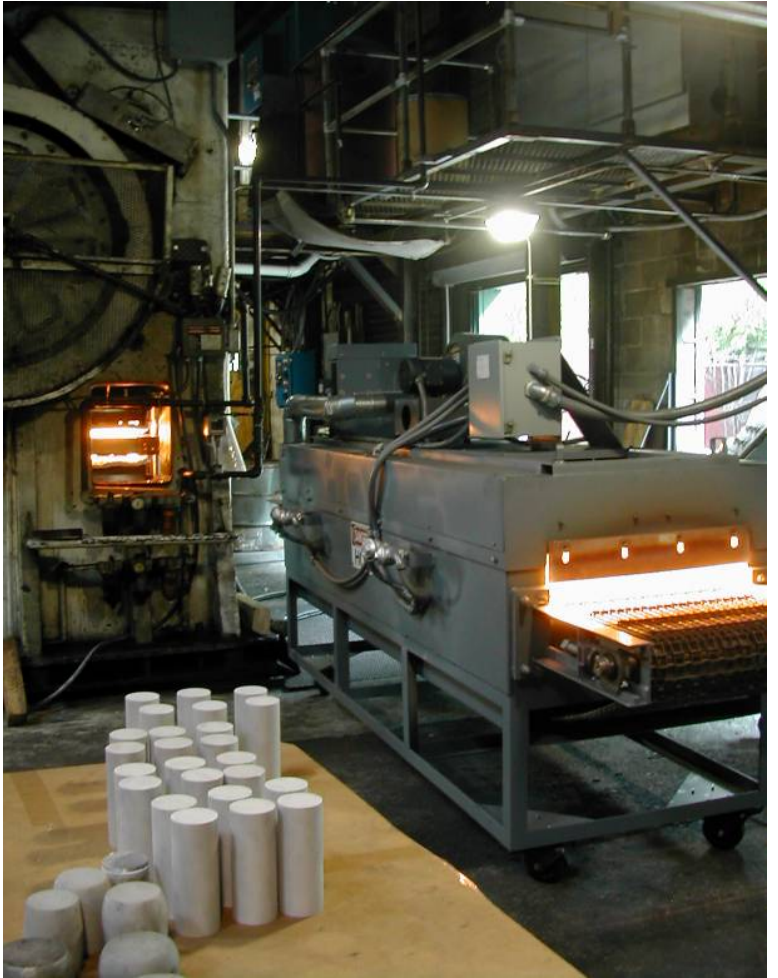

Fig. 4.35. Continuous-belt IR heating furnace installed at Queen City Forging Company, Cincinnati, Ohio. made using a higher deformation rate $\left(2.5 \mathrm{~s}^{-1}\right)$, while the other two were made using a lower deformation rate $\left(0.625 \mathrm{~s}^{-1}\right)$. Deformation rates were varied to study the effect of changing strain rates on the final microstructure of the forging. After forging, the four billets were sent to ORNL for T61 heat treatment under IR-40 heat treating conditions. Figure 4.37 shows the microstructures corresponding to lower and higher deformation rate specimens. Increasing the strain rate from $0.625 \mathrm{~s}^{-1}$ to $2.5 \mathrm{~s}^{-1}$ decreased the grain size somewhat, from 29 to $24 \mu \mathrm{m}$; however, these were still considered within the normal grain size range representative of rapid IR preheating conditions. These results show that the grain sizes achieved in the laboratory were successfully reproduced under industrial settings. 


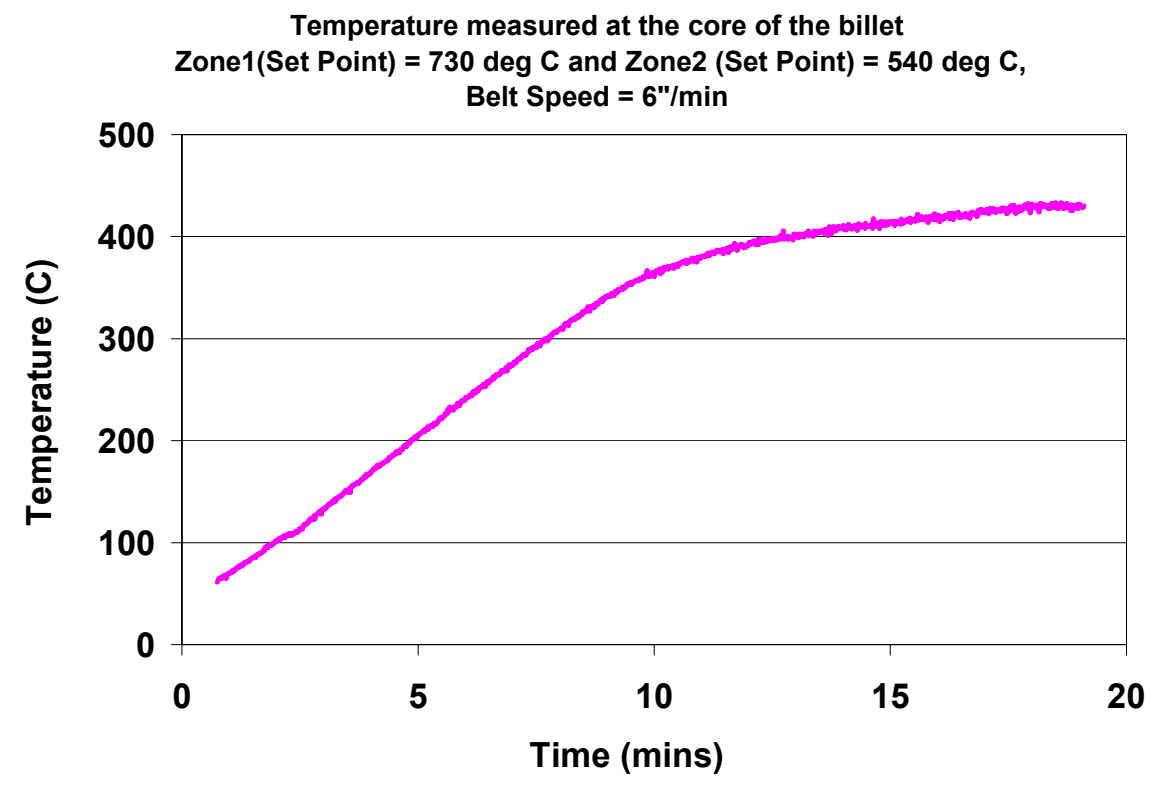

(a)

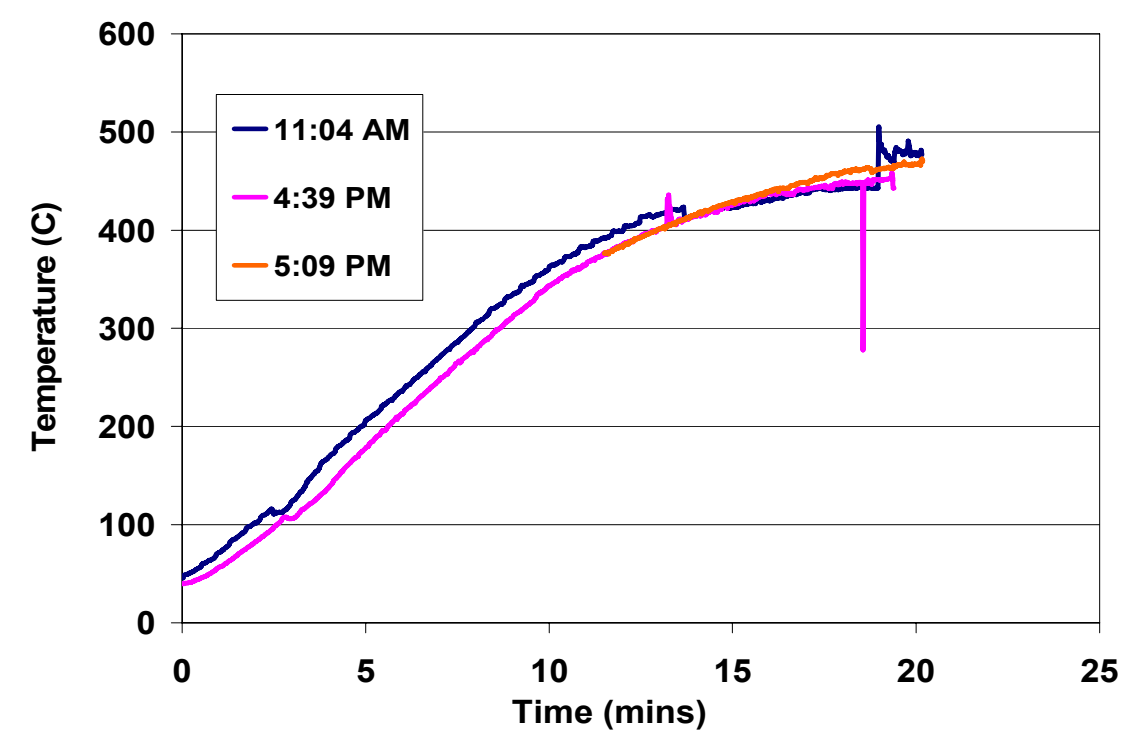

(b)

Fig. 4.36. Calibration of the continuous-belt IR heating furnace for preheating 2.25-in.-diameter aluminum alloy 2618 billets: (a) temperature profile showing that heating rates developed at ORNL were reproducible during field testing; (b) temperature profiles showing consistency of furnace in preheating billets during large-scale production run. 


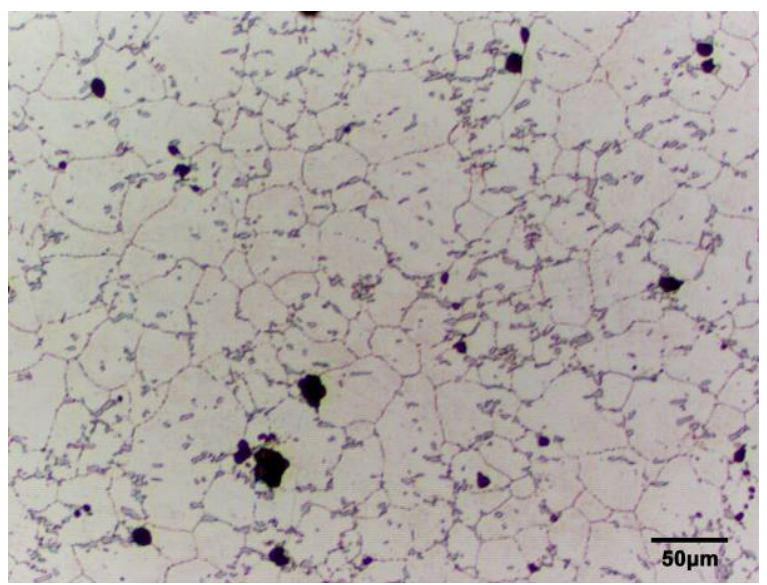

(a) Lower deformation rate, grain size $=29.2 \mu \mathrm{m}$



(b) Higher deformation rate, grain size $=\mathbf{2 4 . 2} \boldsymbol{\mu m}$

Fig. 4.37. Optical micrographs of IR preheating forgings preheated using the continuous-belt setup at Queen City Forging and using (a) lower deformation rate of $0.625 \mathrm{~s}^{-1}$ and $(b)$ higher deformation rate of $2.5 \mathrm{~s}^{-1}$.

\subsection{Energy Analysis Conclusions}

During implementation and calibration of the continuous-belt IR unit at Queen City Forging Company, comparative studies of preheating, forging and heat treating were performed using a batchtype convection gas-fired furnace and energy parameters such as gas consumption, electric energy consumption, and time of consumption. These energy-related numbers along with throughput and downtime during production were used to calculate the energy and cost savings that could be realized by utilization of the hybrid IR system.

Detailed calculations showing the energy and cost savings are presented in Sect. 2.2.1 in this report. This energy analysis shows that implementation of the newly developed hybrid rapid IR heating technology could result in national energy savings of up to 7.2 trillion Btu/year, with cost savings of $\$ 84$ million per year. With the replacement of a gas-fired unit with an electric IR unit, the research efforts in this project comply with the focus of DOE's "Save Energy Now" initiative on reducing natural gas consumption.

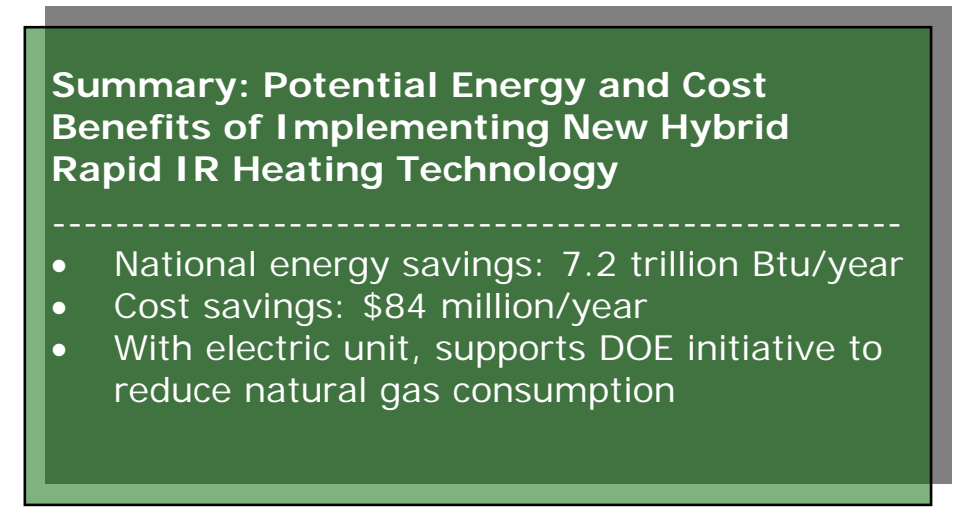





\section{Accomplishments}

\subsection{Technical Accomplishments}

The major technical accomplishments of the project were as follows:

- The application of rapid IR heating resulted in an order of magnitude reduction in the preheating times. Rapid IR heating also enabled a reduction in the heat treatment times for aluminum alloy 2618 forgings from $8 \mathrm{~h}$ to $1 \mathrm{~h}$ without degrading the mechanical properties in the final forgings.

- The key outcome of this project was the development and successful implementation of a new, full-scale production type continuous belt hybrid electric IR preheating system at the Queen City Forging Company (QCF) in Cincinnati OH, Ohio. The calibration and the field test runs that followed the implementation of the system showed that the heating rates identified and the grain refinements achieved in a laboratory setup were reproducible in a shop-floor environment.

- Field test results have demonstrated potential cost savings of up to $40-50 \%$ through reduced energy consumption, increased throughput, and improved consistency in the process and the product using this new heating technique.

- Energy analysis showed that implementation of the newly developed hybrid rapid IR heating technology could result in national energy savings up to 7.2 trillion Btu/year, with cost savings of $\$ 84$ million per year.

- Rapid IR preheating resulted in a 30\% reduction in the grain size of forgings. Grain refinement along with improved age hardening due to shorter heat treatment cycles led to stronger forgings. The IR-preheated and IR-heat-treated forgings lasted two times longer than convection-gas-fired preheated and heat-treated forgings.

\subsection{Commercialization}

The key outcomes of this research project were as follows:

- Successful implementation of the production-scale hybrid IR preheating unit at QCF has led to its commercialization efforts in the forging industry. Today, QCF is producing 1000 proprietary forging components per day using this newly installed preheating unit for a customer in the transportation industry on a commercial basis. QCF also intends to use the equipment for toll processing of aluminum forgings on a commercial basis.

- A discussion has been initiated between the project team members and a potential equipment manufacturer to license the designs and concepts resulting from this project for scale-up to sizes needed by different forging, extrusion, and rolling companies.

- The full-scale hybrid IR unit developed in this project received the prestigious R\&D 100 Award, an award that further endorsed the uniqueness of this technology to the aluminum, forging, and heat-treating industry. 
- As a consequence of this award and of presentations made at technical meetings and conferences, both ORNL and QCF have received numerous inquiries from forging industries. These inquiries reflect the interest and enthusiasm this project has generated in the industrial community.

\subsection{Publications}

Three conference proceedings papers resulted from this research $[2,3,30]$. 


\section{Conclusions}

The goal of this research effort was to investigate the application of a new hybrid IR heating technique to aluminum forging and the subsequent heat treatment operations and evaluate its energy and materials benefits. The objectives outlined were to develop an energy-efficient hybrid IR billet heating system capable of delivering consistent preheated billets for forging in an industrial environment and to develop a basic understanding of aluminum microstructural evolution from forge stock to final part as a function preheating and heat treatment parameters.

The following approach was used to meet the final goal and objectives:

- Identify the mechanisms and rates of rapid preheating of billets required to obtain an order of magnitude refinement in grain size, when compared to convection heating, of a range of aluminum alloys during the forging operation

- Design, construct, and implement the hybrid rapid preheating in order to evaluate the energy efficiency, benefits and competitiveness of the IR heating technology

- Perform energy analysis and predict cost savings through application of this technology to aluminum forgings.

- Determine the improvement in mechanical properties produced by an order of magnitude grain refinement

The results of the research efforts and the field tests performed utilizing this approach were as follows:

- A full-scale hybrid IR billet heating system that is more than three times more energy efficient and four times more productive than the current convection gas-fired furnace was developed.

- Energy analyses showed that the newly developed technology has a potential to provide energy savings of $7.2 \times 10^{12}$ Btu/year if fully utilized by the domestic aluminum forging industry.

- Rapid IR preheating resulted in a 30\% reduction in the grain size of forgings. Grain growth during IR heating of aluminum alloy 2618 forgings was largely controlled by the lower thermal input. Excessive grain growth during longer heat-up times was inhibited because of the pinning of the grain boundaries by the aluminum-iron-nickel $\left(\mathrm{Al}_{9} \mathrm{FeNi}\right)$ intermetallic particles.

- Improvement in mechanical properties was partially due to grain refinement but largely to the retention of larger amounts of solute elements in the matrix during the short heat treatment time made possible by IR heating. Large amounts of solute elements help produce a fine distribution of precipitates that increases the strength of the material. Fatigue testing results showed that IR preheated and IR heat-treated forgings lasted twice as long as convection-gasfired preheated and heat treated forgings. 



\section{Recommendations}

The principal application intended for the hybrid IR system, developed through this project, is heating of extruded or cast aluminum bars prior to forging. However, this process can be extended to heattreating processes, including stress-relieving, annealing, solutionizing, and aging treatments performed after the forging operation. The system can be used for many additional thermal processes that currently use convection gas-fired or induction heating systems. These include annealing and stress relieving; preheating and post weld annealing during joining; and preheating prior to extrusion, rolling, and similar hot-working processes. Furthermore, the hybrid IR heating technology can also be extended to other materials, including steel, brass and bronze, titanium alloys, and nickel- and cobaltbased alloys. Similar energy savings and potential property enhancements through grain refinement using rapid heating of these materials may be possible. It is recommended that similar efforts focused on additional generic industrial heating processes (other than forging including extrusion, rolling, etc.) be initiated to widely distribute the benefits of energy savings across additional industrial sectors. 



\section{References}

[1] C. A. Blue et al., Infrared Heating of Forging Billets and Dies, Research Project Report in the Forging Industry Educational and Research Foundation's Collaborative Research in the Forging Industry series, available online at http://www.forging.org/FIERF/ collaborative_ research.htm.

[2] H. Lu, P. B. Kadolkar, T. Ando, C. A. Blue, and R. Mayer, "Control of Grain Size and Age Hardening in AA2618 Forgings Processed by Rapid Infrared Radiant Heating," TMS Letters 1(3): 47-48.

[3] P. B. Kadolkar, H. Lu, C. A. Blue, T. Ando, and R. Mayer, "Application of Rapid Infrared Heating to Aluminum Forgings," in Proceedings of the 25th Forging Industry Technical Conference of the Forging Industry Association and the Forging Industry Educational and Research Foundation, Detroit, Michigan, April 19-21, 2004, pp. 58-69.

[4] U.S. Department of Energy, Energy Efficiency and Renewable Energy, Industrial Technologies Program, Supporting Industries: Industries of the Future: Fiscal Year 2004 Annual Report, available online at http://www.eere.energy.gov/industry/supporting_industries/about.html.

[5] Forging Industry Association, Forging Industry Technology Roadmap, Forging Industry Association, Cleveland, Ohio, 2002, available online at http://www.forging.org/ TechRoadMap/roadmap.cfm.

[6] U.S. Department of Commerce, 2002 Economic Census, Manufacturing: Nonferrous Forging 2002, Table 6a.

[7] J. G. Hemrick et al., Refractories for Industrial Processing: Opportunities for Improved Energy Efficiency, report prepared by Oak Ridge National Laboratory for DOE-EERE Industrial Technologies Program, January 2005, available online at http://www.eere.energy.gov/ industry/imf/pdfs/refractoriesreportfinal.pdf.

[8] U.S. Department of Energy, Office of Industrial Technologies, 1997 Energy and Environmental Profile of the US Aluminum Industry, Table 1.6, pp. 12-13.

[9] American Society for Metals (ASM), Metals Handbook, vol. 9, Metallography and Microstructures, 9th ed., ed. G. F. Vander Voort, ASM, Materials Park, Ohio, p. 356.

[10] F. D. S. Marquis, "Mechanisms of formation of hydrogen porosity in 7X50 and 2X24 aluminum alloys: Effects on mechanical behavior," pp. 43-62 in Gas Interactions in Nonferrous Metals Processing: Proceedings of a Symposium, 1996 TMS Annual Meeting, Anaheim, Calif., Feb. 4-8, 1996.

[11] D. A. Porter and K. E. Easterling, Phase Transformation in Metals and Alloys, 2nd ed., Chapman \& Hall, Cheltenham, UK, 1992, pp. 139, 304.

[12] C. Zener, quoted by C. S. Smith, Trans. TMS-AIME, 1949, 175:15.

[13] R. N. Wilson and P. J. E. Forsyth, J. Inst. Met. 94 (1966): 8.

[14] J. M. Silcock, J. Inst. Met. 89 (1960-1961): 203.

[15] Y. A. Bagaryatsky, Dokl. Akad. Nauk S.S.S. R. 87 (1952): 559.

[16] A. Charai et al., Acta Mater 48 (2000): 2751-2764.

[17] S. P. Ringer et al., App. Sur. Sci. 94/95 (1996): 253-260. 
[18] I. N. A. Oguocha and S. Yannacopoulos, J. Mater. Sci. 34 (1999): 3335-3340.

[19] C. B. Zhang, W. Sun, and H. Q. Ye, Phil. Mag. Lett. 59, no. 6 (1989): 265-271.

[20] B. D. Cullity, Elements of X-Ray Diffraction, Addison-Wesley, Boston, 1967, p. 324.

[21] K. R. Van Horn, J. Met., 1953, pp. 405-422.

[22] H. J. Axon and W. Hume-Rothery, Proc. Roy. Soc. (London) A193 (1948): 1-24.

[23] S. P. Ringer, T. Sakurai, and I. J. Polmear, Acta Mater. 45, no. 9 (1997): 3731- 3744.

[24] H. C. Shih, N. J. Ho, and J. C. Huang, Metall. Mat. Trans. A, 27A, no. 9 (1996): 24792494.

[25] A. K. Jena, A. K. Gupta, and M. C. Chaturvedi, Acta Metall. 37, no. 3 (1989): 885-895.

[26] M. Murayama, and K. Hono, Acta Mater. 47, no. 5 (1999): 1537-1548.

[27] D. G. Eskin, J. Mater. Sci. 38 (2003): 279-290.

[28] M. K. Miller, and G. D. W. Smith, Atom Probe Microanalysis: Principles and Applications to Materials Problems, Materials Research Society, Warrendale, PA, 1989.

[29] S. P. Ringer, and K. Hono, Mater. Charact. 44 (2000): 101-131.

[30] H. Lu, P. B. Kadolkar, K. Nakazawa, T. Ando, and C. A. Blue, "Age Hardening Behavior of AA2618," published in TMS Letters and presented at the TMS Annual Meeting \& Exhibition, San Antonio, Texas, March 12-16, 2006. 